\title{
WestVirginiaUniversity
}

THE RESEARCH REPOSITORY @ WVU

Graduate Theses, Dissertations, and Problem Reports

2013

\section{Robust Cross-dock Location Model Accounting for Demand Uncertainty}

Stephanie Spangler

West Virginia University

Follow this and additional works at: https://researchrepository.wvu.edu/etd

\section{Recommended Citation}

Spangler, Stephanie, "Robust Cross-dock Location Model Accounting for Demand Uncertainty" (2013). Graduate Theses, Dissertations, and Problem Reports. 398.

https://researchrepository.wvu.edu/etd/398

This Thesis is protected by copyright and/or related rights. It has been brought to you by the The Research Repository @ WVU with permission from the rights-holder(s). You are free to use this Thesis in any way that is permitted by the copyright and related rights legislation that applies to your use. For other uses you must obtain permission from the rights-holder(s) directly, unless additional rights are indicated by a Creative Commons license in the record and/ or on the work itself. This Thesis has been accepted for inclusion in WVU Graduate Theses, Dissertations, and Problem Reports collection by an authorized administrator of The Research Repository @ WVU. For more information, please contact researchrepository@mail.wvu.edu. 


\title{
Robust Cross-dock Location Model Accounting for Demand Uncertainty
}

\author{
Stephanie Spangler
}

Thesis submitted

to the Benjamin M. Statler College of Engineering and Mineral Resources at West Virginia University

in partial fulfillment of the requirements for the degree of

Master of Science in

Civil Engineering

\author{
Avinash Unnikrishnan, Ph.D., Chair \\ Ronald Eck, Ph.D. \\ John Zaniewski, Ph.D. \\ Department of Civil and Environmental Engineering
}

Morgantown, West Virginia

2013

Keywords: Cross-docks, Robust optimization, $\boldsymbol{P}$-median facility location model Copyright 2013 Stephanie Spangler 


\section{ABSTRACT \\ Robust Cross-dock Location Model Accounting for Demand Uncertainty}

\section{Stephanie Spangler}

The objective of this thesis was to develop optimization models to locate cross-docks in supply chain networks. Cross-docks are a type of intermediate facility which aid in the consolidation of shipments, in which the goods spend little or no time in storage. Instead, the goods are quickly and efficiently moved from the inbound trucks to the outbound docks. Two deterministic facility location models were developed. One followed the $p$-median facility problem type, where only $p$ facilities were opened in order to minimize total network costs. In the second model, as many cross-docks as necessary were opened and facility location costs were considered while minimizing total network costs. In order to account for uncertainty in demands, a robust optimization model was created based on the initial deterministic one. Robust counterparts were developed for each equation that contained the demand term. The robust model allowed for the creation of a network with the ability to handle variations in demand due to factors such as inclement weather, seasonal variations, and fuel prices. Numerical analysis was performed extensively on both the deterministic and robust models, following the $p$-median facility problem type, using three networks and parameters coherent with industry standards. The results showed that accounting for uncertainty in demands had a real effect on the facilities which were opened and total network costs. While the deterministic network was less expensive, it was unable to handle increases in demand due to uncertainty, whereas the robust network had no capacity shortages in any scenario. Simple demand inflation, along with the use of a robust model for baseline comparison, also proved to be a legitimate strategy to account for uncertainties in demand among small freight carriers. 


\section{ACKNOWLEDGEMENTS}

I am very grateful to my Graduate Advisor, Dr. Avinash Unnikrishnan, for his support and encouragement throughout my research and classes in graduate school. I am so thankful for all of the time he has spent helping me with my thesis and his constant guidance through this entire process.

I would also like to thank Dr. Ron Eck and Dr. John Zaniewski for being a part of my thesis committee and for their continued support and advice in my graduate studies.

Mehrdad Shahabi has been extremely helpful in debugging codes for the model formulation in this thesis. I cannot thank him enough for his willingness to help and for sharing his knowledge of operations research with me.

A very special thanks to my Mom and Dad for instilling the values of hard work and dedication in me. They have always supported me in everything I do and given me the confidence to follow my dreams, for that I am eternally grateful.

My husband, Harman, has been my greatest supporter and best friend. Without his constant love, encouragement, and sense of humor, I never would have made it through the last couple of months. I cannot even begin to express my appreciation for all that he has done for me.

West Virginia University

December 2013 


\section{TABLE OF CONTENTS}

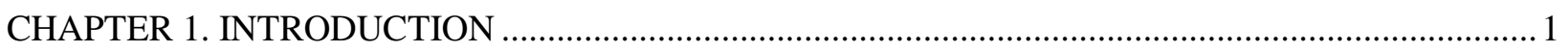

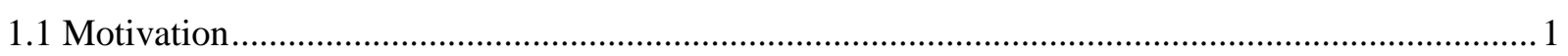

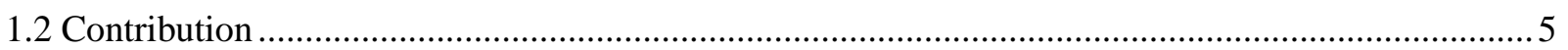

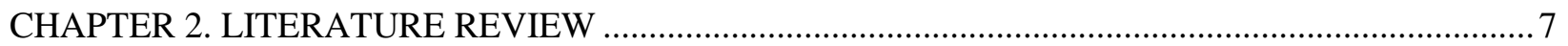

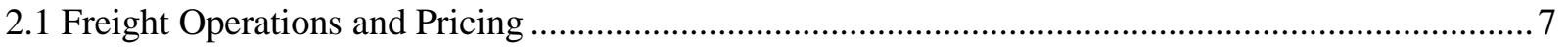

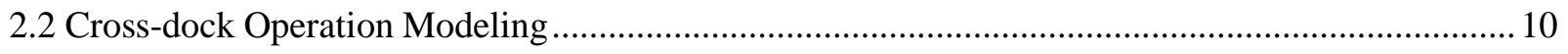

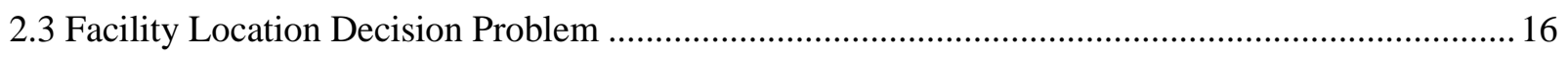

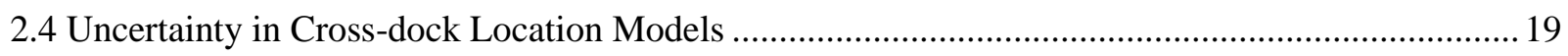

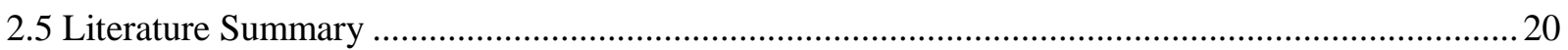

CHAPTER 3. DETERMINISTIC LOCATING MODEL FOR CROSS-DOCK NETWORK DESIGN ... 22

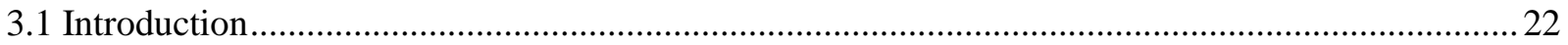

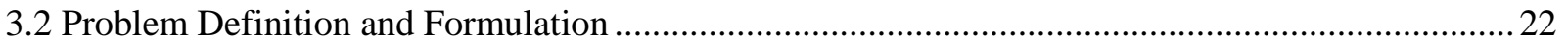

CHAPTER 4. ROBUST LOCATING MODEL FOR CROSS-DOCK NETWORK DESIGN WITH

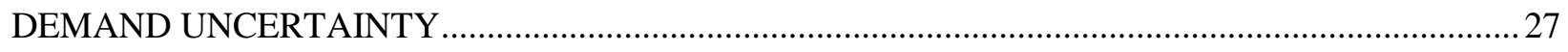

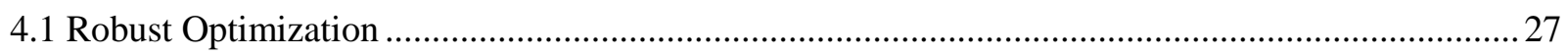

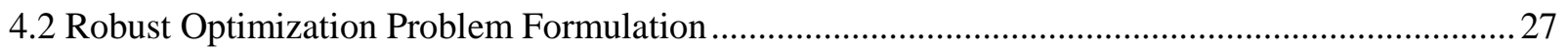

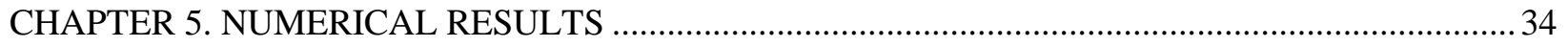

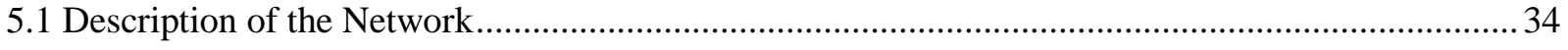

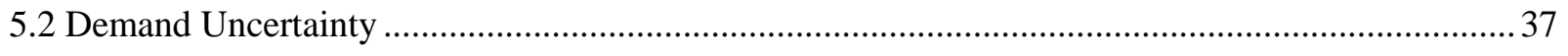

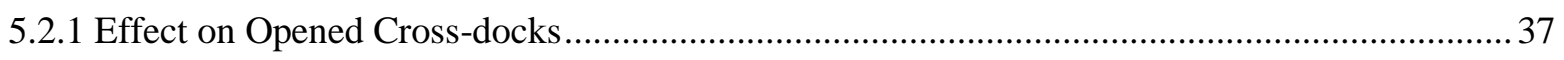

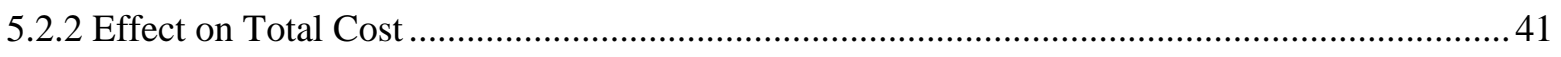

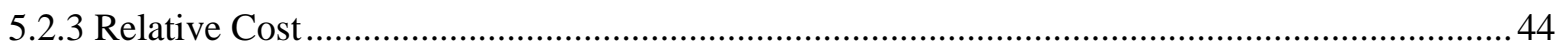

5.3 Deterministic and Robust Performance Comparison ................................................................46

5.3.1 Comparison with Average Demands for Deterministic Case .............................................. 46

5.3.2 Comparison with Inflated Demands for the Deterministic Case.............................................55

CHAPTER 6. CONCLUSIONS AND DIRECTIONS FOR FUTURE RESEARCH .............................61

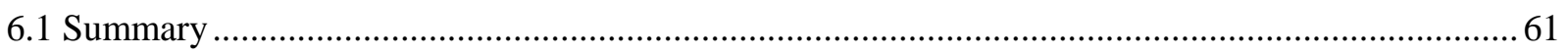

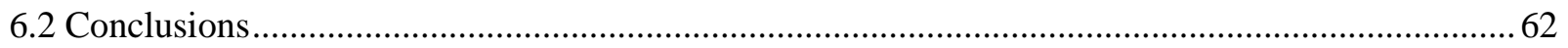

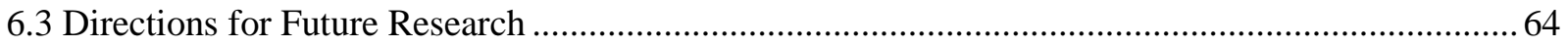

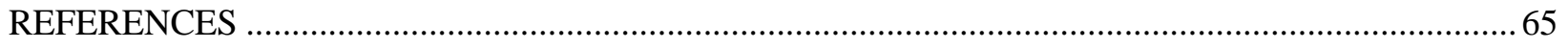

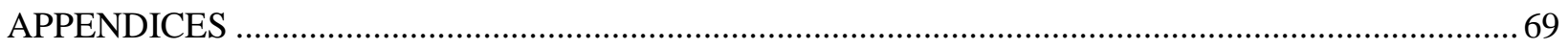

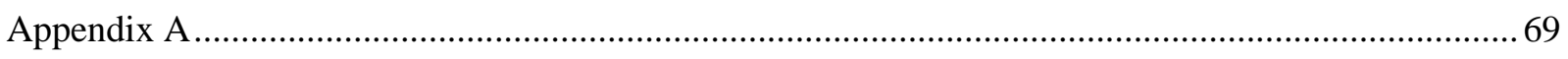

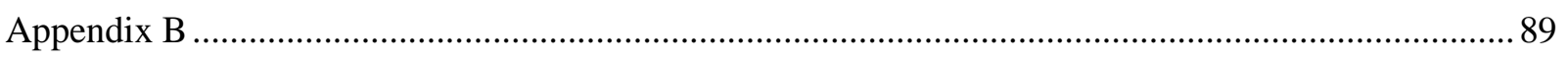

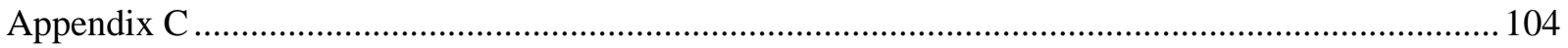




\section{LIST OF TABLES}

Table 1: Robust Counterpart for Constraint Equations Affected with Demand Uncertainty ....... 31

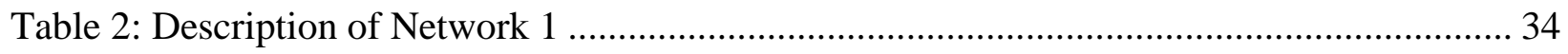

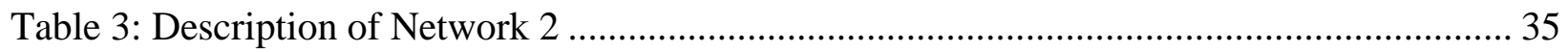

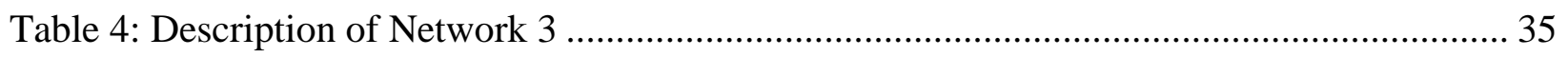

Table 5: Cross-docks Opened for Network 1 with Low Uncertainty ...................................... 38

Table 6: Cross-docks Opened for Network 2 with Medium Uncertainty ................................ 39

Table 7: Cross-docks Opened for Network 3 with High Uncertainty .................................... 40

Table 8: Opened Cross-docks for Each Network and Uncertainty Scenario ............................ 47

Table 9: Initial Total Cost for Each Network and Uncertainty Scenario................................. 47

Table 10: Capacity Shortage and Total Cost for Network 1 ............................................... 49

Table 11: Capacity Shortage and Total Cost for Network 2 .............................................. 50

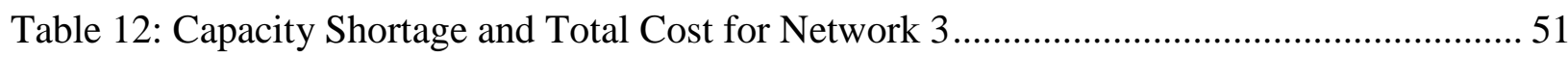

Table 13: Total Cost after Capacity Shortage Penalties for All Three Networks...................... 53

Table 14: Average Capacity Shortages (In Pallets) and Total Costs for All Three Networks ..... 54

Table 15: Average Total Cost after Capacity Shortage Penalties for All Three Networks .......... 55

Table 16: Capacity Shortages (In Pallets) for Demand Inflation of the Deterministic vs. the

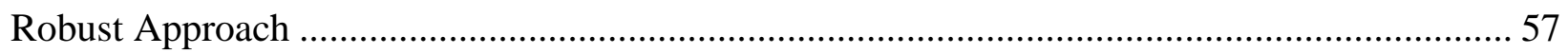

Table 17: Demand Inflation Cost of the Deterministic vs. the Robust Approach ...................... 58

Table 18: Internode Mileage for Network 1 from Origin (i) to Destination (j) ......................... 69

Table 19: Internode Mileage for Network 1 from Origin (i) to Cross-dock (k) ...................... 70

Table 20: Internode Mileage for Network 1 from Cross-dock (k) to Destination (j) .................. 71

Table 21: Internode Mileage for Network 2 from Origin (i) to Destination (j) ........................ 72 
Table 22: Internode Mileage for Network 2 from Origin (i) to Cross-dock (k) ........................ 73

Table 23: Internode Mileage for Network 2 from Cross-dock (k) to Destination (j) .................. 74

Table 24: Internode Mileage for Network 3 from Origin (i) to Destination (j) ......................... 75

Table 25: Internode Mileage for Network 3 from Origin (i) to Destination (j) ......................... 76

Table 26: Internode Mileage for Network 3 from Origin (i) to Cross-dock (k) ...................... 77

Table 27: Internode Mileage for Network 3 from Origin (i) to Cross-dock (k) ....................... 78

Table 28: Internode Mileage for Network 3 from Cross-dock (k) to Destination (j) .................. 79

Table 29: Internode Mileage for Network 3 from Cross-dock (k) to Destination (j) ................. 80

Table 30: Average Demands (in pallets) for Network 1 ................................................. 81

Table 31: Average Demands (in pallets) for Network 2 ................................................. 82

Table 32: Average Demands (in pallets) for Network 3 ................................................. 83

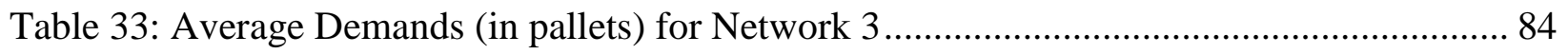

Table 34: Average Demands (in pallets) for Network 3 ................................................ 85

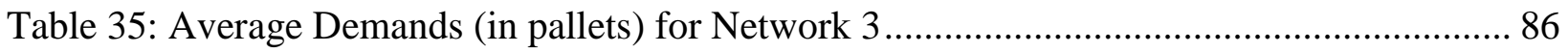

Table 36: Average Demands (in pallets) for Network 3 ................................................ 87

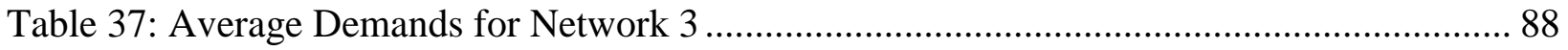

Table 38: Cross-docks Opened for Network 1 with Medium Uncertainty .............................. 104

Table 39: Cross-docks Opened for Network 1 with High Uncertainty .................................. 105

Table 40: Cross-docks Opened for Network 2 with Low Uncertainty .................................. 106

Table 41: Cross-docks Opened for Network 2 with High Uncertainty .................................. 107

Table 42: Cross-docks Opened for Network 3 for Low Uncertainty................................... 108

Table 43: Cross-docks Opened for Network 3 with Medium Uncertainty ............................. 109 


\section{LIST OF FIGURES}

Figure 1: MAUD Cost Structure (Chan et al. 2002) ........................................................... 9

Figure 2: Typical Flow in a Cross-Dock System (Liao et al. 2012) ........................................ 12

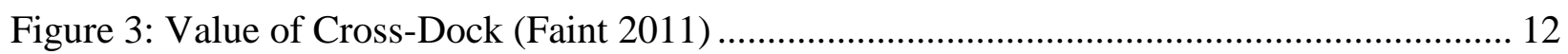

Figure 4: Some Typical Cross-Dock Shapes (Bartholdi and Gue 2004) ................................. 14

Figure 5: Facility Location Decision Problem (Sung and Song 2003) .................................. 17

Figure 6: Total Cost for Network 1 with Low Uncertainty .............................................. 42

Figure 7: Total Cost for Network 2 with Medium Uncertainty .......................................... 42

Figure 8: Total Cost for Network 3 with High Uncertainty............................................. 43

Figure 9: Relative Cost for Network 1 with Low Uncertainty ............................................ 44

Figure 10: Relative Cost for Network 2 with Medium Uncertainty ....................................... 45

Figure 11: Relative Cost for Network 3 with High Uncertainty .......................................... 45

Figure 12: Total Cost for Network 1 with Medium Uncertainty ........................................ 110

Figure 13: Total Cost for Network 1 with High Uncertainty.............................................. 111

Figure 14: Total Cost for Network 2 with Low Uncertainty ........................................... 112

Figure 15: Total Cost for Network 2 with High Uncertainty ............................................ 113

Figure 16: Total Cost for Network 3 with Low Uncertainty ........................................... 114

Figure 17: Total Cost for Network 3 with Medium Uncertainty .......................................... 115

Figure 18: Relative Cost for Network 1 with Medium Uncertainty .................................... 116

Figure 19: Relative Cost for Network 1 with High Uncertainty ........................................ 117

Figure 20: Relative Cost for Network 2 with Low Uncertainty ......................................... 118

Figure 21: Relative Cost for Network 2 with High Uncertainty ......................................... 119

Figure 22: Relative Cost for Network 3 with Low Uncertainty ........................................ 120 
Figure 23: Relative Cost for Network 3 with Medium Uncertainty 


\section{CHAPTER 1. INTRODUCTION}

\subsection{Motivation}

The trucking industry plays a vital role in the United States economy and society. Trucking allows for the transport of goods across the country from inter-city to coastline-tocoastline trips; thus allowing for product specialization in the United States. With the construction of the Eisenhower Interstate System in the 1950's, the trucking industry flourished and became a very popular form of freight transport (USDOT- FHWA 2013). Since a vast number of companies rely on trucking today as their main source of shipping, it is important to make this aspect of business as cost-effective as possible.

From the trucking industry perspective, freight agents have to make both long term strategic decisions as well as short term operational decisions. Freight agent could correspond to the owner of a small trucking company, the supply chain manager of a large business enterprise like FedEx, Caterpillar, or Walmart, or a Third Party Logistics (3PL) company. 3PL companies provide different types of freight services - actual transportation through trucks, recommendations on supply chain management, etc. - depending on their size and scope. One of the main long-term strategic decisions made by freight agents is locating warehouses or facilities for storage and transshipment. Short term operational decisions involve routing decisions associated with trucks - when to pick up, when to deliver, what route to follow, how often deliveries occur, etc. Operational decisions normally change on a daily, weekly, or monthly basis depending on the scope of operations. While the specific details and the costs of operational decisions are not considered while making strategic location decisions, freight agents often use estimates of routing costs. Costs are approximated because it is usually difficult to determine accurate details of routing and the associated costs when making facility location 
decisions for ten to thirty years in the future. The importance of strategic long term and short term operational decision making has increased in recent times. With the rise of fuel prices and all of the regulations placed on trucking companies, including noise and exhaust emissions standards, inspection, repair and maintenance regulations as well as driver regulations, it becomes vital for these companies to work and run efficiently to reduce their environmental impact. This thesis was primarily concerned with developing mathematical models which aid strategic long term facility decision making while accounting for uncertainty in demand. In particular, this research focused on a particular type of facility called cross-docks.

Cross-docking (CD) refers to the method of transporting freight or goods from the manufacturer to a cross-dock facility and then to the customer. At the cross-dock, the goods are unloaded, sorted and then loaded onto another truck to be delivered to the customer. The idea of a cross-dock is different than that of a typical warehouse in that goods spend little or no idle time at the cross-dock facility, while warehouses store goods. Once the goods are delivered at the facility, in most cases, they are immediately taken to their destination truck. Intensive planning and expert logistics must be in place to manage the incoming goods and efficiently allocate them to their destination trucks with little or no wait time. Companies looking to implement crossdocking in their shipping system must first choose the optimal location for their cross-dock facility. Cross-dock facility location is very important because it improves shipping procedures, reduces costs, and also makes freight transport more efficient which reduces the environmental impact (Murray 2013).

The use of cross-docking has many advantages in the shipping field. Unlike traditional warehouses, goods flow through the facility in a timely manner and the goods or products are never stored. Since the products are never stored, there is no wasted time and labor in locating 
the items when they are needed for delivery. Cross-docking saves companies from the costly warehouse procedures of storing and picking. With the removal of storing, delivery to the customer can be expedited since there is no wait time on locating and picking goods. Crossdocking also leads to the benefits of a smaller facility, less equipment, smaller labor force, and a decreased risk of items being damaged or becoming outdated. The use of cross-docking is important in the transportation industry because it reduces the burden of transportation costs on companies (Galbreth et al. 2008). Cross-docking reduces labor costs to stock and move goods in the warehouse, reduces delivery times to customers, and reduces the amount of space needed in the intermediate facilities.

Cross-docking also provides opportunities for consolidation. Shipments arriving at a crossdock may be consolidated into a single truck if they are to be delivered to a single destination. Consolidation creates many benefits for companies including the following: discounts on less than truck load (LTL) shipments, fuel savings, driver wage savings, less empty waste space on trucks, and reduction of environmental impacts. Through consolidation of LTL into truck load (TL) shipments, companies can see a reduction in freight transportation costs by $20-35 \%$, according to Chris Kane, vice president of sales and marketing for a third-party logistics provider based in Scranton, PA (O'Reilly 2009). While consolidation can lead to major cost savings for companies, it also serves as a mechanism to help "green" the freight industry. Ülkü (2012) talks about Green Supply Chain Management (GSCM) which can be used to help reduce freight related pollution, such as emissions and noise pollution. Srivastava (2007) defines GSCM as “integrating environmental thinking into supply chain management, including product design, material sourcing and selection, manufacturing processes, delivery of the final product to the consumers as well as end-of-life management of the product after its useful life." Shipment 
consolidation, cross-docking, and vehicle routing optimize delivery of the final product to consumers and reduce wasted trips and truck space; therefore, these strategies can be seen as excellent ways to help "green" the supply chain.

As stated above, shipment consolidation has the ability to generate cost savings for freight companies. However, determining discounts for companies taking part in LTL consolidation can be quite complicated and time-consuming. Carriers can implement a few different types of cost structures and discounting strategies in order to reward shipment consolidation. The modified all-unit discount (MAUD) cost structure is just one of these methods. Chan et al. (2002) define the MAUD cost structure as a piecewise function in which a small shipment incurs a fixed cost and as the number of units being shipped increases, the transportation cost per unit decreases. These costs per unit are based on predefined ranges of shipment size (in units). This type of cost function allows companies to transport LTL shipments at a lower cost than if they were to use a full truckload, because of the consolidation opportunities. When companies have opportunities for consolidation, they are able to send small shipments via an LTL carrier and only use TL carriers for near truck-load size shipments. With many small shipments consolidated to one truck rather than many large trucks with wasted space, transportation cost reductions are incurred through truck maintenance, fuel, and driver wage savings. Note that the MAUD cost structure is very detailed and is suitable when making optimal operational plans. This thesis focused on long term strategic location decisions. Therefore, a simple discounted cost structure was used rather than the MAUD cost structure.

One major issue in making long term strategic location decisions is accounting for uncertainty in parameters. When freight companies are looking at a time frame of five to ten years, there will be significant sources of uncertainty in terms of the demand for commodities, 
transportation costs, etc. The future is going to become more and more unpredictable from the perspective of freight managers due to changes occurring in the freight industry such as globalization, new industry practices like electronic commerce, and volatility in fuel prices. Lessard (2013) provides a detailed review of the various uncertainties and risks in global supply chain management. Past research has shown that freight decisions which do not account for uncertainty in parameters can lead to poor decisions (Unnikrishnan et al. 2009). In this thesis, the focus was on the impact of demand uncertainty on location decisions. The goal of this thesis was to develop a mathematical model which helps immunize the location decisions against the impact of demand uncertainty.

\subsection{Contribution}

There have been many research papers written concerning the usage of vehicle routing and cross-docking in freight networks. These papers typically involve linear programming formulations used to model particular aspects of the cross-docking or vehicle routing system which serve to minimize total transportation costs. For example, Wen et al. (2009) developed a mathematical formulation to model vehicle routing with cross-docking which placed time constraints on shipment pick-up. Lee et al. (2006) also developed a vehicle routing schedule for cross-docking which placed constraints on vehicle departure time and arrival time. Some just studied cross-docking without vehicle routing such as Chen et al. (2006) who developed a multiple cross-docks model with inventory and time windows. Gümüş and Bookbinder (2004) looked at cross-docking and its impact on location-distribution systems in which their decision variables decide which of a group of potential cross-docks should be opened under certain network circumstances. Sung and Song (2003) also developed a model to determine cross-dock location while adding vehicle allocation, truck load capacities, and service time limits. Galbreth 
et al. (2008) investigated the usage of cross-docking and its potential value for supply chain management in which a modified all unit discount (MAUD) function was used to model LTL costs.

While these formulations were all beneficial to the industry in some way, they only modeled certain aspects of the vehicle routing and cross-docking systems. Most of them ignored the impact of uncertainty in cross-docking networks; whether it was in the form of demand uncertainty, transportation cost uncertainty, or capacity uncertainty. The contributions of this thesis are given below:

(i) Present a cross-docking optimization model which includes a location decision variable following the $p$-median problem, handling cost at the cross-docks, vehicle and cross-dock capacity constraints, multiple commodities, and a discount parameter for consolidated freight transport.

(ii) Develop a cross-docking optimization model which accounts for the impact of demand uncertainty through the utilization of robust optimization techniques.

(iii) Use real world freight networks, demands, and commodities from a Third Party Logistics Company in these models.

(iv) Study the value of accounting for demand uncertainty by comparing deterministic and robust total costs and capacity shortages to each other.

(v) Evaluate the potential of demand inflation strategies to combat demand uncertainty when compared to robust optimization strategies. 


\section{CHAPTER 2. LITERATURE REVIEW}

The literature review of this thesis provides an overview of four pertinent literature areas: freight operations and pricing, cross-dock operation modeling, facility location decision problems, and uncertainty in cross-dock location models.

\subsection{Freight Operations and Pricing}

Since the trucking industry plays such a vital role in the operation and survival of nearly all transportation and distribution networks, it is very important to be familiar with freight classification and pricing when working with cross-dock systems. In the trucking industry, shipments or freight are generally classified as truckload (TL) or as less than truckload (LTL). TL refers to a shipment which fills the entire truck, thus making a full truck load. LTL refers to relatively small freight which does not fill a standard truck, such that it is less than a truckload. LTL shippers often look for consolidation opportunities or use smaller trucks in order to reduce wasted space and cut costs, whereas TL shippers do not have the opportunity for consolidation due to their already full trucks (Carr 2009).

TL and LTL shippers have very different operating systems. TL service providers typically transport single large shipments to one customer or retailer. It is beneficial for them to use the largest truck allowed in order to move as much freight as possible with one trip. TL shippers also try to consult with customers in order to plan shipments for back hauls so that dead loads may be avoided (Carr 2009). An LTL carrier operates in an opposite manner compared to TL, such that the LTL carrier's goal is to carry many small shipments to many different places (Carr 2009). An LTL network operates with intermediate facilities such as hubs or in this case, cross-docks. These intermediate facilities allow the carrier to consolidate small shipments from many different local customers onto one truckload. The individual shipments act as a TL when 
they are transported over a long distance to another hub. At the hub close to the multiple destinations, shipments are usually separated onto smaller trucks and sent to their individual destinations. According to Carr (2009), “LTL networks like Yellow Freight or FedEx may consist of more than one hundred transshipment terminals" or hubs. LTL shipments fall in the weight range of 100 to 20,000 lbs., whereas TL shipments weigh more than 20,000 lbs., up to truck weight allowance (Carr 2009).

Because TL and LTL shipping are so different from each other, they have different pricing mechanisms. TL shipping is rather simple in that the rate is based on a dollar amount per mile. The rate may change due to factors such as "geography, accessory services, and delivery deadline" (Carr 2009). LTL is much more complicated to price than TL shipping. LTL pricing is determined by the National Motor Freight Association who establishes rates based on freight class and other very important parameters. The rates range in value from 50 to $500 \%$ in which $100 \%$ is the base rate. The rates are based on a $100 \mathrm{lb}$. shipment, so that they are defined as cwt (hundred weight). For example, a $400 \mathrm{lb}$. shipment with a rate of $78 \mathrm{cwt}$ would cost $\$ 312$ to ship. When the size of shipments approaches TL capacity, they are often discounted by the trucking company (Carr 2009). In an effort to reduce shipping costs, companies consolidate small shipments with the hope of many benefits such as decreased fuel consumption, reduced pollution, and less wasted space.

Different pricing scenarios may be used in order to determine rates for consolidated shipping. One prominent method is the modified all-unit discount (MAUD) cost function. According to Chan et al. (2002), if a customer orders Q units of a commodity, the transportation cost is determined by the following piecewise function. 


$$
G(Q)=\left\{\begin{array}{cc}
0 & \text { if } Q=0, \\
c & \text { if } 0<Q<M_{1}, \\
\alpha_{1} Q & \text { if } M_{1} \leq Q<M_{2}, \\
\alpha_{i} Q & \text { if } M_{i} \leq Q<M_{i+1}, \quad i=2,3, \ldots, n-1, \\
\alpha_{n} Q & \text { if } M_{n} \leq Q,
\end{array}\right.
$$

Where $\alpha_{1}>\alpha_{2}>\ldots \geq 0$ and $\alpha_{1} \mathrm{M}_{1}=\mathrm{c}$.

In the function, $Q$ is the shipment quantity or units, $M_{i}$ is a cutoff quantity, $c$ is a fixed cost for shipping a small quantity, and $\alpha_{i}$ is the discounted cost greater than or equal to zero. If a shipment size $(Q)$ falls into the range between $M_{l}$ and $M_{2}$, then the shipment cost is equal to the size of the shipment multiplied by the discounted cost, $\alpha_{1}$. Figure 1 below shows how the quantity ranges and discounts are defined.

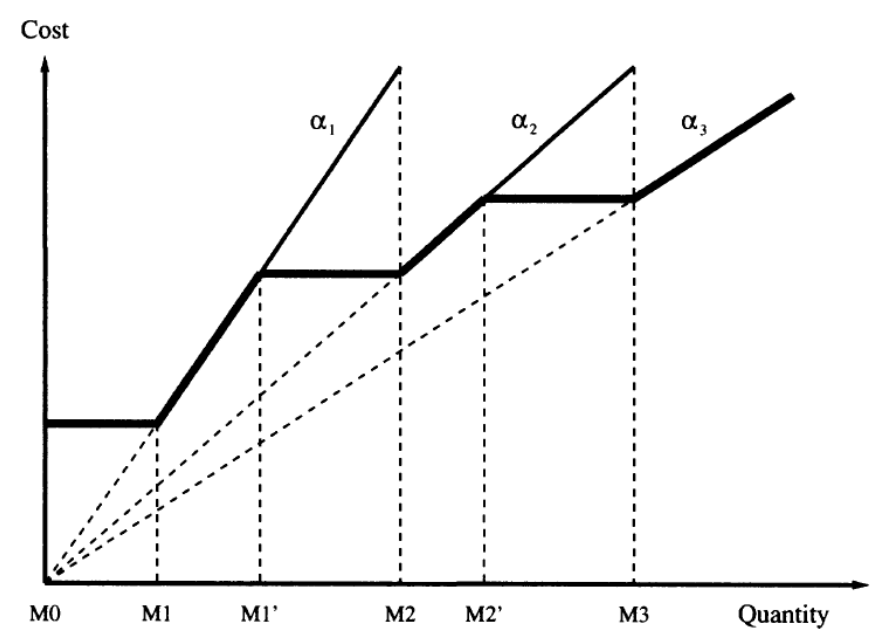

Figure 1: MAUD Cost Structure (Chan et al. 2002)

In some cases, customers may over declare in order to receive a greater discount (Chan et al. 2002). The horizontal lines on the figure above are the areas where customers benefit from over declaring (Galbreth et al. 2008). Because of consolidation, this type of pricing allows customers to ship at lower cost than if they were forced to ship TL.

A quite simpler solution to LTL pricing is the method of using a discount factor on any portions of transport where consolidation takes place. The discount factor pricing method was 
used in this cross-docking model, such that shipments from the cross-dock nodes to the destination nodes had a discount factor ranging from 0 to 1 applied to them. The focus of this thesis was on long term strategic location decisions. For making such decisions, in general, an approximate estimate of the routing costs is needed. When planning for a time frame of five to ten years in the future, it is difficult to come up with accurate estimates of the quantity cutoff points and the prices for each load range. A discount factor of 0.8 was used in this study, which was based on industry standards, as discussed with Aerostream Logistics. This meant that consolidated shipments cost only $80 \%$ of the TL shipping costs, which were charged on a cost per mile basis.

\subsection{Cross-dock Operation Modeling}

Cross-docking is a warehousing strategy in which goods are sent from an origin or supplier to a cross-dock and then to the destination or customer with little or no wait time at the intermediate facility. Many different models have been developed in transportation research in an attempt to capture the system of cross-docking and all of its many facets. These models aim to realistically generate a formulation or algorithm which represents real world transportation and warehousing networks in order to optimize the flow of goods and cut costs. The simplest models of networks using cross-docks are generally the easiest to solve, but models with more realistic constraints usually give a better representation of the actual network. Therefore, researchers must determine which constraints, such as vehicle capacity, warehouse capacity, arrival time window, departure time window, etc., should be integrated into models in order to make them more realistic and what constraints should not be included in order for the models to be able to be solved by computer programs or heuristics. This section synthesizes the various mathematical models used to optimize the different aspects of cross-dock operations. 
According to Apte and Viswanathan (2000) a cross-docking warehouse functions in much the same way as a traditional mixed warehouse, in which truckload shipments enter the facility, are broken up and then consolidated to other trucks to create a variety of product shipments which are then sent direct to the customer. In a traditional warehouse, goods are sent to the warehouse from the supplier and then are stored until they are requested by customer. Once requested, the products are picked from the warehouse and shipped to the customer. According to Van Belle et al. (2012) product storage and order picking are usually the two most expensive activities. This makes cross-docking a realistic cost-saving approach as it eliminates the need to store and pick goods. Cross-docking offers many benefits to the transportation industry including network cost savings and reduced shipping times. However, not all products are right for this type of transport; Richardson (1999) says that goods which have a large, foreseeable demand and rather short delivery times are some of the best contenders for crossdocking. Walmart has realized the benefits of cross-docking in its supply chain network which is vital to the company's logistics management (Sung and Song 2003). In fact, as stated by Stalk et al. (1992), Walmart was able to decrease its "costs of sales by $2 \%$ to $3 \%$ compared with the industry average" by moving a larger percentage of goods through its own warehouses than its competitors, who were moving more goods through a third party warehouse.

The use of cross-docks inherently allows for the removal of the costly warehouse operations of storing and picking. Cross-docks operate in three main steps: 1) products arrive at the facility where they are scanned into the system, 2) products are sorted based on their destination (destination information is generally included in the bar code of the package), 3) products are transferred to the correct shipping dock and sent to their destination (Liao et al. 
2012). The three step process flows continuously unlike a traditional warehouse. The figure below shows a typical flow in a cross-dock facility as described above.

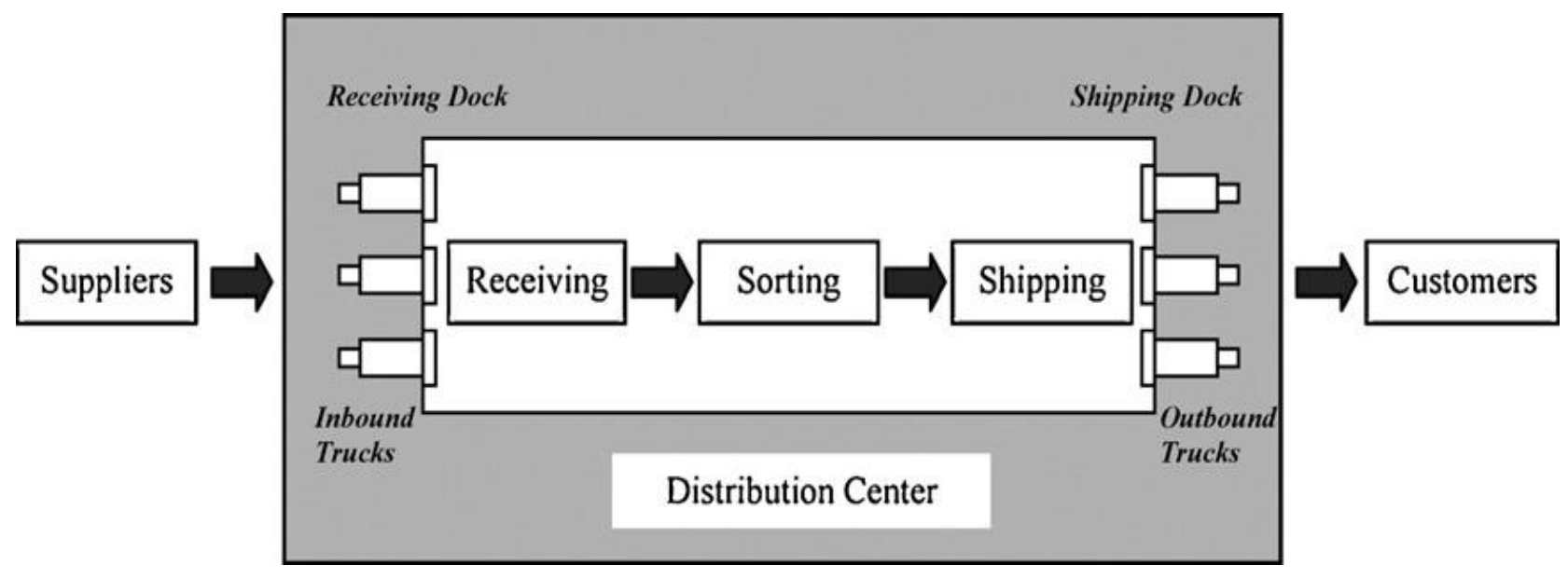

Figure 2: Typical Flow in a Cross-Dock System (Liao et al. 2012)

Cross-docks enable consolidation at centralized or optimal locations between the suppliers and customers. This means that LTL shipments which create inefficiencies due to wasted space can be consolidated into TL shipments which make use of the entire truck. The figure below shows a schematic of a network before and after cross-docking is implemented.
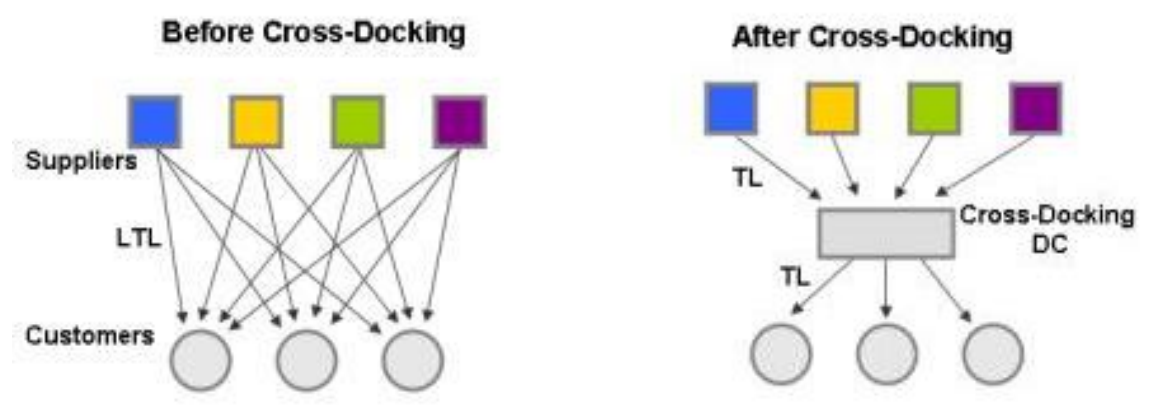

Figure 3: Value of Cross-Dock (Faint 2011)

Figure 3 shows that before cross-docking, an LTL shipment must be sent from each supplier to each destination, totaling 12 LTL shipments. After cross-docking, a single TL shipment is sent from each one of the suppliers to the cross-dock, and a single TL shipment is 
sent to each customer from the cross-dock, totaling seven shipments. The use of the cross-dock in this sample network allows for fewer more cost-effective and efficient shipments.

Schaffer (1998) makes a very logical point in stating that certain activities, such as shipping, receiving, storing, and picking, can be made more efficient to cut down on costs, but the most significant cost reductions would come from removing the operation altogether. When implementing cross-docking, there are many needs that must be met in order to make the warehousing strategy successful. Schaffer (1998) outlines requirements for successful crossdocking which fall into six key groupings including the following: "1) partnering with other members of the distribution chain, 2) absolute confidence in the quality and availability of product, 3) communications between supply chain members, 4) communications and control within the cross docking operation, 5) personnel, equipment and facilities, and 5) tactical management". Most failures within companies attempting to introduce cross-docking occur when proper planning and intensive logistics are not in place to manage the flow of goods (Schaffer 1998).

Another vital aspect of cross-docking is the actual layout of the cross-dock facility. According to Bartholdi and Gue (2004), most of the cross-docks in the United States were operated by LTL carriers due the fact that cross-docking was still a rather new operation. They observed a total of six different shapes for cross-dock layouts. Most cross-docks fell into the Ishape, while L-, U-, T-, H-, and E-shapes have also been found. The wide variety in facility shape can be attributed to many different causes including the following: companies leasing an existing warehouse, constraints on facility size, constraints on land availability, lot restrictions, cost constraints, and poor designs, among other reasons. Figure 4 shows some, but not all, typical cross-dock shapes found in practice (Bartholdi and Gue 2004). 


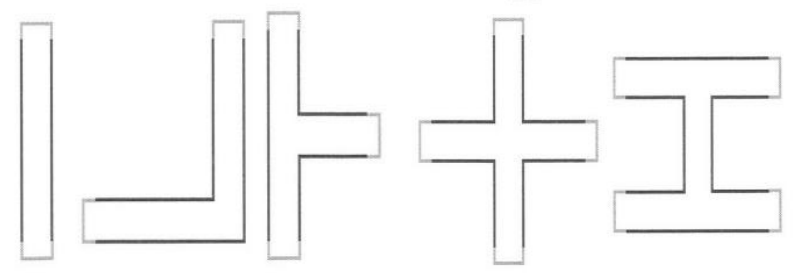

Figure 4: Some Typical Cross-Dock Shapes (Bartholdi and Gue 2004)

Bartholdi and Gue (2004) measured the performance of different cross-dock facility shapes and found that the I-shaped cross-dock was the most efficient for small facilities (less than 150 doors), the T-shaped was best for medium sized cross-docks (between 150 -200 doors) and the X-shape was the most efficient for large warehouses (more than 200 doors). Vis and Roodbergen (2011) outlined three general facility design stages used to minimize handling and waiting times in cross-docks. The first step involved defining the general layout of the facility also called the "block layout", most importantly the location of the loading docks and the temporary product storage space. The second stage was to determine exactly how the loading docks and doors and storage space would be designed. And finally, the last step was to determine procedures that would allow the cross-dock to run efficiently at each individual block and as a whole (Vis and Roodbergen 2011).

Sung and Song (2003) state that a transportation network which has cross-docking centers integrated into its system should cogitate certain constraints and parameters which arise from consolidation. Some of the issues they note involve schedules of vehicles taking part in consolidation, time restrictions on entry, exit and the transfer of goods, determining optimal facility location, and allocating vehicles. Therefore, Sung and Song (2003) develop a model to optimize cross-dock facility location and allocate vehicles to their service network while meeting certain time constraints and staying within vehicle capacity. Lee et al. (2006) model vehicle routing with cross-docking and constraints on vehicle departure and arrival times in order to 
determine an optimal route and schedule for each vehicle and arrival time at a cross-dock center to minimize total transportation costs for the network. Chen et al. (2006) considered a network of cross-docks, rather than just a single cross-dock, in order to better model larger service networks. In the study, they modeled delivery and pickup time windows, cross-dock capacity constraints and handling costs at the cross-dock facilities in order to minimize transportation cost based on known supplies and demands for the network. Gümüş and Bookbinder (2004) developed several cross-docking models in order to compare the effect of different numbers of manufacturers, cross-docks, and retailers. The purpose of their individual models was to determine the number of cross-docks which were opened from a set of potential cross-docks, the number of trucks used to transport goods through the cross-docks, and the consolidation details for each different scenario. Galbreth et al. (2008) created a cross-docking model in which LTL costs were determined using the MAUD cost function, in order to study three main research questions. The three questions Galbreth et al. (2008) were concerned with were the value of cross-docking when demand variability is low, when average demands are close to TL capacity, and when the holding cost at customer locations is high. A mathematical formulation for a cross-docking network with vehicle routing and time constraints for pick-up and delivery as well as consolidation decisions at the cross-dock was developed by Wen et al. (2009).

The extent to which models accurately replicate real world situations defines the complexity of solving them. In general, mathematical formulations developed for cross-docking are binary integer linear programs. Traditional solvers like GAMS and CPLEX can solve binary integer linear programs for small to medium sized formulations, but are unable to handle very large problems. Because of this, other methods have been developed to solve or simplify large problems. Many heuristic search based algorithms can be found in research to help solve large, 
complex programs. Heuristic methods provide near optimal solutions in a computationally efficient manner. According to Chen et al. (2006), using tabu search heuristics generated better solutions, more quickly to their model than CPLEX. Liao et al. (2010) developed a new tabu search algorithm to solve their vehicle routing problem with cross-docking that they said outperformed an existing tabu search algorithm with a shorter solver time. Vahdani and Zandieh (2010) used five meta-heuristic algorithms including a genetic algorithm, tabu search, simulated annealing, electromagnetism-like algorithm, and variable neighborhood search algorithm to solve a cross-docking schedule problem in order to minimize operation time.

The next section reviews relevant literature on strategic location decisions with respect to cross-docks and other general facilities.

\subsection{Facility Location Decision Problem}

Another very important aspect of optimizing a cross-docking network is the facility location decision problem. The facility location decision problem involves determining which of a group of potential cross-docks or other intermediate facilities should be opened and which customers should be served from those facilities in order to maximize efficiency and minimize total cost. Figure 5 shows a typical basic layout to help better explain the facility location decision problem.

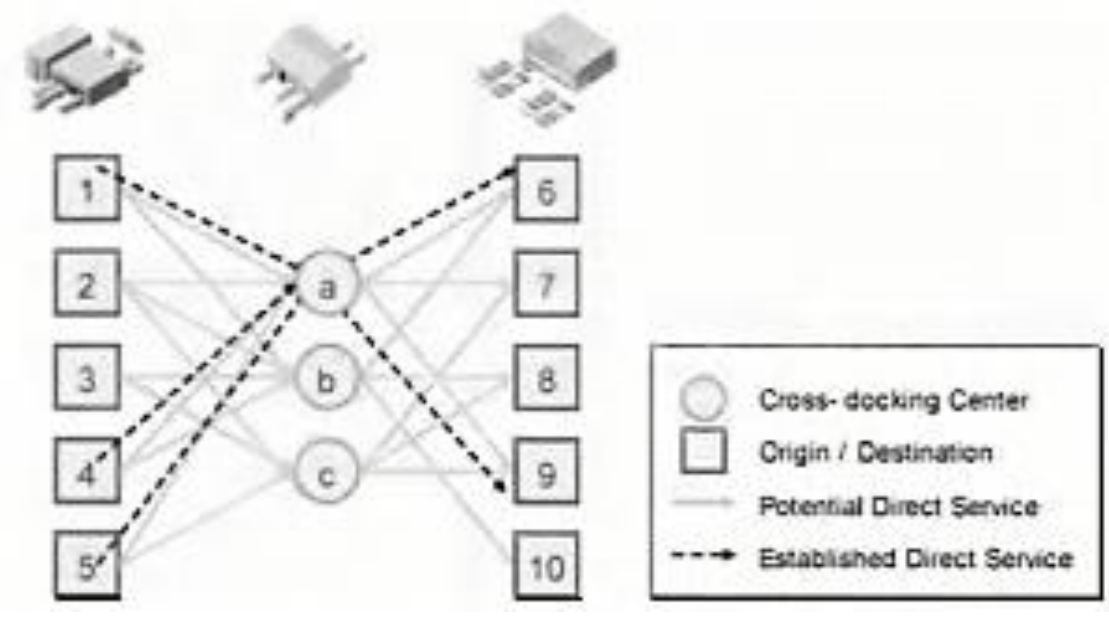


Figure 5: Facility Location Decision Problem (Sung and Song 2003)

In Figure 5, the squares labeled one through ten represent origins or destinations, the circles represent cross-docking centers, the solid lines represent potential direct service, and the dotted lines represent the established direct service. In this problem, three potential cross-dock locations were considered which are represented by a, b, and c. Through optimization techniques, cross-dock location a was chosen to be opened since it generated the lowest transportation cost (Sung and Song 2003).

The location decision for intermediate facilities in a transportation network is a very important aspect in the modeling and optimization of cross-docking networks. In fact, according to Daskin et al. (2005), "location decisions may be the most critical and most difficult of the decisions needed to realize an efficient supply chain". Deciding where to locate cross-docks is a very difficult task because once a facility is built it cannot be easily changed or moved due to changes in demand, transportation costs or availability, and element prices (Daskin et al. 2005). Unlike inventory and transportation plans which can be changed on relatively short notice, facility location is usually permanent and moving cross-docks is very costly. Ko (2005) states that "facilities location and the distribution process are two key components of a distribution system". Because the facility location and the distribution process are interrelated, they should be used together when making decisions about either of these two elements (Ko 2005). Clearly, cross-dock location decision should be included in models developed to optimize transportation networks because of the important role it plays in the overall distribution system.

Sung and Song (2003) developed a model to locate cross-dock facilities and allocate vehicles for a supply chain network in order to minimize costs. The model was optimized using both a proposed tabu search heuristic algorithm and the valid-inequality separation algorithm. Gümüş and Bookbinder (2004) solved a cross-docking model using four varieties of distributor, 
cross-dock, customer, and product combinations in order to determine which cross-docks should be opened from a set of feasible locations, how many trucks should be used for direct shipment and shipment through the cross-docks, and how consolidation should be executed.

Daskin et al. (2005) discuss a few facility location decision models including the fixed charge facility location problem, integrated location/routing models, integrated location/inventory models, planning under uncertainty, and location models with facility failures. The literature on facility location models can be primarily classified into $p$-median facility location models and transportation and facility location cost minimizing models. The model developed in this research is most similar to the $p$-median facility problem. According to Alp et al. (2003) "the goal of the model is to select the locations of $p$ facilities to serve $n$ demand points so as to minimize the total travel." In the $p$-median problem, there is no cost incurred for opening a certain cross-dock facility. It is assumed that the cross-docks are already built and all that needs to be determined is which ones to open and use. The number of facilities to be opened is set to a certain number, $p$. The facility location decision problem is included in order to realistically model transportation network scenarios for companies wishing to begin cross-docking or optimize their current system. The goal of the transportation and facility location cost minimizing models are to establish any number of facilities so that the total cost of transporting goods, establishing facilities, and operating facilities is minimized. The literature can be further classified into uncapacitated and capacitated facility location problems. In the uncapacitated variant, no hard capacities are established at the facilities. The facilities can handle any number of commodities. In the capacitated variant, the facilities have a hard capacity which depends on the type of facility, number of workers, quantity of machinery available to process the goods, etc. The amount of goods handled by the facility has to be less than the capacity. Owen and Daskin 
(1998), Melo et al. (2009), and Klose and Drexl (2005) provide a detailed review of the various mathematical models used for network facility location.

This research focused on the cross-dock facility location which is marginally more complicated than a simple facility location. The simple facility location models are from the perspective of a warehouse supplying goods to consumers or collecting goods from suppliers. The cross-docks are established from the perspective of consolidation. In addition, this research considered the capacity of trucks and cross-docks. Another important contribution of this work was the consideration of demand uncertainty in a cross-dock facility location context.

\subsection{Uncertainty in Cross-dock Location Models}

Researchers have used two main mathematical paradigms to capture the impact of uncertainty in optimization models - stochastic programming and robust optimization based strategies. Stochastic programming models assume that the uncertainty of a parameter or input is captured by a pre-specified probability distribution (Birge and Louveaux 1997; Kall and Wallace 1994). In this thesis, a stochastic programming approach would have implied that the probability distribution of the demand was known. In many situations, it is difficult to predict the future probability distribution of demand. Several researchers have recognized this shortcoming of stochastic programming and are of the view that while stochastic programming is a theoretically rigorous way of capturing uncertainty, it is often difficult to obtain accurate estimates of the probability distribution. They assumed that the uncertain parameters can vary in a pre-specified interval or range. Ranges of the uncertain parameters are easier to obtain than the probability distribution. In fact, freight agents with significant experience in the field should be able to come up with reasonable estimates on the ranges in which the demand should lie. This stream of work is collectively known as robust optimization (Ben-Tal and Nemirovski 1998, 1999, 2000; 
Bertsimas and Sim 2003, 2004). Accounting for uncertainty significantly increases the complexity of both the formulations and the solution algorithms as compared to deterministic models. However, past work in relevant areas such as transportation network analysis and supply chain management have shown that not accounting for uncertainty can lead to incorrect estimates of system performance, as well as poor strategic and operational decisions (Waller and Ziliaskopoulos 2001; Waller et al. 2001; Gardner et al. 2008, 2009; Unnikrishnan 2008; Duthie et al. 2009; Unnikrishnan and Waller 2009; Unnikrishnan et al. 2009; Unnikrishnan and Figliozzi 2011).

Snyder (2006) provides a detailed review of literature on the impact of various forms of uncertainty on facility location models. However, the work on capturing the impact of uncertainty in the context of cross-dock facility location is limited. Soanpet (2012) adopted a stochastic programming approach to model capacity uncertainty in cross-dock facility location models. In this thesis, a robust optimization approach was adopted to capture the impact of demand uncertainty in cross-dock facility location models. The robust optimization approach was chosen as it was believed that the inputs to the model could be more easily estimated by practitioners.

\subsection{Literature Summary}

A review of the literature shows that various models have been developed to locate crossdocks and route trucks to optimize freight networks through minimizing total transportation costs. In this study, a cross-dock facility location formulation was developed which followed the $p$-median facility problem, as explained above. The major contributions come from the use of real world data and the modeling of demand uncertainties. In most studies, demands and networks are randomly generated, but in this study a real freight network was used with real origin-destination demands for dry, refrigerated, and frozen goods. Also, in the other cross- 
docking models, demands were assumed to be known, or deterministic. But, in this study, the demands were assumed to be uncertain and were modeled through the utilization of robust optimization. In reality, exact demands are not generally known, but are subject to outside forces, such as seasons, fuel prices, weather, economic stability, etc. Robust optimization accounts for these variations in demand in order to better model real world situations. The performance and total cost of the deterministic and the robust models were also compared to each other. The next chapter provides the deterministic cross-dock facility location formulation. 


\section{CHAPTER 3. DETERMINISTIC LOCATING MODEL FOR CROSS-DOCK NETWORK DESIGN}

\subsection{Introduction}

This section describes the basic deterministic cross-dock network design formulation. This deterministic formulation has been used by Soanpet (2012). The deterministic formulation was used as a basis for generating the robust formulation accounting for demand uncertainty in the next chapter.

\subsection{Problem Definition and Formulation}

Let $N$ denote the set of nodes and $A$ the set of arcs. Let $O, D, K$ represent the set of origin, destination, and potential cross-dock location nodes, respectively. Let $L$ represent the set of commodities and $Z_{+}$the set of positive integers. Let $i, j, k$ represent indexes for nodes and $l \in L$ represent indexes for the commodities.

The inputs to the model are described next. Let $q_{i j}^{l}$ represent the demand in pallets of commodity $l \in L$ which needs to be transported from origin node $i \in O$ to destination node $j \in D$. Let $U$ and $W$ represent the capacities of the truck and the cross-dock, respectively. Let $c_{i j}^{l}$ represent the unit truckload cost, in dollars per mile, for transporting commodity $l \in L$. Let $\gamma$ represent the discount factor in transporting goods from cross-docks to destinations. Let $s_{i j}$ denote the distance, in miles, between node $i \in N$ and node $j \in N$. Let $h_{k}$ denote the unit cost of handling a pallet in a cross-dock at location $k \in K$.

The mathematical formulation is provided from the perspective of a Third Party Logistics (3PL) company. The goal of the 3PL firm is to choose $\mathrm{P}$ facilities out of established cross-docks with the objective of minimizing the total transportation and facility handling costs subject to constraints on routing and capacity. 
The decision variables for the model are described next. The decision variables can be categorized into those corresponding to flow and those corresponding to location. The decision variable $x_{i j k}^{l}$ takes the value 1 if commodity $l \in L$ is transported from origin node $i \in O$ to destination node $j \in D$ through cross-dock location $k \in K$ and 0 otherwise. The decision variable $v_{i j}^{l}$ takes the value 1 if commodity $l \in L$ is transported from origin node $i \in O$ to destination node $j \in D$ directly without using cross-docks. The decision variable $y_{i j}^{l}$ denotes the number of trucks transporting commodity $l \in L$ from origin node node $i \in O$ to destination node $j \in D$. The decision variable $z_{k}$ takes the value 1 if a cross-dock facility is established at location $k \in K$ and 0 otherwise. The mathematical programming formulation which corresponds to the objective of the 3PL company and flow constraints is provided next.

$$
\begin{aligned}
\operatorname{Min} \quad \sum_{i \in O} & \sum_{k \in K} \sum_{l \in L} c_{i k}^{l} s_{i k} y_{i k}^{l}+\gamma \sum_{k \in K} \sum_{j \in D} \sum_{l \in L} c_{k j}^{l} s_{k j} y_{k j}^{l}+\sum_{i \in O} \sum_{j \in D} \sum_{l \in L} c_{i j}^{l} s_{i j} y_{i j}^{l} \\
& +\sum_{k \in K} h_{k} \sum_{i \in O} \sum_{j \in D} \sum_{l \in L} q_{i j}^{l} X_{i j k}^{l}
\end{aligned}
$$

Subject to:

$$
\sum_{k \in K} z_{k}=P
$$

$$
\begin{array}{ll}
\sum_{k \in K} x_{i j k}^{l}+v_{i j}^{l}=1 & \forall i \in O, j \in D, l \in L \\
\sum_{j \in D} q_{i j}^{l} x_{i j k}^{l} \leq U y_{i k}^{l} & \forall i \in O, k \in K, l \in L
\end{array}
$$




$$
\begin{array}{lr}
\sum_{i \in O} q_{i j}^{l} x_{i j k}^{l} \leq U y_{k j}^{l} & \forall j \in D, k \in K, l \in L \\
q_{i j}^{l} v_{i j}^{l} \leq U y_{i j}^{l} & \forall i \in O, j \in D, l \in L \\
x_{i j k}^{l} \leq z_{k} & \forall i \in O, j \in D, k \in K, l \in L \\
\sum_{i \in O} \sum_{j \in D} \sum_{l \in L} q_{i j}^{l} x_{i j k}^{l} \leq W z_{k} & \forall k \in K \\
z_{k} \in\{0,1\} & \forall i \in O, j \in D, l \in L, k \in K \\
x_{i j k}^{l} \in\{0,1\} & \forall i \in K, j \in D, l \in L \\
v_{i j}^{l} \in\{0,1\} & \forall i \in N, j \in N, l \in L
\end{array}
$$

Equation (1) corresponds to the objective function which has four terms. The first term of equation (1) corresponds to the total routing costs from origins to cross-docks; the second term denotes the total routing cost from cross-docks to destinations; the third term represents the total routing cost of all goods which are transported directly from origins to destinations without using cross-docks. The final and fourth term denotes handling costs of all goods at the cross-docks.

Equations (2)-(12) denote the constraints of the optimization formulation. Equation (2) constrains the total number of cross-docks to be opened to be equal to P. Equation (3) ensures that all demands are transported to their destinations either through the cross-docks or directly 
without using a cross-dock. Equation (4), (5), and (6) correspond to truck capacity constraints. Equation (4) ensures that the volume of goods being transported between origin node $i \in O$ and cross-dock $k \in K$ for a specific commodity $l \in L$ is less than the capacity of the trucks operating between those two nodes. Similarly equation (5) ensures the volume of goods being transported between cross-dock $k \in K$ and destination node $j \in J$ for specific commodity $l \in L$ is less than the truck capacity on that route. Equation (6) enforces the truck capacity constraint on the direct route between origin node $i \in O$ and destination node $j \in D$. Constraint (7) ensures that goods are transported through a cross-dock only if it is opened. If a cross-dock at location $k \in K$ is not opened, then $z_{k}=0$ which makes $W z_{k}=0$. Since $\sum_{i \in O} \sum_{j \in D} \sum_{l \in L} q_{i j}^{l} x_{i j k}^{l} \leq W z_{k}$, this will ensure $\sum_{i \in O} \sum_{j \in D} \sum_{l \in L} q_{i j}^{l} x_{i j k}^{l}=0$ which implies if the cross-dock is not selected, it will not be used to handle goods. Equation (8) ensures that the total volume of goods being transported through a cross-dock is less than the capacity of the cross-dock. Equation (9) defines the location decision variable to be a binary variable. Equations (10) and (11) define the routing variables to be binary variables. Equation (12) enforces integrality constraints on the number of trucks on each route.

The above formulation can be easily modified to consider the case where the objective of the 3PL company is to minimize both the transportation and the facility location costs. In this case let $f_{k}$ denote the cost of establishing the facility at location $k \in K$. The objective function can be modified as follows.

$$
\begin{aligned}
\operatorname{Min} \quad \sum_{i \in O} \sum_{k \in K} \sum_{l \in L} c_{i k}^{l} s_{i k} y_{i k}^{l}+\gamma \sum_{k \in K} \sum_{j \in D} \sum_{l \in L} c_{k j}^{l} s_{k j} y_{k j}^{l}+\sum_{i \in O} \sum_{j \in D} \sum_{l \in L} c_{i j}^{l} s_{i j} y_{i j}^{l} \\
+\sum_{k \in K} h_{k} \sum_{i \in O} \sum_{j \in D} \sum_{l \in L} q_{i j}^{l} X_{i j k}^{l}+\sum_{k \in K} f_{k} z_{k}
\end{aligned}
$$


The constraints of this formulation correspond to equations (3) to (12). The only modification in the constraint is the removal of equation (2). In this case the number of facilities to be opened is not constrained to be equal to $\mathrm{P}$. 


\section{CHAPTER 4. ROBUST LOCATING MODEL FOR CROSS-DOCK NETWORK DESIGN WITH DEMAND UNCERTAINTY}

\subsection{Robust Optimization}

In general, there are two major streams of research for dealing with the uncertainty in data, namely: robust optimization and stochastic programming. While stochastic optimization relies on the distribution of the uncertain parameters, robust optimization does not make any assumptions regarding the distributions of the uncertain parameters. Instead, it seeks to minimize the worst case realization of the uncertain parameters with respect to a predefined uncertainty set. Therefore, considering the limited information on specifications of the distribution function for the uncertain parameter, robust optimization framework is a desired approach for dealing with the uncertainty in models. Specifically, Wagner et al. (2009), Baron et al. (2011), and Gülpinar et al. (2013) have adopted a robust optimization framework for solving facility location problems.

\subsection{Robust Optimization Problem Formulation}

In this section, the robust optimization framework was adopted to deal with the uncertainty in demand. More specifically, it is assumed that the demand is uncertain and limited information regarding its distribution function is available. Mathematically it is also assumed

that the demand is described by mean $\bar{q}_{i j}^{l}$ and an associated uncertainty term $\Delta_{i j}^{l}$. The random uncertainty term $\Delta_{i j}$ is a representation of variation in demand which mathematically can be expressed as the combination of $M$ independent sources of uncertainty. Each source has an associated weight of $b_{i j}^{l m}$. Therefore, uncertain demand $\tilde{q}_{i j}^{l}$ can be expressed as the following equation. Note that Chen et al. (2007) and Wagner et al. (2009) have adopted a similar approach for modeling input parameter uncertainty. Specifically, Wagner et al. (2009) discussed how the 
following uncertainty form can capture the long term and short term demand uncertainties in facility location problems.

$\tilde{q}_{i j}^{l}=\bar{q}_{i j}^{l}+\sum_{m=1}^{M} b_{i j}^{l m} \tilde{r}_{m}$

In the above equation $\tilde{r}_{m}$ is a random variable which can be described based on three following assumptions:

i) $E\left(\tilde{r}_{m}\right)=0$

ii) $\left|\tilde{r}_{m}\right| \leq 1$

iii) $\tilde{r}_{m}$ are all independent.

Also, it is assumed that the uncertain random variables can be described by an ellipsoidal uncertainty set $U=\left\{\tilde{\mathrm{r}}_{m},\|\mathrm{r}\| \leq \Omega\right\}$ as described by Bertsimas and Sim (2004). The goal of the robust cross-dock network design problem is to determine the locations of cross-docks under worst-case outcomes of the uncertain variables belonging to the uncertainty set. In the above set, $\Omega$ corresponds to the budget of uncertainty, which adjusts the desired level of robustness. The size of the uncertainty set is a reflection of the uncertainty protection needed at cross-dock locations. Since the uncertain demand is affecting the constraints, the robust counterpart for the constraints which are affected by the uncertain demand must be provided. For example, considering demand based on equation (14), the robust counterpart for constraint (2) can be obtained according to the following procedure:

$\max _{\|r\| \leq \Omega}\left\{\sum_{j \in D} \bar{q}_{i j}^{l} x_{i j k}^{l}+\sum_{j \in D} \sum_{m=1}^{M} b_{i j}^{l m} \tilde{r}_{m} x_{i j k}^{l}\right\} \leq U y_{i k}^{l}$ 
The goal of equation (15) is to maximize the worst case realization of demand based on ellipsoidal uncertainty set of $\|r\| \leq \Omega$.

$$
\sum_{j \in D} \bar{q}_{i j}^{l} x_{i j k}^{l}+\max _{\|r\| \leq \Omega} \sum_{j \in D} \sum_{m=1}^{M} b_{i j}^{l m} \tilde{r}_{m} x_{i j k}^{l} \leq U y_{i k}^{l}
$$

Consider $Z_{2}$ as the following maximization problem:

$Z_{2}=\max _{\|r\| \leq \Omega} \sum_{j \in D} \sum_{m=1}^{M} b_{i j}^{l m} \tilde{r}_{m} x_{i j k}^{l}$

In order to solve the above maximization problem, the Lagrangian relaxation method was adopted in which the constraint $\|r\| \leq \Omega$ is relaxed assuming the Lagrangian multiplier $\alpha$. The derivation below is based on Gülpinar et al. (2013). Therefore, the Lagrangian function can be written as below:

$L(r, \alpha)=\min _{r_{m}} \max _{\alpha} \sum_{j \in D} \sum_{m=1}^{M}-b_{i j}^{l m} \mathrm{r}_{m} x_{i j k}^{l}+\alpha(\|r\|-\Omega)$

The solution of the Lagrangian function (18) can be achieved by first order optimality condition as below:

$\frac{\partial L(r, \alpha)}{\partial r_{m}}=\sum_{j \in D}-b_{i j}^{l m} x_{i j k}^{l}+\alpha \frac{r_{m}}{\|r\|}=0$

Therefore the optimal value for $r_{m}$ is obtained by equation (20):

$r_{m}=\frac{\|r\|}{\alpha} \sum_{j \in D} b_{i j}^{l m} x_{i j k}^{l} \quad \forall m \in M$ 
Considering the complementary condition $\alpha(\|r\|-\Omega)=0$ and assuming $\alpha \neq 0,\|r\|$ can be set equal to $\Omega$. Therefore

$r_{m}=\frac{\Omega}{\alpha} \sum_{j \in D} b_{i j}^{l m} x_{i j k}^{l}$

Given the expression for $r_{m},\|r\|$ can be derived as below:

$\|r\|=\frac{\Omega}{\alpha} \sqrt{\sum_{m=1}^{M}\left(\sum_{j \in D} b_{i j}^{l m} x_{i j k}^{l}\right)^{2}}$

Similarly since $\|r\|=\Omega$ the optimal value for Lagrangian multiplier $\alpha$ can be achieved through the following equation:

$\alpha=\sqrt{\sum_{m=1}^{M}\left(\sum_{j \in D} b_{i j}^{l m} x_{i j k}^{l}\right)^{2}}$

Substituting optimal value of $\alpha$ into equation (21) will provide us with the optimal expression for $r_{m}$ as below:

$r_{m}=\Omega \frac{\sum_{j \in D} b_{i j}^{l m} x_{i j k}^{l}}{\sqrt{\sum_{m=1}^{M}\left(\sum_{j \in D} b_{i j}^{l m} x_{i j k}^{l}\right)^{2}}} \quad \forall m \in M$

Finally the optimal value for $\mathrm{Z}_{2}$ is updated through the following expression

$$
Z_{2}=\Omega \frac{\sum_{m}\left(\sum_{j \in D} b_{i j}^{l m} x_{i j k}^{l}\right)^{2}}{\sqrt{\sum_{m}\left(\sum_{j \in D} b_{i j}^{l m} x_{i j k}^{l}\right)^{2}}}=\Omega \sqrt{\sum_{m=1}^{M}\left(\sum_{j \in D} b_{i j}^{l m} x_{i j k}^{l}\right)^{2}}
$$

And the robust counterpart for constraint (2) can be written as below:

$$
\sum_{j \in D} \bar{q}_{i j}^{l} x_{i j k}^{l}+\Omega \sqrt{\sum_{m=1}^{M}\left(\sum_{j \in D} b_{i j}^{l m} x_{i j k}^{l}\right)^{2}} \leq U y_{i k}^{l}
$$


Following the same strategy the robust counterpart for constraint equations which are affected with demand uncertainty (equations: (3), (4) and (6)) can be presented as according to the following table:

Table 1: Robust Counterpart for Constraint Equations Affected with Demand Uncertainty

\begin{tabular}{|c|c|}
\hline Base Equation & Robust Counterpart \\
\hline$\sum_{i \in O} q_{i j}^{l} x_{i j k}^{l} \leq U y_{k j}^{l}$ & $\sum_{i \in O} \bar{q}_{i j}^{l} x_{i j k}^{l}+\Omega \sqrt{\sum_{m=1}^{M}\left(\sum_{i \in O} b_{i j}^{l m} x_{i j k}^{l}\right)^{2}} \leq U y_{k j}^{l}$ \\
\hline$q_{i j}^{l} v_{i j}^{l} \leq U y_{i j}^{l}$ & $\bar{q}_{i j}^{l} v_{i j}^{l}+\Omega \sqrt{\sum_{m=1}^{M}\left(b_{i j}^{l m} v_{i j}^{l}\right)^{2} \leq U y_{i j}^{l}}$ \\
\hline$\sum_{i \in O} q_{i j}^{l} x_{i j k}^{l} \leq U y_{k j}^{l}$ & $\sum_{i \in O} \sum_{j \in D} \sum_{l \in L} \bar{q}_{i j}^{l} x_{i j k}^{l}+\Omega \sqrt{\sum_{m}^{M}\left(\sum_{i \in O} \sum_{j \in D} \sum_{l \in L} b_{i j}^{l m} x_{i j k}^{l}\right)^{2}} \leq W z_{k}$ \\
\hline
\end{tabular}

Also, the robust counterpart for the objective function can be formulated as the following equation:

Min

$$
\begin{aligned}
\sum_{i \in O} \sum_{k \in K} \sum_{l \in L} c_{i k}^{l} s_{i k} y_{i k}^{l}+\gamma \sum_{k \in K} \sum_{j \in D} \sum_{l \in L} c_{k j}^{l} s_{k j} y_{k j}^{l}+\sum_{i \in O} \sum_{j \in D} \sum_{l \in L} c_{i j}^{l} s_{i j} y_{i j}^{l} \\
+\sum_{k \in K} h_{k} \sum_{i \in O} \sum_{j \in D} \sum_{l \in L} q_{i j}^{l} X_{i j k}^{l}+\Omega \sum_{k \in K} h_{k} \sqrt{\sum_{m}^{M}\left(\sum_{i \in O} \sum_{j \in D} \sum_{l \in L} b_{i j}^{l m} x_{i j k}^{l}\right)^{2}}
\end{aligned}
$$

Therefore the robust modeling for the p-median cross docks network design is presented as below: 
Min

$$
\begin{aligned}
& \sum_{i \in O} \sum_{k \in K} \sum_{l \in L} c_{i k}^{l} s_{i k} y_{i k}^{l}+\gamma \sum_{k \in K} \sum_{j \in D} \sum_{l \in L} c_{k j}^{l} s_{k j} y_{k j}^{l}+\sum_{i \in O} \sum_{j \in D} \sum_{l \in L} c_{i j}^{l} s_{i j} y_{i j}^{l} \\
& +\sum_{k \in K} h_{k} \sum_{i \in O} \sum_{j \in D} \sum_{l \in L} \bar{q}_{i j}^{l} X_{i j k}^{l}+\Omega \sum_{k \in K} h_{k} \sqrt{\sum_{m}^{M}\left(\sum_{i \in O} \sum_{j \in D} \sum_{l \in L} b_{i j}^{l m} x_{i j k}^{l}\right)^{2}}
\end{aligned}
$$

Subject to:

$$
\begin{aligned}
& \sum_{k \in K} z_{k}=P \\
& \sum_{k \in K} x_{i j k}^{l}+v_{i j}^{l}=1
\end{aligned}
$$

$\forall i \in O, j \in D, l \in L$

$\sum_{j \in D} \bar{q}_{i j}^{l} x_{i j k}^{l}+\Omega \sqrt{\sum_{m=1}^{M}\left(\sum_{j \in D} b_{i j}^{l m} x_{i j k}^{l}\right)^{2}} \leq U y_{i k}^{l}$

$\forall i \in O, k \in K, l \in L$

$\sum_{i \in O} \bar{q}_{i j}^{l} x_{i j k}^{l}+\Omega \sqrt{\sum_{m=1}^{M}\left(\sum_{i \in O} b_{i j}^{l m} x_{i j k}^{l}\right)^{2}} \leq U y_{k j}^{l}$

$\forall j \in D, k \in K, l \in L$

$\bar{q}_{i j}^{l} v_{i j}^{l}+\Omega \sqrt{\sum_{m=1}^{M}\left(b_{i j}^{l m} v_{i j}^{l}\right)^{2}} \leq U y_{i j}^{l}$

$\forall i \in O, j \in D, l \in L$

$x_{i j k}^{l} \leq z_{k}$

$\forall i \in O, j \in D, k \in K, l \in L$

$\sum_{i \in O} \sum_{j \in D} \sum_{l \in L} \bar{q}_{i j}^{l} x_{i j k}^{l}+\Omega \sqrt{\sum_{m}^{M}\left(\sum_{i \in O} \sum_{j \in D} \sum_{l \in L} b_{i j}^{l m} x_{i j k}^{l}\right)^{2}} \leq W z_{k} \quad \forall k \in K$

$z_{k} \in\{0,1\}$

$\forall k \in K$ 


$$
x_{i j k}^{l} \in\{0,1\}
$$

$$
v_{i j}^{l} \in\{0,1\}
$$

$$
\forall i \in O, j \in D, l \in L
$$

$$
y_{i j}^{l} \in Z_{+}
$$

The above formulation is the robust model for $p$-median cross-dock network design where demand is assumed to be uncertain. Compared with the deterministic formulation it is observed that the equations including the uncertain parameters have been replaced by their robust counterpart. Also, it is worth mentioning that the $p$-median assumption in the above formulation can simply be relaxed by dropping equation (28) which guarantees location of $p$ facilities. However, in this study, the $p$-median variant of problem is just considered where it is assumed that all of the cross-docks are already located and built and all that must be decided is which ones to open and use.

The above formulation is a nonlinear binary integer program. General nonlinear binary integer programs are difficult problems to solve. However, the above nonlinear binary integer programs belong to a category of models called Second Order Conic Integer Programs (Atamtürk et al. 2012). Recently solvers like CPLEX have developed efficient algorithms to solve Second Order Conic Integer Programs. In this thesis, the transformation using the Lagrangian enables the exploitation of advances made by CPLEX to solve reasonably sized problems efficiently. 


\section{CHAPTER 5. NUMERICAL RESULTS}

The purpose of this chapter is to demonstrate the importance of cross-docking networks and the effects of accounting for demand uncertainties in real world freight situations through the utilization of robust optimization. The next section describes the real world freight networks, datasets, and parameters used in this study. The experimental runs for the robust and deterministic networks are then defined along with the significant results. The formulation was programmed in GAMS software and solved using the CPLEX 12.0 solver.

\subsection{Description of the Network}

Three networks were used for the analysis of robust optimization and comparison with deterministic demand. Network 1 consisted of five origin nodes, five destination nodes, and five potential cross-dock nodes. Network 2 consisted of ten origin nodes, ten destination nodes, and ten potential cross-dock nodes. Network 3 consisted of 20 origin nodes, 20 destination nodes, and 20 potential cross-dock nodes, descriptions of the three networks are in Tables 2, 3, and 4, respectively. The distance, in miles, between each node, $s_{i j}$, was found using an online mapping website. The internode mileage for Network 1 can be found in Tables 18, 19 and 20 in Appendix A. The internode mileage for Network 2 can be found in Tables 21, 22, and 23 in Appendix A. The internode mileage for Network 3 can be found in Tables 24-29 in Appendix A, as well.

Table 2: Description of Network 1

\begin{tabular}{|c|c|c|}
\hline \multicolumn{3}{|c|}{ Network 1 } \\
\hline Origins & Destinations & Potential Cross-docks \\
\hline Montgomery, AL & Westborough, MA & Lexington, KY \\
\hline Atlanta, GA & Kirkwood, NY & Charlotte, NC \\
\hline Unadilla, GA & Columbus, OH & Knoxville, TN \\
\hline Haines City, FL & Fairborn, OH & Charlottesville, VA \\
\hline Hattiesburg, MS & Eighty Four, PA & Charleston, WV \\
\hline
\end{tabular}


Table 3: Description of Network 2

\begin{tabular}{|c|c|c|}
\hline \multicolumn{3}{|c|}{ Network 2 } \\
\hline Origins & Destinations & Potential Cross-docks \\
\hline Everett, MA & Alsip, IL & Indianapolis, IN \\
\hline Franklin, MA & Danville, IL & Fort Wayne, IN \\
\hline Baltimore, MD & Des Plaines, IL & Cumberland, MD \\
\hline Elizabeth, NJ & Hanover Park, IL & Canton, OH \\
\hline Newark, NJ & Monroe, MI & Cincinnati, OH \\
\hline Sayreville, NJ & Troy, MI & Columbus, OH \\
\hline Delhi, NY & Kansas City, MO & Altoona, PA \\
\hline Waterford, NY & Springfield, MO & Pittsburgh, PA \\
\hline Hanover, PA & St. Louis, MO & Parkersburg, WV \\
\hline Hatfield, PA & Milwaukee, WI & Wheeling, WV \\
\hline
\end{tabular}

Table 4: Description of Network 3

\begin{tabular}{|c|c|c|}
\hline \multicolumn{3}{|c|}{ Network 3 } \\
\hline Origins & Destinations & Potential Cross-docks \\
\hline New Haven, CT & Alsip, IL & Fairfield, IL \\
\hline Everett, MA & Chicago, IL & Bloomington, IN \\
\hline Franklin, MA & Danville, IL & Fort Wayne, IN \\
\hline Baltimore, MD & Des Plaines, IL & Hebron, IN \\
\hline Belcamp, MD & Hanover Park, IL & Indianapolis, IN \\
\hline Elizabeth, NJ & Taylorville, IL & Lexington, KY \\
\hline Kearny, NJ & Mason City, IA & Summit, KY \\
\hline Newark, NJ & Louisville, KY & Cumberland, MD \\
\hline Sayreville, NJ & Dearborn, MI & Canton, OH \\
\hline Delhi, NY & Monroe, MI & Cincinnati, OH \\
\hline Rochester, NY & Troy, MI & Columbus, OH \\
\hline Waterford, NY & Rogers, MN & Lima, OH \\
\hline Williamson, NY & St. Paul, MN & Altoona, PA \\
\hline Blandon, PA & Kansas City, MO & Mansfield, PA \\
\hline Hanover, PA & Springfield, MO & Oil City, PA \\
\hline Hatfield, PA & St. Louis, MO & Pittsburgh, PA \\
\hline Alexandria, VA & Arlington, TN & Beckley, WV \\
\hline Lyndhurst, VA & Elkhorn, WI & Buckhannon, WV \\
\hline Newport News, VA & Milwaukee, WI & Parkersburg, WV \\
\hline Richmond, VA & Oak Creek, WI & Wheeling, WV \\
\hline
\end{tabular}


The system demands, $q_{i j}^{l}$, were defined as the number of pallets which need to be transported from origin node $\mathrm{i}$ to destination node $\mathrm{j}$. The demands consisted of three types of commodities, l: dry goods (D), refrigerated goods (R), and frozen goods (F). All of the networks along with their origin-destination demands and commodity type were extracted from real world data provided by a Third Party Logistics Company, Aerostream Logistics. Average demands for Networks 1 and 2 are in Tables 30 and 31, respectively, in Appendix A. Average demands for Network 3 are in Tables 32 through 37 in Appendix A as well. The demands for Network 3 had to be split into six tables, because of the immense size of Network 3.

Each of the commodities had a different shipping cost per mile, $c_{i j}^{l}$, which were as follows: $\$ 1.40$ for dry, $\$ 1.60$ for refrigerated, and $\$ 1.80$ for frozen. The truck capacity, $\mathrm{U}$, was set to be equal to 28 pallets. The discount factor, $\gamma$, was set to be 0.8 . The handling cost at each cross-dock, $h_{k}$, was set to be equal to $\$ 3.00$ per pallet. The number of opened cross-docks, $\mathrm{P}$, was chosen to be four for all of the networks. The values for the above parameters were based on industry standards as discussed with Aerostream Logistics.

The cross-dock capacity, W, in Network 1 was set to 175 pallets, Network 2 was set to 150 pallets, and Network 3 was set to 250 pallets. The cross-dock capacities in each network were determined based on total average demands for that specific network. The number of uncertain parameters, m, was set to be equal to three to account for inclement weather, seasonal variations, and fuel prices. The weights associated with each random variable, $b_{i j}^{l m}$, were varied for low, medium, and high uncertainty. Such that for low uncertainty, the demand could be increased anywhere from zero to $30 \%$; for medium uncertainty, the demand could be increased anywhere from zero to $60 \%$; and for high uncertainty, the demand could be increased anywhere from zero to $90 \%$. The bound on overall uncertainty, omega, ranged from zero to three. When 
omega was set equal to zero, this was defined as the deterministic case, because no variance from the mean was allowed. Therefore, the demand was equal to the average demand.

\subsection{Demand Uncertainty}

In this section, the impact of accounting for uncertainty in demand was studied by varying the bound on overall uncertainty. It is important to remember that omega $=0.0$ represents the deterministic case, or known demand.

\subsubsection{Effect on Opened Cross-docks}

The goal of varying the bound on the overall uncertainty, or omega, was to see how the decision variables were affected when uncertainty in demand was accounted for and when it was not accounted for. All three networks were studied at three levels of uncertainty (low, medium, and high), while varying omega from zero to three at 0.1 increments. The resulting opened crossdocks were as follows (Tables 5, 6, and 7). 
Table 5: Cross-docks Opened for Network 1 with Low Uncertainty

\begin{tabular}{|c|c|c|c|c|c|c|c|}
\hline Omega & CD's Opened & Omega & CD's Opened & Omega & CD's Opened & Omega & CD's Opened \\
\hline 0.0 & $\begin{array}{c}\text { Charlotte } \\
\text { Knoxville } \\
\text { Charlottesville } \\
\text { Charleston } \\
\end{array}$ & 0.8 & $\begin{array}{c}\text { Lexington } \\
\text { Charlotte } \\
\text { Knoxville } \\
\text { Charlottesville } \\
\end{array}$ & 1.6 & $\begin{array}{l}\text { Lexington } \\
\text { Charlotte } \\
\text { Knoxville } \\
\text { Charleston } \\
\end{array}$ & 2.4 & $\begin{array}{l}\text { Lexington } \\
\text { Charlotte } \\
\text { Knoxville } \\
\text { Charleston } \\
\end{array}$ \\
\hline 0.1 & $\begin{array}{l}\text { Lexington } \\
\text { Charlotte } \\
\text { Knoxville } \\
\text { Charleston } \\
\end{array}$ & 0.9 & $\begin{array}{l}\text { Lexington } \\
\text { Charlotte } \\
\text { Knoxville } \\
\text { Charleston } \\
\end{array}$ & 1.7 & $\begin{array}{l}\text { Lexington } \\
\text { Charlotte } \\
\text { Knoxville } \\
\text { Charleston } \\
\end{array}$ & 2.5 & $\begin{array}{c}\text { Lexington } \\
\text { Charlotte } \\
\text { Knoxville } \\
\text { Charlottesville }\end{array}$ \\
\hline 0.2 & $\begin{array}{l}\text { Lexington } \\
\text { Charlotte } \\
\text { Knoxville } \\
\text { Charleston }\end{array}$ & 1.0 & $\begin{array}{c}\text { Charlotte } \\
\text { Knoxville } \\
\text { Charlottesville } \\
\text { Charleston }\end{array}$ & 1.8 & $\begin{array}{c}\text { Lexington } \\
\text { Charlotte } \\
\text { Knoxville } \\
\text { Charlottesville }\end{array}$ & 2.6 & $\begin{array}{c}\text { Lexington } \\
\text { Charlotte } \\
\text { Knoxville } \\
\text { Charlottesville }\end{array}$ \\
\hline 0.3 & $\begin{array}{c}\text { Lexington } \\
\text { Charlotte } \\
\text { Knoxville } \\
\text { Charlottesville } \\
\end{array}$ & 1.1 & $\begin{array}{l}\text { Lexington } \\
\text { Charlotte } \\
\text { Knoxville } \\
\text { Charleston } \\
\end{array}$ & 1.9 & $\begin{array}{l}\text { Lexington } \\
\text { Charlotte } \\
\text { Knoxville } \\
\text { Charleston } \\
\end{array}$ & 2.7 & $\begin{array}{l}\text { Lexington } \\
\text { Charlotte } \\
\text { Knoxville } \\
\text { Charleston } \\
\end{array}$ \\
\hline 0.4 & $\begin{array}{c}\text { Charlotte } \\
\text { Knoxville } \\
\text { Charlottesville } \\
\text { Charleston } \\
\end{array}$ & 1.2 & $\begin{array}{c}\text { Lexington } \\
\text { Charlotte } \\
\text { Knoxville } \\
\text { Charleston } \\
\end{array}$ & 2.0 & $\begin{array}{c}\text { Lexington } \\
\text { Charlotte } \\
\text { Knoxville } \\
\text { Charlottesville } \\
\end{array}$ & 2.8 & $\begin{array}{l}\text { Lexington } \\
\text { Charlotte } \\
\text { Knoxville } \\
\text { Charleston } \\
\end{array}$ \\
\hline 0.5 & $\begin{array}{c}\text { Lexington } \\
\text { Charlotte } \\
\text { Knoxville } \\
\text { Charlottesville } \\
\end{array}$ & 1.3 & $\begin{array}{c}\text { Lexington } \\
\text { Charlotte } \\
\text { Knoxville } \\
\text { Charlottesville }\end{array}$ & 2.1 & $\begin{array}{c}\text { Lexington } \\
\text { Charlotte } \\
\text { Knoxville } \\
\text { Charlottesville } \\
\end{array}$ & 2.9 & $\begin{array}{l}\text { Lexington } \\
\text { Charlotte } \\
\text { Knoxville } \\
\text { Charleston } \\
\end{array}$ \\
\hline 0.6 & $\begin{array}{l}\text { Lexington } \\
\text { Charlotte } \\
\text { Knoxville } \\
\text { Charleston } \\
\end{array}$ & 1.4 & $\begin{array}{l}\text { Lexington } \\
\text { Charlotte } \\
\text { Knoxville } \\
\text { Charleston } \\
\end{array}$ & 2.2 & $\begin{array}{l}\text { Lexington } \\
\text { Charlotte } \\
\text { Knoxville } \\
\text { Charleston } \\
\end{array}$ & 3.0 & $\begin{array}{c}\text { Lexington } \\
\text { Charlotte } \\
\text { Knoxville } \\
\text { Charlottesville }\end{array}$ \\
\hline 0.7 & $\begin{array}{l}\text { Lexington } \\
\text { Charlotte } \\
\text { Knoxville } \\
\text { Charleston } \\
\end{array}$ & 1.5 & $\begin{array}{c}\text { Charlotte } \\
\text { Knoxville } \\
\text { Charlottesville } \\
\text { Charleston } \\
\end{array}$ & 2.3 & $\begin{array}{l}\text { Lexington } \\
\text { Charlotte } \\
\text { Knoxville } \\
\text { Charleston } \\
\end{array}$ & & \\
\hline
\end{tabular}


Table 6: Cross-docks Opened for Network 2 with Medium Uncertainty

\begin{tabular}{|c|c|c|c|c|c|c|c|}
\hline Omega & CD's Opened & Omega & CD's Opened & Omega & CD's Opened & Omega & CD's Opened \\
\hline 0.0 & $\begin{array}{c}\text { Cumberland } \\
\text { Canton } \\
\text { Altoona } \\
\text { Pittsburgh }\end{array}$ & 0.8 & $\begin{array}{c}\text { Cumberland } \\
\text { Canton } \\
\text { Altoona } \\
\text { Pittsburgh }\end{array}$ & 1.6 & $\begin{array}{c}\text { Cumberland } \\
\text { Canton } \\
\text { Altoona } \\
\text { Pittsburgh }\end{array}$ & 2.4 & $\begin{array}{c}\text { Columbus } \\
\text { Altoona } \\
\text { Pittsburgh } \\
\text { Wheeling } \\
\end{array}$ \\
\hline 0.1 & $\begin{array}{c}\text { Fort_Wayne } \\
\text { Altoona } \\
\text { Pittsburgh } \\
\text { Wheeling } \\
\end{array}$ & 0.9 & $\begin{array}{c}\text { Fort_Wayne } \\
\text { Columbus } \\
\text { Altoona } \\
\text { Pittsburgh } \\
\end{array}$ & 1.7 & $\begin{array}{c}\text { Canton } \\
\text { Columbus } \\
\text { Altoona } \\
\text { Wheeling } \\
\end{array}$ & 2.5 & $\begin{array}{c}\text { Fort_Wayne } \\
\text { Cumberland } \\
\text { Altoona } \\
\text { Pittsburgh }\end{array}$ \\
\hline 0.2 & $\begin{array}{c}\text { Canton } \\
\text { Altoona } \\
\text { Pittsburgh } \\
\text { Wheeling } \\
\end{array}$ & 1.0 & $\begin{array}{c}\text { Indianapolis } \\
\text { Cumberland } \\
\text { Altoona } \\
\text { Pittsburgh } \\
\end{array}$ & 1.8 & $\begin{array}{c}\text { Fort_Wayne } \\
\text { Cumberland } \\
\text { Altoona } \\
\text { Pittsburgh } \\
\end{array}$ & 2.6 & $\begin{array}{c}\text { Cumberland } \\
\text { Columbus } \\
\text { Altoona } \\
\text { Pittsburgh } \\
\end{array}$ \\
\hline 0.3 & $\begin{array}{c}\text { Columbus } \\
\text { Altoona } \\
\text { Pittsburgh } \\
\text { Wheeling } \\
\end{array}$ & 1.1 & $\begin{array}{c}\text { Fort_Wayne } \\
\text { Cumberland } \\
\text { Canton } \\
\text { Pittsburgh }\end{array}$ & 1.9 & $\begin{array}{c}\text { Fort_Wayne } \\
\text { Cumberland } \\
\text { Altoona } \\
\text { Pittsburgh } \\
\end{array}$ & 2.7 & $\begin{array}{c}\text { Indianapolis } \\
\text { Columbus } \\
\text { Altoona } \\
\text { Wheeling }\end{array}$ \\
\hline 0.4 & $\begin{array}{c}\text { Fort_Wayne } \\
\text { Altoona } \\
\text { Pittsburgh } \\
\text { Wheeling } \\
\end{array}$ & 1.2 & $\begin{array}{c}\text { Indianapolis } \\
\text { Cumberland } \\
\text { Columbus } \\
\text { Pittsburgh } \\
\end{array}$ & 2.0 & $\begin{array}{c}\text { Cumberland } \\
\text { Columbus } \\
\text { Altoona } \\
\text { Pittsburgh } \\
\end{array}$ & 2.8 & $\begin{array}{c}\text { Cumberland } \\
\text { Columbus } \\
\text { Altoona } \\
\text { Pittsburgh } \\
\end{array}$ \\
\hline 0.5 & $\begin{array}{l}\text { Cumberland } \\
\text { Columbus } \\
\text { Altoona } \\
\text { Pittsburgh } \\
\end{array}$ & 1.3 & $\begin{array}{c}\text { Canton } \\
\text { Altoona } \\
\text { Pittsburgh } \\
\text { Wheeling } \\
\end{array}$ & 2.1 & $\begin{array}{c}\text { Fort_Wayne } \\
\text { Cumberland } \\
\text { Altoona } \\
\text { Pittsburgh }\end{array}$ & 2.9 & $\begin{array}{c}\text { Cumberland } \\
\text { Canton } \\
\text { Altoona } \\
\text { Pittsburgh }\end{array}$ \\
\hline 0.6 & $\begin{array}{c}\text { Cumberland } \\
\text { Canton } \\
\text { Altoona } \\
\text { Pittsburgh } \\
\end{array}$ & 1.4 & $\begin{array}{c}\text { Cumberland } \\
\text { Canton } \\
\text { Pittsburgh } \\
\text { Wheeling } \\
\end{array}$ & 2.2 & $\begin{array}{c}\text { Cumberland } \\
\text { Columbus } \\
\text { Altoona } \\
\text { Pittsburgh }\end{array}$ & 3.0 & $\begin{array}{c}\text { Fort_Wayne } \\
\text { Cumberland } \\
\text { Pittsburgh } \\
\text { Wheeling }\end{array}$ \\
\hline 0.7 & $\begin{array}{c}\text { Cumberland } \\
\text { Canton } \\
\text { Altoona } \\
\text { Pittsburgh } \\
\end{array}$ & 1.5 & $\begin{array}{c}\text { Fort_Wayne } \\
\text { Columbus } \\
\text { Altoona } \\
\text { Pittsburgh } \\
\end{array}$ & 2.3 & $\begin{array}{c}\text { Cumberland } \\
\text { Canton } \\
\text { Altoona } \\
\text { Wheeling } \\
\end{array}$ & & \\
\hline
\end{tabular}


Table 7: Cross-docks Opened for Network 3 with High Uncertainty

\begin{tabular}{|c|c|c|c|c|c|c|c|}
\hline Omega & CD's Opened & Omega & CD's Opened & Omega & CD's Opened & Omega & CD's Opened \\
\hline 0.0 & $\begin{array}{c}\text { Fort_Wayne } \\
\text { Cumberland } \\
\text { Altoona } \\
\text { Mansfield }\end{array}$ & 0.8 & $\begin{array}{c}\text { Cumberland } \\
\text { Lima } \\
\text { Oil_City } \\
\text { Pittsburgh }\end{array}$ & 1.6 & $\begin{array}{c}\text { Fort_Wayne } \\
\text { Cumberland } \\
\text { Altoona } \\
\text { Pittsburgh }\end{array}$ & 2.4 & $\begin{array}{c}\text { Cumberland } \\
\text { Lima } \\
\text { Altoona } \\
\text { Pittsburgh }\end{array}$ \\
\hline 0.1 & $\begin{array}{c}\text { Hebron } \\
\text { Cumberland } \\
\text { Altoona } \\
\text { Oil_City } \\
\end{array}$ & 0.9 & $\begin{array}{c}\text { Fort_Wayne } \\
\text { Cumberland } \\
\text { Altoona } \\
\text { Oil_City } \\
\end{array}$ & 1.7 & $\begin{array}{c}\text { Fort_Wayne } \\
\text { Cumberland } \\
\text { Columbus } \\
\text { Altoona }\end{array}$ & 2.5 & $\begin{array}{c}\text { Fort_Wayne } \\
\text { Columbus } \\
\text { Altoona } \\
\text { Pittsburgh } \\
\end{array}$ \\
\hline 0.2 & $\begin{array}{c}\text { Cumberland } \\
\text { Canton } \\
\text { Altoona } \\
\text { Oil_City } \\
\end{array}$ & 1.0 & $\begin{array}{c}\text { Fort_Wayne } \\
\text { Cumberland } \\
\text { Columbus } \\
\text { Wheeling }\end{array}$ & 1.8 & $\begin{array}{c}\text { Fort_Wayne } \\
\text { Cumberland } \\
\text { Altoona } \\
\text { Pittsburgh } \\
\end{array}$ & 2.6 & $\begin{array}{c}\text { Fort_Wayne } \\
\text { Columbus } \\
\text { Altoona } \\
\text { Oil_City } \\
\end{array}$ \\
\hline 0.3 & $\begin{array}{l}\text { Cumberland } \\
\text { Lima } \\
\text { Altoona } \\
\text { Mansfield }\end{array}$ & 1.1 & $\begin{array}{l}\text { Cumberland } \\
\text { Columbus } \\
\text { Oil_City } \\
\text { Pittsburgh }\end{array}$ & 1.9 & $\begin{array}{c}\text { Hebron } \\
\text { Cumberland } \\
\text { Columbus } \\
\text { Altoona } \\
\end{array}$ & 2.7 & $\begin{array}{c}\text { Hebron } \\
\text { Columbus } \\
\text { Altoona } \\
\text { Pittsburgh } \\
\end{array}$ \\
\hline 0.4 & $\begin{array}{c}\text { Canton } \\
\text { Altoona } \\
\text { Pittsburgh } \\
\text { Wheeling } \\
\end{array}$ & 1.2 & $\begin{array}{c}\text { Cumberland } \\
\text { Canton } \\
\text { Mansfield } \\
\text { Pittsburgh } \\
\end{array}$ & 2.0 & $\begin{array}{c}\text { Cumberland } \\
\text { Lima } \\
\text { Altoona } \\
\text { Wheeling } \\
\end{array}$ & 2.8 & $\begin{array}{c}\text { Hebron } \\
\text { Cumberland } \\
\text { Columbus } \\
\text { Altoona } \\
\end{array}$ \\
\hline 0.5 & $\begin{array}{c}\text { Cumberland } \\
\text { Lima } \\
\text { Altoona } \\
\text { Pittsburgh } \\
\end{array}$ & 1.3 & $\begin{array}{c}\text { Cumberland } \\
\text { Lima } \\
\text { Altoona } \\
\text { Pittsburgh } \\
\end{array}$ & 2.1 & $\begin{array}{c}\text { Hebron } \\
\text { Cumberland } \\
\text { Altoona } \\
\text { Oil_City } \\
\end{array}$ & 2.9 & $\begin{array}{c}\text { Fort_Wayne } \\
\text { Indianapolis } \\
\text { Altoona } \\
\text { Oil_City }\end{array}$ \\
\hline 0.6 & $\begin{array}{c}\text { Fort_Wayne } \\
\text { Hebron } \\
\text { Cumberland } \\
\text { Altoona } \\
\end{array}$ & 1.4 & $\begin{array}{c}\text { Hebron } \\
\text { Altoona } \\
\text { Oil_City } \\
\text { Pittsburgh } \\
\end{array}$ & 2.2 & $\begin{array}{c}\text { Cumberland } \\
\text { Lima } \\
\text { Altoona } \\
\text { Pittsburgh } \\
\end{array}$ & 3.0 & $\begin{array}{c}\text { Fort_Wayne } \\
\text { Altoona } \\
\text { Pittsburgh } \\
\text { Wheeling }\end{array}$ \\
\hline 0.7 & $\begin{array}{c}\text { Fort_Wayne } \\
\text { Cumberland } \\
\text { Oil_City } \\
\text { Pittsburgh }\end{array}$ & 1.5 & $\begin{array}{c}\text { Fort_Wayne } \\
\text { Cumberland } \\
\text { Altoona } \\
\text { Oil_City }\end{array}$ & 2.3 & $\begin{array}{c}\text { Fort_Wayne } \\
\text { Cumberland } \\
\text { Pittsburgh } \\
\text { Wheeling }\end{array}$ & & \\
\hline
\end{tabular}


As can be seen from Tables 5, 6, and 7, the cross-docks which were opened varied with omega for all three networks and uncertainty levels. This means that accounting for uncertainty in demand had a distinct effect on the outputs of a system. If a particular network had uncertain demand, but it was assumed to be deterministic, and the average value of demand was used, the wrong cross-docks would be opened. In some cases, this could mean that the cross-dock capacity may be exceeded or that the total transportation cost would be much greater than expected. While deterministic models may be easier to solve and lead to less costly solutions, they may not be practical in cases where demand or other inputs are uncertain. Ignoring such uncertainty can lead to serious design flaws, such as too little warehouse capacity, too few trucks and even unexpected transportation costs. Tables containing the results for medium and high uncertainty for Network 1, low and high uncertainty for Network 2, and low and medium uncertainty for Network 3 are included in Appendix C; the results for those scenarios were consistent with the ones shown in Tables 5, 6, and 7.

\subsubsection{Effect on Total Cost}

In this section, the effects of demand uncertainty on total system costs are presented. Once again, all three networks were studied at three levels of uncertainty (low, medium, and high), while varying omega from zero to three at 0.1 increments. The resulting total system costs are shown on Figures 6, 7, and 8. 


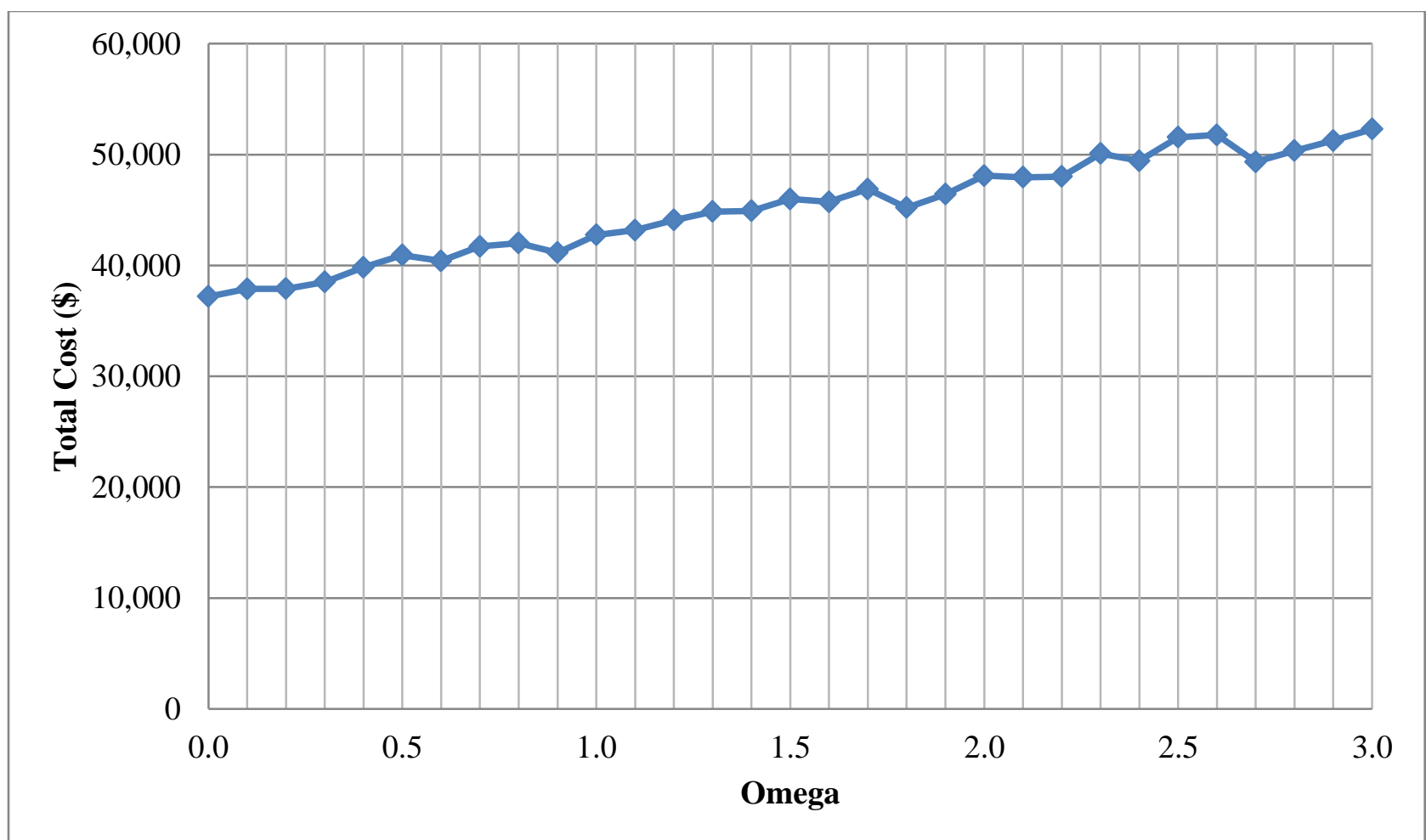

Figure 6: Total Cost for Network 1 with Low Uncertainty

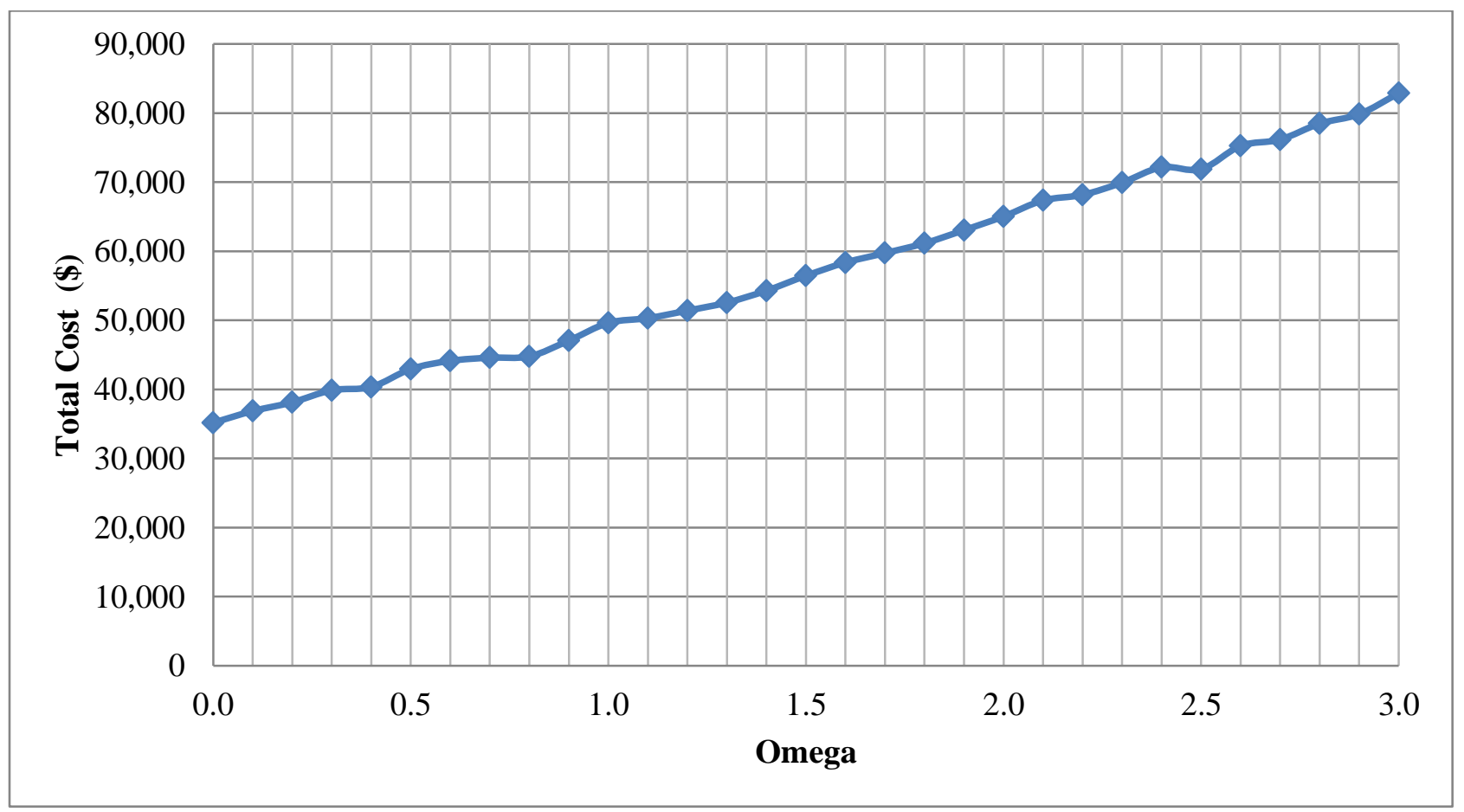

Figure 7: Total Cost for Network 2 with Medium Uncertainty 


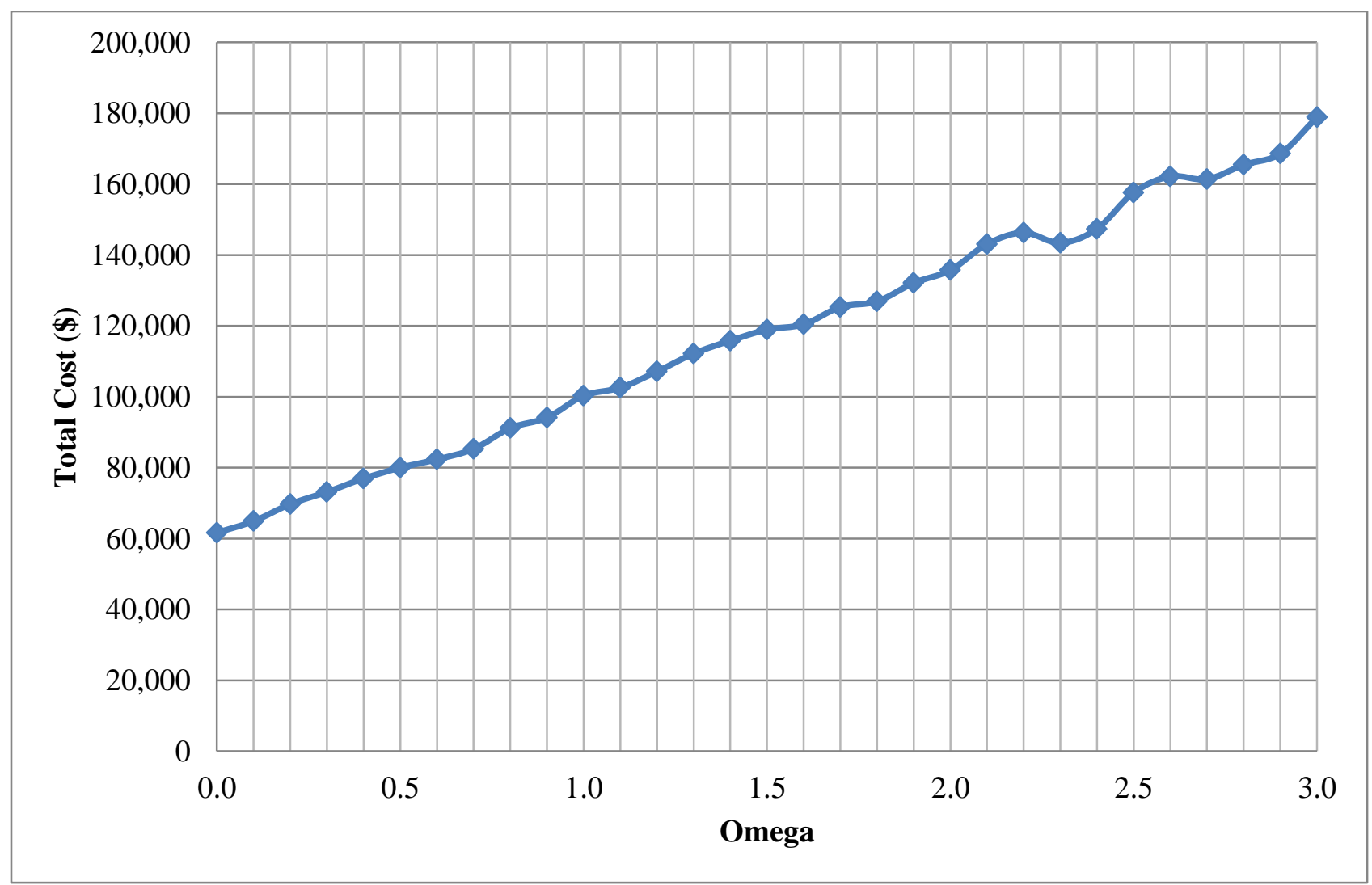

Figure 8: Total Cost for Network 3 with High Uncertainty

As expected, the total cost of the system tended to increase as omega increased. This occurred because the increase in omega allowed for higher demands, higher demands meant more trucks, and more trucks meant higher transportation prices. Network 3 had the highest total cost, because it had the largest overall demand and also had high uncertainty. High uncertainty meant that the factors that cause uncertainty, inclement weather, seasonal variations, and fuel prices, had a larger effect on the increases in demand than in the case of low and medium uncertainty. Networks 1 and 2 had very similar total demands and therefore, their cost at omega $=0$ was similar. However, because Network 2 had medium uncertainty its total cost increased much more rapidly than the total cost of Network 1 with low uncertainty. Graphs containing the results for medium and high uncertainty for Network 1, low and high uncertainty 
for Network 2, and low and medium uncertainty for Network 3 are included in Appendix C; the results for those scenarios were consistent with the ones shown in Figures 6, 7, and 8.

\subsubsection{Relative Cost}

In order to better compare the deterministic and robust solutions for the cross-dock facility location problem, the relative costs were calculated. The relative cost was simply the total cost of a network for a certain scenario (evaluated at mean demands) divided by the base total cost of the network. In this case, the deterministic model solution was used, where omega is set equal to zero, as the base total cost. It was then expected that the relative cost for the deterministic case would be equal to one. Once again, all three networks were studied at three levels of uncertainty (low, medium, and high), while varying omega from zero to three at 0.1 increments. The resulting relative costs are shown in the following graphs.

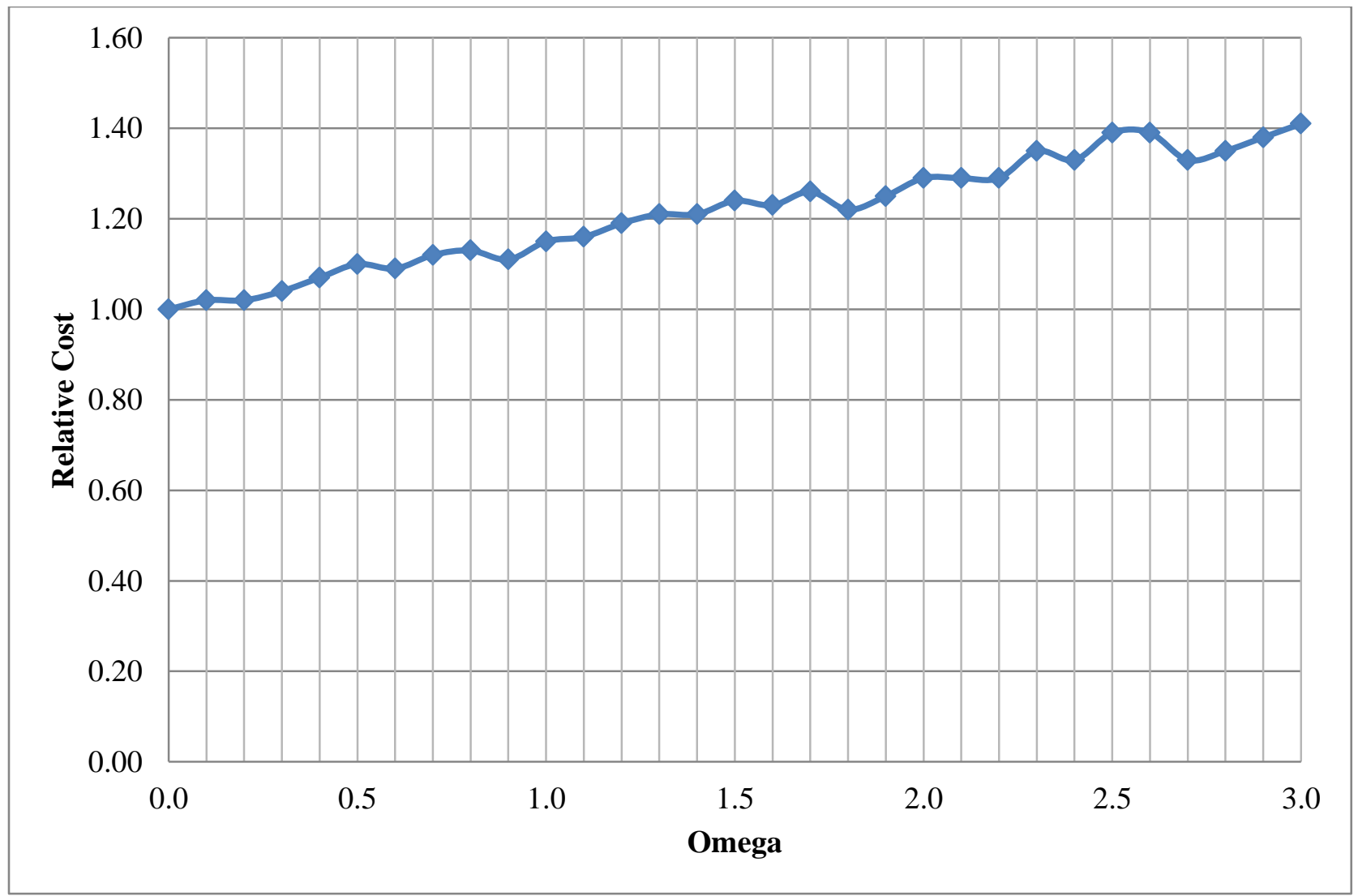

Figure 9: Relative Cost for Network 1 with Low Uncertainty 


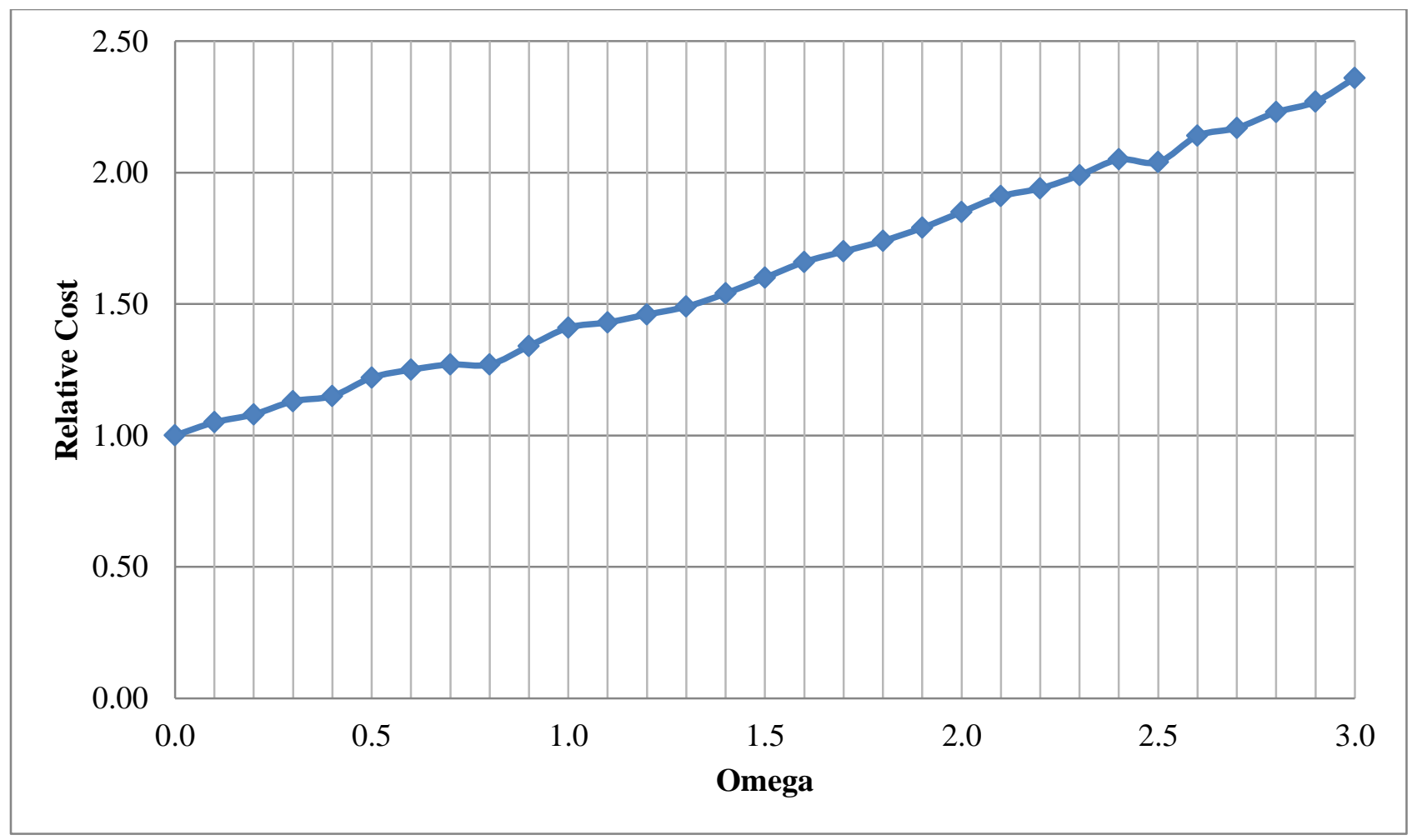

Figure 10: Relative Cost for Network 2 with Medium Uncertainty

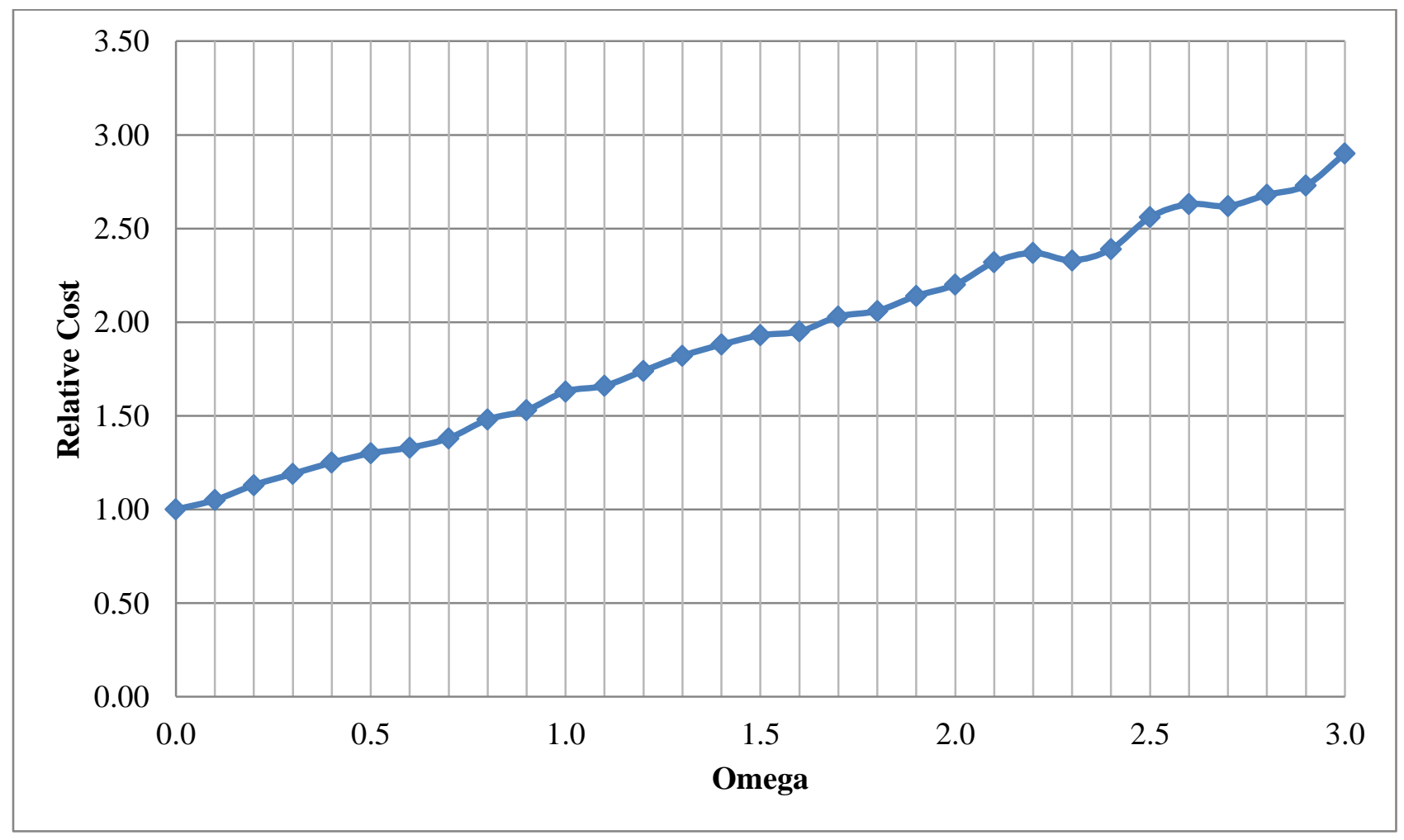

Figure 11: Relative Cost for Network 3 with High Uncertainty 
As expected, the relative cost increased as omega increased. The relative cost was equal to one for the deterministic solution for all three networks, because omega equal to zero was used as the base scenario. In Figure 9, the relative cost when omega was equal to three was 1.41. This means that for network 1, under low uncertainty, accounting for total demand uncertainty with a budget of three, the total cost was $41 \%$ more than the deterministic case at mean demand levels. This shows that there was a significant difference in the deterministic and robust cases. While the deterministic solution may look more appealing, because it costs less, the robust solution is more resilient and can handle variations in demand. If assuming an average demand and modeling using a deterministic model, even slight increases in demand or slight uncertainties can cause the network to be overloaded or exceed capacity at the nodes or on the trucks. The above graphs show how much more a robust network, which is able to handle uncertainty, will cost as compared to the deterministic case. Graphs containing the results for medium and high uncertainty for Network 1, low and high uncertainty for Network 2, and low and medium uncertainty for Network 3 are included in Appendix C; the results for those scenarios were consistent with the ones shown in Figures 9, 10, and 11.

\subsection{Deterministic and Robust Performance Comparison}

In order to further compare the performance of the deterministic and robust cross-docking models, their ability to handle demand uncertainties was studied. The first comparison used the average demands for the deterministic case and the second used inflated demands for the deterministic case.

\subsubsection{Comparison with Average Demands for Deterministic Case}

This comparison was achieved by first solving each of the cross-dock location decision and routing problems for the deterministic case $($ omega $=0)$ and a robust case (omega $=3$, high 
uncertainty) for each of the three networks. The resulting opened cross-docks and total system costs are given below.

Table 8: Opened Cross-docks for Each Network and Uncertainty Scenario

\begin{tabular}{|c|c|c|c|c|c|}
\hline \multicolumn{5}{|c|}{ Cross-dock's Opened } \\
\hline \multicolumn{2}{|c|}{ Network 1 } & \multicolumn{2}{c|}{ Network 2 } & \multicolumn{2}{c|}{ Network 3 } \\
\hline Deterministic & Robust & Deterministic & Robust & Deterministic & Robust \\
\hline Charlotte & Lexington & Columbus & Fort_Wayne & Fort_Wayne & Hebron \\
Knoxville & Charlotte & Altoona & Cumberland & Cumberland & Cumberland \\
Charlottesville & Knoxville & Pittsburgh & Altoona & Canton & Oil_City \\
Charleston & Charlottesville & Wheeling & Pittsburgh & Altoona & Pittsburgh \\
\hline
\end{tabular}

Table 9: Initial Total Cost for Each Network and Uncertainty Scenario

\begin{tabular}{|c|c|c|c|c|c|}
\hline \multicolumn{5}{|c|}{ Initial Total Cost (\$) } \\
\hline \multicolumn{2}{|c|}{ Network 1 } & \multicolumn{2}{c|}{ Network 2 } & \multicolumn{2}{c|}{ Network 3 } \\
\hline Deterministic & Robust & Deterministic & Robust & Deterministic & Robust \\
\hline 37,197 & 116,013 & 35,992 & 104,878 & 62,676 & 175,307 \\
\hline
\end{tabular}

As can be seen in the above tables, the opened cross-docks were different in each network for the deterministic and robust cases; this was consistent with the results in the previous section. The total costs were also much higher for the robust cases due to the increases in demands.

After the four cross-docks were established for each uncertainty level and network, and the numbers of trucks that were scheduled to transport commodities for each node pair were determined, the ability of each network to handle uncertainty was tested. This was done by creating 30 scenarios in which the demands were subject to uncertainty. The random demand values were calculated as follows:

Random demand $=$ average demand $+\sum_{m}$ uniform $(0,0.9)($ average demand $)$ 
This means that the demand values were increased by a value equal to the average demand multiplied by a random value between 0 and 0.9 with a uniform distribution, summed over $m$ uncertain parameters. In all cases, $\mathrm{m}$ was set equal to three as previously discussed and the random value between 0 and 0.9 meant high uncertainty, such that the demand could be increased by up to $90 \%$.

The main premise behind this study was that a network was established with four opened cross-docks chosen from a set of potential locations, and a set number of trucks traveling between different origins and destinations and cross-dock locations was determined. For the deterministic case, these outputs were determined based on average demands. For the robust case, these outputs were determined based on uncertain demands, with high uncertainty and a budget of uncertainty, omega, equal to three. The next set of experiments tested the resilience of the deterministic solution and the robust solution to demand uncertainty. It was assumed that the robust network would be better able to handle the variations in demand as compared to the deterministic case.

The ability of a network to handle uncertainty was based on the total capacity shortage in the network. The total shortage was calculated as the sum of truck capacity shortage plus the sum of cross-dock capacity shortage. The truck capacity shortage was equal to the truck capacity minus the total demand needing shipped by the truck. The cross-dock capacity shortage was equal to the cross-dock capacity minus the total demand needing to be sorted and consolidated at the cross-dock. The following three tables show the capacity shortages and total costs for the deterministic and robust case in each network, with 30 demand scenarios. 
Table 10: Capacity Shortage and Total Cost for Network 1 $(\Omega=3$ for Robust Case)

\begin{tabular}{|c|c|c|c|c|}
\hline \multirow{2}{*}{$\begin{array}{l}\text { Demand } \\
\text { Scenario }\end{array}$} & \multicolumn{2}{|c|}{ Total Capacity Shortage (In Pallets) } & \multicolumn{2}{|c|}{ Total Cost (\$) } \\
\hline & Deterministic & Robust & Deterministic & Robust \\
\hline 1 & 1,327 & 0 & 38,851 & 115,796 \\
\hline 2 & 1,068 & 0 & 38,612 & 115,853 \\
\hline 3 & 1,400 & 0 & 38,869 & 115,815 \\
\hline 4 & 1,712 & 0 & 39,116 & 115,910 \\
\hline 5 & 1,161 & 0 & 38,812 & 115,779 \\
\hline 6 & 940 & 0 & 38,485 & 115,688 \\
\hline 7 & 982 & 0 & 38,497 & 115,673 \\
\hline 8 & 1,311 & 0 & 38,681 & 115,688 \\
\hline 9 & 1,133 & 0 & 38,804 & 115,685 \\
\hline 10 & 1,014 & 0 & 38,541 & 115,656 \\
\hline 11 & 1,159 & 0 & 38,603 & 115,687 \\
\hline 12 & 1,134 & 0 & 38,785 & 115,911 \\
\hline 13 & 889 & 0 & 38,417 & 115,718 \\
\hline 14 & 986 & 0 & 38,681 & 115,696 \\
\hline 15 & 886 & 0 & 38,633 & 115,722 \\
\hline 16 & 1,344 & 0 & 38,839 & 115,785 \\
\hline 17 & 1,371 & 0 & 38,874 & 115,729 \\
\hline 18 & 1,240 & 0 & 38,689 & 115,692 \\
\hline 19 & 1,232 & 0 & 38,964 & 115,824 \\
\hline 20 & 1,241 & 0 & 38,770 & 115,859 \\
\hline 21 & 952 & 0 & 38,547 & 115,687 \\
\hline 22 & 1,031 & 0 & 38,699 & 115,853 \\
\hline 23 & 1,300 & 0 & 38,747 & 115,728 \\
\hline 24 & 826 & 0 & 38,609 & 115,737 \\
\hline 25 & 1,022 & 0 & 38,559 & 115,680 \\
\hline 26 & 1,256 & 0 & 38,618 & 115,771 \\
\hline 27 & 1,283 & 0 & 39,000 & 115,843 \\
\hline 28 & 1,336 & 0 & 38,846 & 115,837 \\
\hline 29 & 1,006 & 0 & 38,614 & 115,699 \\
\hline 30 & 1,009 & 0 & 38,613 & 115,810 \\
\hline
\end{tabular}


Table 11: Capacity Shortage and Total Cost for Network 2 $(\Omega=3$ for Robust Case)

\begin{tabular}{|c|c|c|c|c|}
\hline \multirow{2}{*}{$\begin{array}{l}\text { Demand } \\
\text { Scenario }\end{array}$} & \multicolumn{2}{|c|}{ Total Capacity Shortage (In Pallets) } & \multicolumn{2}{|c|}{ Total Cost $(\$)$} \\
\hline & Deterministic & Robust & Deterministic & Robust \\
\hline 1 & 1,202 & 0 & 37,795 & 104,892 \\
\hline 2 & 1,498 & 0 & 38,080 & 104,987 \\
\hline 3 & 1,368 & 0 & 37,969 & 104,897 \\
\hline 4 & 1,472 & 0 & 38,057 & 104,911 \\
\hline 5 & 1,503 & 0 & 38,081 & 104,989 \\
\hline 6 & 1,450 & 0 & 38,033 & 105,000 \\
\hline 7 & 1,269 & 0 & 37,909 & 104,839 \\
\hline 8 & 1,263 & 0 & 37,888 & 104,847 \\
\hline 9 & 1,424 & 0 & 37,984 & 104,959 \\
\hline 10 & 1,408 & 0 & 38,002 & 104,919 \\
\hline 11 & 1,129 & 0 & 37,711 & 104,933 \\
\hline 12 & 1,094 & 0 & 37,681 & 104,956 \\
\hline 13 & 1,295 & 0 & 37,869 & 104,881 \\
\hline 14 & 1,380 & 0 & 37,958 & 104,879 \\
\hline 15 & 1,169 & 0 & 37,761 & 104,802 \\
\hline 16 & 1,068 & 0 & 37,651 & 104,879 \\
\hline 17 & 1,411 & 0 & 38,000 & 104,965 \\
\hline 18 & 1,130 & 0 & 37,705 & 104,921 \\
\hline 19 & 1,500 & 0 & 38,139 & 104,917 \\
\hline 20 & 1,166 & 0 & 37,780 & 104,971 \\
\hline 21 & 1,240 & 0 & 37,834 & 104,863 \\
\hline 22 & 1,239 & 0 & 37,844 & 104,856 \\
\hline 23 & 1,140 & 0 & 37,728 & 104,855 \\
\hline 24 & 1,520 & 0 & 38,124 & 105,009 \\
\hline 25 & 1,261 & 0 & 37,838 & 104,875 \\
\hline 26 & 1,064 & 0 & 37,632 & 104,701 \\
\hline 27 & 1,053 & 0 & 37,647 & 104,851 \\
\hline 28 & 1,242 & 0 & 37,805 & 104,899 \\
\hline 29 & 1,353 & 0 & 37,946 & 104,885 \\
\hline 30 & 1,271 & 0 & 37,888 & 104,841 \\
\hline
\end{tabular}


Table 12: Capacity Shortage and Total Cost for Network 3 $(\Omega=3$ for Robust Case)

\begin{tabular}{|c|c|c|c|c|}
\hline \multirow{2}{*}{$\begin{array}{l}\text { Demand } \\
\text { Scenario }\end{array}$} & \multicolumn{2}{|c|}{ Total Capacity Shortage (In Pallets) } & \multicolumn{2}{|c|}{ Total Cost (\$) } \\
\hline & Deterministic & Robust & Deterministic & Robust \\
\hline 1 & 2,231 & 0 & 66,101 & 175,670 \\
\hline 2 & 2,109 & 0 & 66,016 & 175,701 \\
\hline 3 & 2,433 & 0 & 66,314 & 175,663 \\
\hline 4 & 2,071 & 0 & 65,958 & 175,573 \\
\hline 5 & 2,195 & 0 & 66,070 & 175,604 \\
\hline 6 & 2,336 & 0 & 66,211 & 175,792 \\
\hline 7 & 2,308 & 0 & 66,205 & 175,613 \\
\hline 8 & 2,193 & 0 & 66,050 & 175,609 \\
\hline 9 & 2,276 & 0 & 66,151 & 175,573 \\
\hline 10 & 2,264 & 0 & 66,160 & 175,787 \\
\hline 11 & 2,140 & 0 & 66,038 & 175,594 \\
\hline 12 & 2,184 & 0 & 66,037 & 175,616 \\
\hline 13 & 2,427 & 0 & 66,281 & 175,924 \\
\hline 14 & 2,095 & 0 & 65,966 & 175,612 \\
\hline 15 & 2,349 & 0 & 66,245 & 175,792 \\
\hline 16 & 2,236 & 0 & 66,144 & 175,849 \\
\hline 17 & 2,469 & 0 & 66,372 & 175,550 \\
\hline 18 & 2,114 & 0 & 65,995 & 175,908 \\
\hline 19 & 2,435 & 0 & 66,354 & 175,768 \\
\hline 20 & 2,491 & 0 & 66,369 & 175,657 \\
\hline 21 & 2,274 & 0 & 66,175 & 175,789 \\
\hline 22 & 2,128 & 0 & 66,009 & 175,637 \\
\hline 23 & 2,024 & 0 & 65,955 & 175,723 \\
\hline 24 & 1,954 & 0 & 65,853 & 175,539 \\
\hline 25 & 1,850 & 0 & 65,755 & 175,619 \\
\hline 26 & 2,199 & 0 & 66,089 & 175,633 \\
\hline 27 & 1,953 & 0 & 65,845 & 175,552 \\
\hline 28 & 2,023 & 0 & 65,914 & 175,470 \\
\hline 29 & 2,434 & 0 & 66,331 & 175,762 \\
\hline 30 & 2,313 & 0 & 66,197 & 175,776 \\
\hline
\end{tabular}


In all three networks, there were large capacity shortages for every scenario in the deterministic model, but in every scenario for each network, the robust model was able to transport all of the pallets with no capacity shortages. It is obvious that the robust models were better equipped to handle demand uncertainty, than the deterministic models. The total costs were still much lower for the deterministic cases than the robust cases. However, in most real world situations, trucking companies would be largely penalized for being unable to move demand; they would either lose clients, be forced to buy or lease more trucks to ship directly, open more cross-docks or find other carriers to ship their excess demands. All of these solutions would be extremely costly and detrimental to the trucking company.

In order to better compare the real world costs for the deterministic and robust models, a penalty charge was added for each pallet that could not be transported. The tables below show the total costs adjusted for penalized capacity shortages, based on a penalty cost of $\$ 100$ per pallet. The penalty value was an estimate based on an assumed monthly leasing cost of about $\$ 2,000$ per truck. If a truck can hold 28 pallets, the cost per pallet would be about $\$ 71.00$ plus the price of fuel. The penalty value could be changed based on the trucking company or the alternative solution to ship excess capacity. If a trucking company loses a client because of its inability to ship the excess demand, the cost would likely be much greater than $\$ 100$ per pallet. The total cost after penalty was calculated by:

Total Cost $(\$)$ after Penalty $=$ total cost $+(\$ 100 *$ capacity shortage $)$ 
Table 13: Total Cost after Capacity Shortage Penalties for All Three Networks $(\Omega=3$ for Robust Case)

\begin{tabular}{|c|c|c|c|c|c|c|}
\hline \multirow{3}{*}{$\begin{array}{l}\text { Demand } \\
\text { Scenario }\end{array}$} & \multicolumn{6}{|c|}{ Total Cost (\$) After Penalty } \\
\hline & \multicolumn{2}{|c|}{ Network 1} & \multicolumn{2}{|c|}{ Network 2} & \multicolumn{2}{|c|}{ Network 3} \\
\hline & Deterministic & Robust & Deterministic & Robust & Deterministic & Robust \\
\hline 1 & 171,502 & 115,796 & 157,984 & 104,892 & 289,142 & 175,670 \\
\hline 2 & 145,395 & 115,853 & 187,877 & 104,987 & 276,842 & 175,701 \\
\hline 3 & 178,863 & 115,815 & 174,738 & 104,897 & 309,586 & 175,663 \\
\hline 4 & 210,306 & 115,910 & 185,189 & 104,911 & 273,031 & 175,573 \\
\hline 5 & 154,893 & 115,779 & 188,321 & 104,989 & 285,568 & 175,604 \\
\hline 6 & 132,480 & 115,688 & 182,967 & 105,000 & 299,753 & 175,792 \\
\hline 7 & 136,656 & 115,673 & 164,760 & 104,839 & 296,928 & 175,613 \\
\hline 8 & 169,755 & 115,688 & 164,171 & 104,847 & 285,303 & 175,609 \\
\hline 9 & 152,012 & 115,685 & 180,310 & 104,959 & 293,723 & 175,573 \\
\hline 10 & 139,881 & 115,656 & 178,785 & 104,919 & 292,514 & 175,787 \\
\hline 11 & 154,459 & 115,687 & 150,602 & 104,933 & 279,993 & 175,594 \\
\hline 12 & 152,147 & 115,911 & 147,043 & 104,956 & 284,375 & 175,616 \\
\hline 13 & 127,240 & 115,718 & 167,272 & 104,881 & 308,945 & 175,924 \\
\hline 14 & 137,273 & 115,696 & 175,941 & 104,879 & 275,380 & 175,612 \\
\hline 15 & 127,166 & 115,722 & 154,610 & 104,802 & 301,076 & 175,792 \\
\hline 16 & 173,185 & 115,785 & 144,420 & 104,879 & 289,729 & 175,849 \\
\hline 17 & 175,895 & 115,729 & 179,002 & 104,965 & 313,200 & 175,550 \\
\hline 18 & 162,602 & 115,692 & 150,613 & 104,921 & 277,322 & 175,908 \\
\hline 19 & 162,097 & 115,824 & 188,092 & 104,917 & 309,834 & 175,768 \\
\hline 20 & 162,817 & 115,859 & 154,354 & 104,971 & 315,428 & 175,657 \\
\hline 21 & 133,728 & 115,687 & 161,806 & 104,863 & 293,568 & 175,789 \\
\hline 22 & 141,719 & 115,853 & 161,665 & 104,856 & 278,727 & 175,637 \\
\hline 23 & 168,687 & 115,728 & 151,711 & 104,855 & 268,301 & 175,723 \\
\hline 24 & 121,164 & 115,737 & 190,079 & 105,009 & 261,241 & 175,539 \\
\hline 25 & 140,753 & 115,680 & 163,929 & 104,875 & 250,738 & 175,619 \\
\hline 26 & 164,149 & 115,771 & 143,990 & 104,701 & 285,975 & 175,633 \\
\hline 27 & 167,296 & 115,843 & 142,939 & 104,851 & 261,145 & 175,552 \\
\hline 28 & 172,405 & 115,837 & 162,002 & 104,899 & 268,150 & 175,470 \\
\hline 29 & 139,118 & 115,699 & 173,152 & 104,885 & 309,653 & 175,762 \\
\hline 30 & 139,487 & 115,810 & 164,930 & 104,841 & 297,413 & 175,776 \\
\hline
\end{tabular}

In the above table, the total costs for the robust models are now less than the total costs for the deterministic models. Because, there were no capacity shortages for the robust models, their adjusted total costs did not change; they incurred no penalties. Penalizing for capacity 
shortages made the robust models look much more appealing than the deterministic. As stated above, the penalty value was simply an estimate. It would be better determined on a case by case basis for trucking companies to estimate the penalties or loss in business they would incur for not accounting for uncertainties in demand.

The analysis was repeated to test different values of omega, but instead of listing values for every demand scenario, the averages were computed. The average capacity shortages and total costs for the three networks across the thirty demand scenarios for the deterministic and three robust optimization strategies (omega $=1,2$, and 3) are shown below in Table 14. The results confirm the fact that the deterministic solution suffered from capacity shortages in all the scenarios whereas this was not an issue in the robust framework.

Table 14: Average Capacity Shortages (In Pallets) and Total Costs for All Three Networks

\begin{tabular}{|c|c|c|c|c|c|c|c|c|c|c|}
\hline \multicolumn{2}{|c|}{ Network } & \multicolumn{3}{|c|}{ N1 } & \multicolumn{3}{|c|}{$\mathrm{N} 2$} & \multicolumn{3}{|c|}{ N3 } \\
\hline \multirow{2}{*}{\multicolumn{2}{|c|}{$\begin{array}{c}\text { Uncertainty } \\
\text { Budget }\end{array}$}} & \multicolumn{3}{|c|}{ Omega } & \multicolumn{3}{|c|}{ Omega } & \multicolumn{3}{|c|}{ Omega } \\
\hline & & 1 & 2 & 3 & 1 & 2 & 3 & 1 & 2 & 3 \\
\hline \multirow{2}{*}{ 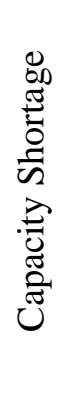 } & 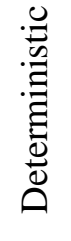 & 1,045 & 1,045 & 1,045 & 1,338 & 1,338 & 1,338 & 2,102 & 2,102 & 2,102 \\
\hline & $\begin{array}{l}\overrightarrow{\tilde{a}} \\
\overrightarrow{0} \\
\ddot{0}\end{array}$ & 0 & 0 & 0 & 0 & 0 & 0 & 0 & 0 & 0 \\
\hline \multirow{2}{*}{$\begin{array}{l}\hat{\theta} \\
\tilde{\tilde{n}} \\
0 \\
0 \\
0 \\
0 \\
0\end{array}$} & 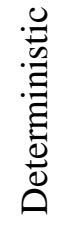 & 49,881 & 49,881 & 49,881 & 29,420 & 29,420 & 29,420 & 65,997 & 65,997 & 65,997 \\
\hline & $\begin{array}{l}\overrightarrow{\tilde{n}} \\
\overrightarrow{0} \\
\tilde{0}\end{array}$ & 62,252 & 99,856 & 110,081 & 57,855 & 73,539 & 95,347 & 103,544 & 141,826 & 179,350 \\
\hline
\end{tabular}


The average total cost of 30 simulated demand scenarios for the three networks considered in this research is reported in Table 15, with the appropriate capacity shortage penalty added. The cost of the deterministic setting, assuming the penalty cost on capacity shortage, was higher than the robust approach. The total costs for all of the robust scenarios are now lower than the deterministic. These results were consistent with the results in Table 13 .

Table 15: Average Total Cost after Capacity Shortage Penalties for All Three Networks

\begin{tabular}{|c|c|c|c|c|c|c|c|c|c|c|}
\hline \multicolumn{2}{|c|}{ Network } & \multicolumn{3}{|c|}{ N1 } & \multicolumn{3}{|c|}{$\mathrm{N} 2$} & \multicolumn{3}{|c|}{ N3 } \\
\hline \multirow{2}{*}{\multicolumn{2}{|c|}{$\begin{array}{l}\text { Uncertainty } \\
\text { Budget }\end{array}$}} & \multicolumn{3}{|c|}{ Omega } & \multicolumn{3}{|c|}{ Omega } & \multicolumn{3}{|c|}{ Omega } \\
\hline & & 1 & 2 & 3 & 1 & 2 & 3 & 1 & 2 & 3 \\
\hline \multirow{2}{*}{ 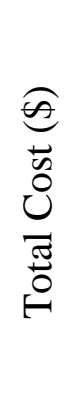 } & 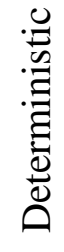 & 154,381 & 154,381 & 154,381 & 163,220 & 163,220 & 163,220 & 276,197 & 276,197 & 276,197 \\
\hline & $\begin{array}{l}0 \\
0 \\
0 \\
0\end{array}$ & 62,252 & 99,856 & 110,081 & 57,855 & 73,539 & 95,347 & 103,544 & 141,826 & 179,350 \\
\hline
\end{tabular}

\subsubsection{Comparison with Inflated Demands for the Deterministic Case}

One specific way to deal with uncertainty in demand is to plan for an inflated demand.

For example, in a number of civil engineering applications the uncertainty in loads is accounted for by inflating the load using a safety factor. The goal of this set of experiments was to determine if a similar safety inflation factor could be applied to the demand. The advantage of this method is that freight companies need not do complicated robust optimization or stochastic optimization based planning. However, before embarking on such a method it was crucial to compare the performance of the deterministic model with an inflated demand to the robust model. First the deterministic demand was inflated according to five levels: $10 \%, 20 \%, 30 \%$, $40 \%$, and $50 \%$. The optimal strategy was obtained for the five inflated demand levels. Then the 
robust optimization strategy was determined for high uncertainty for three uncertainty budget levels. Then the performances of the inflated demand deterministic strategy and the robust strategy were compared by simulating 30 random demand values. The capacity shortages as well as the average costs (considering capacity shortage penalties) are shown in Table 16 and Table 17 on the next two pages. 
Table 16: Capacity Shortages (In Pallets) for Demand Inflation of the Deterministic vs. the Robust Approach

\begin{tabular}{|c|c|c|c|c|c|c|c|c|c|c|c|}
\hline \multirow{3}{*}{\multicolumn{3}{|c|}{\begin{tabular}{|c} 
Network \\
Uncertainty Budget
\end{tabular}}} & \multicolumn{3}{|c|}{$\mathrm{N} 1$} & \multicolumn{3}{|c|}{$\mathrm{N} 2$} & \multicolumn{3}{|c|}{ N3 } \\
\hline & & & \multicolumn{3}{|c|}{ Omega } & \multicolumn{3}{|c|}{ Omega } & \multicolumn{3}{|c|}{ Omega } \\
\hline & & & 1 & 2 & 3 & 1 & 2 & 3 & 1 & 2 & 3 \\
\hline \multirow{10}{*}{ 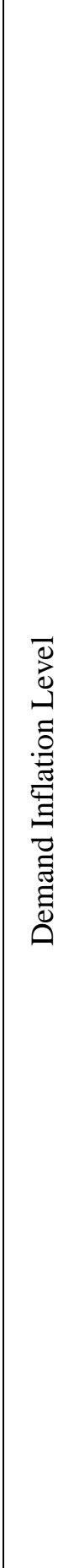 } & \multirow[t]{2}{*}{$\stackrel{8}{0}$} & 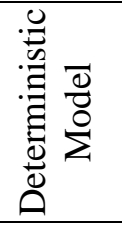 & 504.3 & 504.3 & 504.3 & 821.5 & 821.5 & 821.5 & $1,401.3$ & $1,401.3$ & $1,401.3$ \\
\hline & & 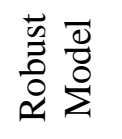 & 0 & 0 & 0 & 0 & 0 & 0 & 0 & 0 & 0 \\
\hline & \multirow[t]{2}{*}{ 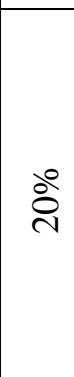 } & 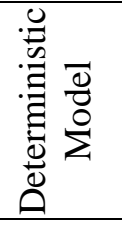 & 12.36 & 12.36 & 12.36 & 0 & 0 & 0 & 94.3 & 94.3 & 94.3 \\
\hline & & 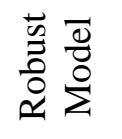 & 0 & 0 & 0 & 0 & 0 & 0 & 0 & 0 & 0 \\
\hline & \multirow[t]{2}{*}{$\stackrel{8}{8}$} & 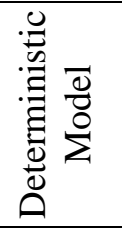 & 0 & 0 & 0 & 0 & 0 & 0 & 0 & 0 & 0 \\
\hline & & 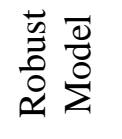 & 0 & 0 & 0 & 0 & 0 & 0 & 0 & 0 & 0 \\
\hline & \multirow[t]{2}{*}{ 号 } & 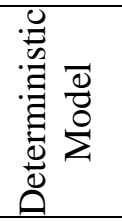 & 0 & 0 & 0 & 0 & 0 & 0 & 0 & 0 & 0 \\
\hline & & 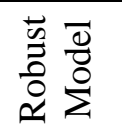 & 0 & 0 & 0 & 0 & 0 & 0 & 0 & 0 & 0 \\
\hline & \multirow[t]{2}{*}{ 宫 } & 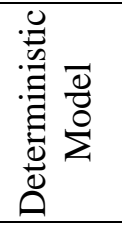 & 0 & 0 & 0 & 0 & 0 & 0 & 0 & 0 & 0 \\
\hline & & 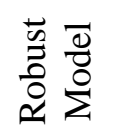 & 0 & 0 & 0 & 0 & 0 & 0 & 0 & 0 & 0 \\
\hline
\end{tabular}


Table 17: Demand Inflation Cost of the Deterministic vs. the Robust Approach (Accounting for Capacity Shortage Penalties)

\begin{tabular}{|c|c|c|c|c|c|c|c|c|c|c|c|}
\hline \multicolumn{3}{|c|}{ Network } & \multicolumn{3}{|c|}{ N1 } & \multicolumn{3}{|c|}{ N2 } & \multicolumn{3}{|c|}{ N3 } \\
\hline \multirow{2}{*}{\multicolumn{3}{|c|}{ Uncertainty Budget }} & \multicolumn{3}{|c|}{ Omega } & \multicolumn{3}{|c|}{ Omega } & \multicolumn{3}{|c|}{ Omega } \\
\hline & & & 1 & 2 & 3 & 1 & 2 & 3 & 1 & 2 & 3 \\
\hline \multirow{10}{*}{ 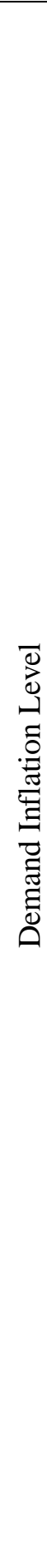 } & \multirow[t]{2}{*}{$\stackrel{\circ}{\circ}$} & 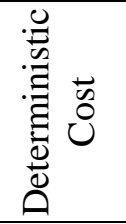 & 94,636 & 94,636 & 94,636 & 122,632 & 122,632 & 122,632 & 143,103 & 143,103 & 143,103 \\
\hline & & $\begin{array}{l}\overrightarrow{\tilde{a}} \\
\overrightarrow{0} \\
\overrightarrow{0} \\
\stackrel{0}{0}\end{array}$ & 62,608 & 88,844 & 116,352 & 67,007 & 78,702 & 101,281 & 110,174 & 151,751 & 182,466 \\
\hline & \multirow[t]{2}{*}{ 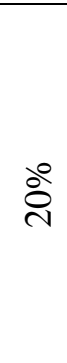 } & 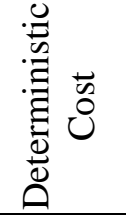 & 58,524 & 58,524 & 58,524 & 78,619 & 78,619 & 78,619 & 94,680 & 94,680 & 94,680 \\
\hline & & 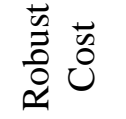 & 62,608 & 88,844 & 116,352 & 67,007 & 78,702 & 101,281 & 110,174 & 151,751 & 182,466 \\
\hline & \multirow[t]{2}{*}{ 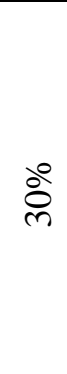 } & 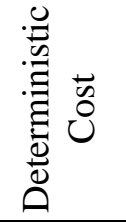 & 63,145 & 63,145 & 63,145 & 58,255 & 58,255 & 58,255 & 108,406 & 108,406 & 108,406 \\
\hline & & $\begin{array}{l}\overrightarrow{\tilde{a}} \\
\overrightarrow{0} \\
\overrightarrow{0} \\
\stackrel{0}{0}\end{array}$ & 62,608 & 88,844 & 116,352 & 67,007 & 78,702 & 101,281 & 110,174 & 151,751 & 182,466 \\
\hline & \multirow[t]{2}{*}{ 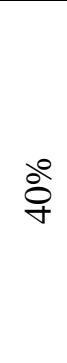 } & 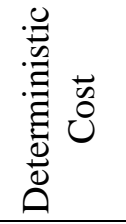 & 73,640 & 73,640 & 73,640 & 67,847 & 67,847 & 67,847 & $129,597$. & 129,597 & 129,597 \\
\hline & & $\begin{array}{l}\overrightarrow{\hat{n}} \\
\overrightarrow{0} \\
\overrightarrow{0} \\
\tilde{\alpha}\end{array}$ & 62,608 & 88,844 & 116,352 & 67,007 & 78,702 & 101,281 & 110,174 & 151,751 & 182,466 \\
\hline & \multirow[t]{2}{*}{$\stackrel{\circ}{\circ}$} & 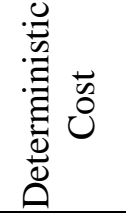 & 87,839 & 87,839 & 87,839 & 71,262 & 71,841 & 72,126 & 142,191 & 142,191 & 142,191 \\
\hline & & $\begin{array}{l}\overrightarrow{\tilde{n}} \\
\overrightarrow{0} \\
\overrightarrow{0} \\
\tilde{2}\end{array}$ & 62,608 & 88,844 & 116,352 & 67,007 & 78,702 & 101,281 & 110,174 & 151,751 & 182,466 \\
\hline
\end{tabular}


It can be seen in Table 16 that the robust model had no capacity shortages for any of the networks or omega values. The robust model was able to handle all of the demands in this case just as it was in the comparison in Section 5.3.1. The deterministic models had shortages when the demands were only increased by $10 \%$ in all three networks, and shortages in Networks 1 and 3 when the demands were increased by $20 \%$. When the demands were increased by 30,40 , and $50 \%$ there were no capacity shortages for the deterministic cases. This observation shows that inflating demands by a reasonable percentage can allow the model to handle uncertainty. In order to better compare the demand inflation strategy to the robust strategy, the total costs were also considered. Table 17 shows the total costs for all scenarios. Penalties have already been applied to the costs in Table 17 in cases where capacity shortages occurred. The penalty was $\$ 100$ per pallet, which was the same as in Section 5.3.1. When demands were inflated by $10 \%$ and $20 \%$ for the deterministic case, shortages still occurred and thus a penalty was added to the average total cost for every pallet not shipped. In this test of demand inflation, increasing the demands by $10 \%$ or $20 \%$ would be undesirable because not only were there capacity shortages in these cases, but the total costs were increased because of the inflation. In other words, the total costs were increasing even without the penalties and the networks were still unable to handle uncertainty in demand.

After studying Tables 16 and 17, it was clear that inflating demands by $30 \%$ would be the "best strategy". There were no capacity shortages in these cases and the average total costs were either less than the robust or comparable. Inflating demands by 40 and $50 \%$ began to increase the total costs by a rather large amount, which would be undesirable to freight carriers.

The idea behind testing demand inflation against the robust strategy was not to negate the usefulness of robust optimization. Instead it was to test the effects of demand inflation and how 
this method compared to the robust model. Based on the results, the demand inflation or "factor of safety" strategy could be a very useful tool for small freight carriers who do not have the means or knowledge to use robust optimization. Telling a carrier to inflate demands by $30 \%$ is much simpler than giving them a robust model to use. This simple strategy could allow even small carriers to account for some demand uncertainty. However, the robust model is still vital such that it gives a basis to which the results of inflated demands can be compared. The robust optimization is also a powerful tool for larger freight companies who have the ability to understand and use this method. Unlike demand inflation, there is a sound analytical process behind the robust approach. 


\section{CHAPTER 6. CONCLUSIONS AND DIRECTIONS FOR FUTURE RESEARCH}

\subsection{Summary}

Innovations in technology, population booms, fuels prices, traffic congestion, tighter trucking restrictions, and the demand for overnight and next-day delivery have led trucking companies to seek ways to reduce costs and increase efficiency. The desire to reduce wasted space on trucks led to the implementation of LTL consolidation and better planning for return shipments to eliminate empty backhauling. The idea of shipment consolidation created a need for intermediate facilities where trucks could consolidate their loads with other loads from different origins. Cross-dock warehouses filled that need. The use of cross-docks allowed for the efficient consolidation of shipments at intermediate points. Because goods spend little or no time in the actual facility, storage costs are eliminated as well as costs for picking. In order to utilize crossdocks, companies must first decide where to locate and open these facilities.

Therefore, a formulation was presented in order to choose which cross-docks should be opened from a set of potential nodes with the goal of minimizing total transportation costs. The first formulation assumed deterministic, or known, demands and followed the $p$-median facility problem. Three separate networks were studied, each of a different size. All networks and demands were extracted from real world data from a Third Party Logistics Company. The purpose of the deterministic formulation was to determine which cross-docks would be opened for each network and the total network costs.

The deterministic model then served as the baseline or control for the robust optimization. In the robust formulation, demand uncertainty was accounted for in each of the three networks at three levels of uncertainty - low, medium, and high. The robust formulation 
was created as a variation of the deterministic formulation by adding uncertainty terms to the appropriate constraints and the objective function.

\subsection{Conclusions}

The effects of demand uncertainty and the comparison between the performance of the deterministic and robust scenarios were tested on three realistic freight networks with parameters that followed industry standards. First, the deterministic and robust networks were compared to see simply how their results differed. In other words, the goal was to determine if accounting for uncertainty in demands changed which cross-docks would be opened and the overall total costs. In order to compare the costliness of the robust solutions, the relative costs were determined for various levels of omega. While the opened cross-docks, total costs, and relative costs provided important information regarding the differing results between deterministic and robust optimization, a better way to test the performance of each scenario was needed. This was accomplished in section 5.3, where the ability of each "optimized" network to handle uncertainty was studied.

Numerical analysis revealed that varying values of omega and the level of uncertainty for each network resulted in the opening of different cross-docks. This is an important result because it showed that accounting for uncertainty in demand did affect the results of the optimization. In other words, if demands are assumed to be known but in reality the demands actually vary, the system may have too little capacity or much greater total cost than anticipated. As expected, the total costs rose with the increase in omega and demand uncertainty. This occurred because larger omega values and higher uncertainty allowed the demands to increase by greater amounts. Larger demands resulted in higher transportation and handling costs. The relative cost showed the comparison between the total cost of the deterministic scenario (omega $=0$ ) and all of the 
robust scenarios. Because the total costs of the robust scenarios were greater than the deterministic case, all relative costs were greater than one, as expected. Of course, because omega set equal to zero was used as the baseline, that relative cost was one.

Simply looking at the total costs and relative costs could be misleading, because it makes the deterministic case look most appealing. In situations where demands are certain, the deterministic case is the best solution as it provides the lowest total cost. However, in networks where uncertainty exists, the robust optimization may be the best choice. Comparing the ability of the deterministic case (with average demands) and the robust case to handle uncertainty showed that the robust case was in fact more resilient when demands vary. In all networks, demand scenarios, and budgets of uncertainty in Section 5.3.1, the deterministic case came up short, such that it did not have enough capacity on either the trucks or in the cross-docks to handle increases in demand due to uncertainty. The robust case had no capacity shortages in any of the networks, demand scenarios, or budgets of uncertainty; it was able to handle and transport all random demands. In real world situations if a trucking company were unable to transport all of their demands, they would face some type of penalty. In this study, a penalty of $\$ 100$ per pallet was estimated. When the penalties were added to the total costs, the robust case ended up being less expensive than the deterministic case for every network, demand scenario, and budget of uncertainty.

In the analysis (Section 5.3.2) where demands were inflated by a percentage for the deterministic model and compared to the robust optimization, there were some valuable results. While small inflations still led to capacity shortages, and large inflations led to very high costs, a $30 \%$ demand inflation had no capacity shortages and total costs less than or comparable to the robust case. 
This analysis demonstrated the importance of accounting for uncertainty in demands. While assuming deterministic demands may result in more attractive total costs, accounting for uncertainties with a robust formulation can save money and reputation in the long run. In some situations for small carriers, simple demand inflation can be an extremely effective planning method. However, the robust model is still needed as a baseline to determine what percent of inflation will yield the best results. When inputs, such as demand, are uncertain, robust optimization is a powerful tool to develop a network that is able to handle increases in demand without shortages or unexpected costs.

\subsection{Directions for Future Research}

The work in this thesis could be expanded in a few ways. The first would be to model other parameters that may be uncertain, such as capacity or travel times, in order to see how they affect the cross-dock locations and total costs. This formulation could also be tested on even larger networks with much higher demands to see how the robust solution is able to handle greater uncertainty.

The discounts created due to consolidation could be modeled in other ways, such as using the MAUD function or some type of discount sharing technique. Another way to expand upon this work would be to discuss the penalty cost with real freight companies to get a more accurate or realistic value. This would allow for better comparison of the deterministic and robust cases. Finally, adding more constraints, such as delivery and pick-up times, would make the model more realistic, but also greatly increase the complexity. 


\section{REFERENCES}

Alp, O., Erkut, E., and Drezner, Z. (2003). “An Efficient Genetic Algorithm for the p-Median Problem.” Annals of operations Research, 122, 21-42.

Apte, U. M., and Viswanathan, S. (2000). "Effective Cross Docking for Improving Distribution Efficiencies." International Journal of Logistics: Research and Applications, 3(3), 291-302.

Atamtürk, A., Berenguer, G., and Shen, Z-J. (2012). "A Conic Integer Programming Approach to Stochastic Joint Location-Inventory Problems.” Operations Research, 60(2), 366-381.

Baron, O., Milner, J., and Naseraldin, H. (2011). "Facility location: a robust optimization approach.” Production and Operations Management, 20(5), 772-785.

Bartholdi III, J. J., and Gue, K. R. (2004). “The Best Shape for a Crossdock.” Transportation Science, 38(2), 235-244.

Ben-Tal, A., and Nemirovski, A. (1998). "Robust Convex Optimization." Mathematics of Operations Research, 23(4), 769-805.

Ben-Tal, A., and Nemirovski, A. (1999). "Robust Solutions of Uncertain Linear Programs." Operations Research Letters, 25(1), 1-14.

Ben-Tal, A., and Nemirovski, A. (2000). "Robust Solutions of Linear Programming Problems Contaminated with Uncertain Data.” Mathematical Programming, 88(3), 411-424.

Bertsimas, D., and Sim, M. (2003). "Robust Discrete Optimization and Network Flows." Mathematical Programming, 98(1), 49-71.

Bertsimas, D., and Sim, M. (2004). "The Price of Robustness.” Operations Research, 52(1), 3553.

Birge, J. R., and Louveaux, F. (1997). “Introduction to Stochastic Programming.” SpringerVerlag, New York.

Carr, S. (2009). "Hub Arc Selection for Less-than-truckload Consolidation.” M.S. thesis, Univ. of Missouri, Columbia, MO.

Chan, L. M. A., Muriel, A., Shen, Z-J. M., Simchi-Levi, D., and Teo, C-P. (2002). "Effective Zero-Inventory-Ordering Policies for the Single-Warehouse Multiretailer Problem with Piecewise Linear Cost Structures.” Management Science, 48(11), 1447.

Chen, P., Guo, Y., Lim, A., and Rodrigues, B.. (2006). "Multiple crossdocks with inventory and time windows.” Computers \& Operations Research, 33, 43-63.

Chen, X., Sim, M., and Sun, P. (2007). "A robust optimization perspective on stochastic programming." Operations Research, 55(6), 1058-1071. 
Daskin, M. S., Snyder, L. V., and Berger, R. T. (2005). "Facility Location in Supply Chain Design.” Logistics System: Design and Optimization, Chapter 2, 39-65.

Duthie, J. C., Unnikrishnan, A., and Waller, S. T. (2009). "Influence of Demand Uncertainty and Correlations on Traffic Predictions and Decisions." Computer Aided Civil and Infrastructure Engineering, 26(1), 16-29.

Faint, R. (2011). "How warehousing adds value.” Supply Chain, Logistics, and General Business, <http://supplychainlogistics.wordpress.com/2011/08/11/how-warehousing-addsvalue/> (Oct. 9, 2012).

Galbreth, M. R., Hill, J. A., and Handley, S. (2008). "AN INVESTIGATION OF THE VALUE OF CROSS-DOCKING FOR SUPPLY CHAIN MANAGEMENT.” Journal of Business Logistics, 29(1), 225-239.

Gardner, L. M., Unnikrishnan, A., and Waller, S. T. (2008). "Robust Pricing of Transportation Networks Under Uncertain Demand." Transportation Research Record: Journal of the Transportation Research Board, 2085, 21-30.

Gardner, L. M., Unnikrishnan, A., and Waller, S. T. (2009). "Solution Methods for Robust Pricing of Transportation Networks under Uncertain Demand." Transportation Research Part $C$, 18(5), 656-677.

Gülpinar, N., Pachamanova, D., and Çanakoglu, E. (2013). "Robust strategies for facility location under uncertainty." European Journal of Operational Research, 225(1), 21-35.

Gümüş, M., and Bookbinder, J. H. (2004). "CROSS-DOCKING AND ITS IMPLICATIONS IN LOCATION-DISTRIBUTION SYSTEMS.” Journal of Business Logistics, 25(2), 199-228.

Kall, P., and Wallace, S. W. (1994). "Stochastic Programming.” Wiley, Chichester, West Sussex, England.

Klose, A., and Drexl, A. (2005). "Facility location models for distribution system design." European Journal of Operational Research, 162(1), 4-29.

Ko, J. (2005). "SOLVING A DISTRIBUTION FACILITY LOCATION PROBLEM USING AN ANALYTIC HIERARCHY PROCESS APPROACH." 8th International Symposium on the Analytic Hierarchy Process, University of Hawaii, Honolulu, HI, 1-6.

Lee, Y. H., Jung, J. W., and Lee, K. M. (2006). "Vehicle routing scheduling for cross-docking in the supply chain." Computers \& Industrial Engineering, 51, 247-256.

Lessard, D. (2013). "Uncertainty and Risk in Global Supply Chains.” Social Science Research Network, 4991-13, 1-40. 
Liao, C-J., Lin, Y., and Shih, S. C. (2010). "Vehicle routing with cross-docking in the supply chain." Expert Systems with Applications, 37, 6868-6873.

Liao, T. W., Egbelu, P. J., and Chang, P. C. (2012). "Two hybrid differential evolution algorithms for optimal inbound and outbound truck sequencing in cross docking operations." Applied Soft Computing, 12, 3683-3697.

Melo, M. T., Nickel, S., and Saldanha-da-Gama, F. (2009). "Facility location and supply chain management - A review." European Journal of Operational Research, 196(2), 401-412.

Murray, M. (2013). "Cross Docking in the Warehouse.” Logistics, <http://logistics.about.com/od/tacticalsupplychain/a/cross_dock.htm> (Apr. 25, 2013).

O’Reilly, J. (2009). "Rediscovering The Classics, Volume III: Truckload Consolidation.” Inbound logistics, < http://www.inboundlogistics.com/cms/article/rediscovering-the-classicsvolume-iii-truckload-consolidation/> (Sep. 21, 2012).

Owen, S. H., and Daskin, M. S. (1998). "Strategic facility location: A review." European Journal of Operational Research, 111(3), 423-447.

Richardson, H. L. (1999). “Cross Docking: Information Flow Saves Space.” Transportation \& Distribution, 40(11), 51-54.

Schaffer, B. (1998). "Cross docking can increase efficiency.” Automatic I.D. News, 14(8), 34-36.

Snyder, L. V. (2006). "Facility Location under Uncertainty: A Review." IIE Transactions, 38(7), 547-564.

Soanpet, A. (2012). "Optimization Models for Locating Cross-docks under Capacity Uncertainty.” M.S. thesis, West Virginia Univ., Morgantown, WV.

Srivastava, S. K. (2007). "Green supply-chain management: A state-of-the-art literature review." International Journal of Management Reviews, 9(1), 54-55.

Stalk, G., Evans, P., and Shulman, L. E. (1992). "Competing on Capabilities: The New Rules of Corporate Strategy.” Harvard Business Review, 70(2), 57-69.

Sung, C. S., and Song, S. H. (2003). "Integrated Service Network Design for a Cross-Docking Supply Chain Network." The Journal of the Operational Research Society, 54(12), 1283-1295.

Ülkü, M. A. (2012). "Dare to care: Shipment consolidation reduces not only costs, but also environmental damage." International Journal Production Economics, 139, 438.

United States Department of Transportation- Federal Highway Administration. (2013). "History of the Interstate Highway System." Celebrating the Eisenhower Interstate Highway System, <https://www.fhwa.dot.gov/interstate/history.htm> (Aug. 30, 2013). 
Unnikrishnan, A. (2008). "Equilibrium Models Accounting for Uncertainty and Information Provision in Transportation Networks." Ph.D. thesis, The Univ. of Texas, Austin, TX.

Unnikrishnan, A., and Figliozzi, M. (2011). “An Online Freight Network Assignment Model Accounting for Transportation Disruptions and Recourse." Transportation Research Record: Journal of the Transportation Research Board, 2224, 17-25.

Unnikrishnan, A., and Waller, S. T. (2009). "Freight Transportation Network Design Problem for Maximizing Throughput Under Uncertainty." Transportation Research Record: Journal of the Transportation Research Board, 2090, 105-114.

Unnikrishnan, A., Valsaraj, V., and Waller, S.T. (2009). "Stochastic and Dynamic Shipper Carrier Network Design Problem.” Networks and Spatial Economics, 9(4), 525-550.

Vahdani, B., and Zandieh, M. (2010). "Scheduling trucks in cross-docking systems: Robust meta-heuristics." Computers \& Industrial Engineering, 58, 12-24.

Van Belle, J., Valckenaers, P., and Cattrysse, D. (2012). "Cross-docking: State of the art." Omega, 40, 827-846.

Vis, I. F.A., and Roodbergen, K. J. (2011). "Layout and control policies for cross docking operations." Computers \& Industrial Engineering, 61, 911-919.

Wagner, M. R., Bhadury, J., and Peng, S. (2009). "Risk management in uncapacitated facility location models with random demands." Computers \& Operations Research, 36(14), 1002-1011.

Waller, S. T., and Ziliaskopoulos, A. K. (2001). "Stochastic Dynamic Network Design Model." Transportation Research Record: Journal of the Transportation Research Board, 1771, 106-113.

Waller, S.T., Schofer, J. L., and Ziliaskopoulos, A. K. (2001). "Evaluation with Traffic Assignment Under Demand Uncertainty." Transportation Research Record: Journal of the Transportation Research Board, 1771, 69-74.

Wen, M., Larsen, J., Clausen, J., Cordeau, J-F., and Laporte, G. (2009). "Vehicle routing with cross-docking." Journal of the Operational Research Society, 60, 1708-1718. 


\section{APPENDICES}

\section{Appendix A}

Table 18: Internode Mileage for Network 1 from Origin (i) to Destination (j)

\begin{tabular}{|c|c|c|c|c|c|c|}
\hline & & \multicolumn{5}{|c|}{ Destination } \\
\hline & & Westborough & Kirkwood & Columbus & Fairborn & Eighty Four \\
\hline \multirow{5}{*}{ Origin } & Montgomery & 1233 & 1047 & 660 & 616 & 819 \\
\hline & Atlanta & 1082 & 897 & 570 & 524 & 674 \\
\hline & Unadilla & 1128 & 976 & 694 & 645 & 753 \\
\hline & Haines City & 1310 & 1176 & 1025 & 982 & 982 \\
\hline & Hattiesburg & 1379 & 1197 & 799 & 755 & 960 \\
\hline
\end{tabular}


Table 19: Internode Mileage for Network 1 from Origin (i) to Cross-dock (k)

\begin{tabular}{|c|c|c|c|c|c|c|}
\hline & & \multicolumn{5}{|c|}{ Cross-dock } \\
\hline & & Lexington & Charlotte & Knoxville & Charlottesville & Charleston \\
\hline \multirow{5}{*}{ Origin } & Montgomery & 494 & 405 & 343 & 671 & 661 \\
\hline & Atlanta & 380 & 245 & 214 & 511 & 502 \\
\hline & Unadilla & 501 & 333 & 334 & 603 & 596 \\
\hline & Haines City & 830 & 562 & 664 & 847 & 825 \\
\hline & Hattiesburg & 635 & 622 & 489 & 855 & 798 \\
\hline
\end{tabular}


Table 20: Internode Mileage for Network 1 from Cross-dock (k) to Destination (j)

\begin{tabular}{|c|c|c|c|c|c|c|}
\hline & & \multicolumn{5}{|c|}{ Destination } \\
\hline & & Westborough & Kirkwood & Columbus & Fairborn & Eighty Four \\
\hline \multirow{5}{*}{ Cross-dock } & Lexington & 891 & 696 & 191 & 148 & 351 \\
\hline & Charlotte & 808 & 646 & 426 & 454 & 422 \\
\hline & Knoxville & 892 & 709 & 357 & 314 & 467 \\
\hline & Charlottesville & 527 & 413 & 410 & 437 & 293 \\
\hline & Charleston & 717 & 533 & 162 & 189 & 202 \\
\hline
\end{tabular}


Table 21: Internode Mileage for Network 2 from Origin (i) to Destination (j)

\begin{tabular}{|c|c|c|c|c|c|c|c|c|c|c|c|}
\hline & \multicolumn{10}{|c|}{ Destination } \\
\hline & & Alsip & Danville & Des Plaines & Hanover Park & Monroe & Troy & Kansas City & Springfield & St. Louis & Milwaukee \\
\hline \multirow{10}{*}{ Origin } & Everett & 982 & 1036 & 1005 & 1018 & 776 & 713 & 1439 & 1411 & 1196 & 1079 \\
\hline & Franklin & 965 & 1020 & 988 & 1002 & 759 & 696 & 1423 & 1394 & 1179 & 1062 \\
\hline & Baltimore & 696 & 667 & 718 & 733 & 491 & 549 & 1060 & 1036 & 821 & 797 \\
\hline & Elizabeth & 778 & 800 & 800 & 814 & 575 & 622 & 1203 & 1159 & 953 & 880 \\
\hline & Newark & 775 & 788 & 798 & 811 & 572 & 627 & 1181 & 1167 & 941 & 871 \\
\hline & Sayreville & 799 & 787 & 822 & 819 & 580 & 651 & 1180 & 1161 & 941 & 895 \\
\hline & Delhi & 769 & 829 & 792 & 806 & 565 & 525 & 1222 & 1202 & 983 & 866 \\
\hline & Waterford & 818 & 878 & 843 & 856 & 612 & 687 & 1271 & 1247 & 1064 & 930 \\
\hline & Hanover & 676 & 651 & 699 & 694 & 455 & 528 & 1054 & 1015 & 808 & 773 \\
\hline & Hatfield & 748 & 734 & 770 & 783 & 544 & 592 & 1127 & 1103 & 902 & 849 \\
\hline
\end{tabular}


Table 22: Internode Mileage for Network 2 from Origin (i) to Cross-dock (k)

\begin{tabular}{|c|c|c|c|c|c|c|c|c|c|c|c|}
\hline & \multicolumn{10}{|c|}{ Cross-dock } \\
\hline & & $\begin{array}{c}\text { Fort } \\
\text { Wayne }\end{array}$ & Indianapolis & Cumberland & Canton & Cincinnati & Columbus & Altoona & Pittsburgh & Parkersburg & Wheeling \\
\hline \multirow{10}{*}{ Origin } & Everett & 847 & 940 & 525 & 663 & 858 & 755 & 483 & 576 & 706 & 628 \\
\hline & Franklin & 830 & 912 & 508 & 646 & 841 & 737 & 466 & 559 & 689 & 611 \\
\hline & Baltimore & 560 & 579 & 139 & 366 & 508 & 404 & 181 & 244 & 319 & 278 \\
\hline & Elizabeth & 643 & 701 & 293 & 454 & 630 & 526 & 274 & 363 & 478 & 400 \\
\hline & Newark & 636 & 699 & 291 & 447 & 628 & 524 & 267 & 360 & 476 & 398 \\
\hline & Sayreville & 660 & 699 & 289 & 470 & 628 & 524 & 279 & 354 & 471 & 392 \\
\hline & Delhi & 634 & 740 & 347 & 461 & 671 & 564 & 281 & 374 & 528 & 434 \\
\hline & Waterford & 682 & 789 & 439 & 523 & 722 & 615 & 366 & 470 & 620 & 530 \\
\hline & Hanover & 538 & 565 & 119 & 317 & 488 & 384 & 133 & 199 & 299 & 237 \\
\hline & Hatfield & 610 & 646 & 237 & 420 & 575 & 471 & 233 & 307 & 418 & 345 \\
\hline
\end{tabular}


Table 23: Internode Mileage for Network 2 from Cross-dock (k) to Destination (j)

\begin{tabular}{|c|c|c|c|c|c|c|c|c|c|c|c|}
\hline & \multicolumn{10}{|c|}{ Destination } \\
\hline & & Alsip & Danville & $\begin{array}{c}\text { Des } \\
\text { Plaines }\end{array}$ & $\begin{array}{c}\text { Hanover } \\
\text { Park }\end{array}$ & Monroe & Troy & $\begin{array}{c}\text { Kansas } \\
\text { City }\end{array}$ & Springfield & St. Louis & Milwaukee \\
\hline \multirow{10}{*}{$\begin{array}{c}\text { Cross- } \\
\text { dock }\end{array}$} & Fort Wayne & 155 & 180 & 179 & 191 & 127 & 185 & 608 & 584 & 368 & 253 \\
\hline & Indianapolis & 174 & 89.3 & 206 & 210 & 251 & 309 & 482 & 458 & 242 & 280 \\
\hline & Cumberland & 556 & 529 & 579 & 592 & 350 & 408 & 922 & 898 & 683 & 652 \\
\hline & Canton & 372 & 389 & 396 & 420 & 177 & 231 & 782 & 758 & 543 & 469 \\
\hline & Cincinnati & 287 & 202 & 319 & 323 & 227 & 285 & 589 & 565 & 350 & 392 \\
\hline & Columbus & 318 & 264 & 342 & 384 & 163 & 227 & 657 & 633 & 418 & 416 \\
\hline & Altoona & 548 & 547 & 567 & 584 & 342 & 400 & 940 & 915 & 700 & 645 \\
\hline & Pittsburgh & 456 & 448 & 475 & 492 & 250 & 308 & 841 & 817 & 602 & 553 \\
\hline & Parkersburg & 458 & 375 & 453 & 492 & 279 & 337 & 768 & 743 & 528 & 526 \\
\hline & Wheeling & 445 & 391 & 505 & 510 & 272 & 330 & 784 & 759 & 544 & 543 \\
\hline
\end{tabular}


Table 24: Internode Mileage for Network 3 from Origin (i) to Destination (j)

(Destinations 1 through 10 are shown)

\begin{tabular}{|c|c|c|c|c|c|c|c|c|c|c|c|}
\hline & \multicolumn{10}{|c|}{ Destination } \\
\hline & & Alsip & Chicago & Danville & $\begin{array}{c}\text { Des } \\
\text { Plaines }\end{array}$ & $\begin{array}{c}\text { Hanover } \\
\text { Park }\end{array}$ & Taylorville & $\begin{array}{c}\text { Mason } \\
\text { City }\end{array}$ & Louisville & Dearborn & Monroe \\
\hline \multirow{20}{*}{ Origin } & New Haven & 858 & 864 & 906 & 882 & 895 & 989 & 1231 & 817 & 683 & 652 \\
\hline & Everett & 982 & 987 & 1036 & 1005 & 1018 & 1141 & 1355 & 973 & 719 & 776 \\
\hline & Franklin & 965 & 971 & 1020 & 988 & 1002 & 1124 & 1338 & 956 & 702 & 759 \\
\hline & Baltimore & 696 & 704 & 667 & 718 & 733 & 779 & 1070 & 610 & 522 & 491 \\
\hline & Belcamp & 724 & 729 & 694 & 748 & 760 & 806 & 1094 & 638 & 549 & 518 \\
\hline & Elizabeth & 778 & 787 & 800 & 800 & 814 & 902 & 1154 & 730 & 603 & 575 \\
\hline & Kearny & 776 & 785 & 805 & 798 & 813 & 902 & 1149 & 731 & 602 & 571 \\
\hline & Newark & 775 & 780 & 788 & 798 & 811 & 899 & 1147 & 728 & 599 & 572 \\
\hline & Sayreville & 799 & 789 & 787 & 822 & 819 & 900 & 1157 & 728 & 609 & 580 \\
\hline & Delhi & 769 & 775 & 829 & 792 & 806 & 951 & 1142 & 773 & 532 & 565 \\
\hline & Rochester & 597 & 602 & 657 & 620 & 633 & 777 & 970 & 601 & 333 & 391 \\
\hline & Waterford & 818 & 825 & 878 & 843 & 856 & 1001 & 1192 & 823 & 552 & 612 \\
\hline & Williamson & 624 & 629 & 684 & 648 & 660 & 806 & 997 & 628 & 361 & 418 \\
\hline & Blandon & 719 & 724 & 697 & 743 & 755 & 809 & 1092 & 668 & 544 & 513 \\
\hline & Hanover & 676 & 654 & 651 & 699 & 694 & 738 & 1022 & 590 & 474 & 455 \\
\hline & Hatfield & 748 & 756 & 734 & 770 & 783 & 861 & 1118 & 674 & 573 & 544 \\
\hline & Alexandria & 699 & 704 & 669 & 723 & 735 & 781 & 1072 & 613 & 524 & 493 \\
\hline & Lyndhurst & 706 & 714 & 623 & 738 & 742 & 753 & 1057 & 470 & 566 & 535 \\
\hline & Newport News & 855 & 860 & 784 & 879 & 892 & 915 & 1218 & 631 & 680 & 649 \\
\hline & Richmond & 793 & 798 & 714 & 817 & 829 & 847 & 1150 & 563 & 618 & 587 \\
\hline
\end{tabular}


Table 25: Internode Mileage for Network 3 from Origin (i) to Destination (j) (Destinations 11 through 20 are shown)

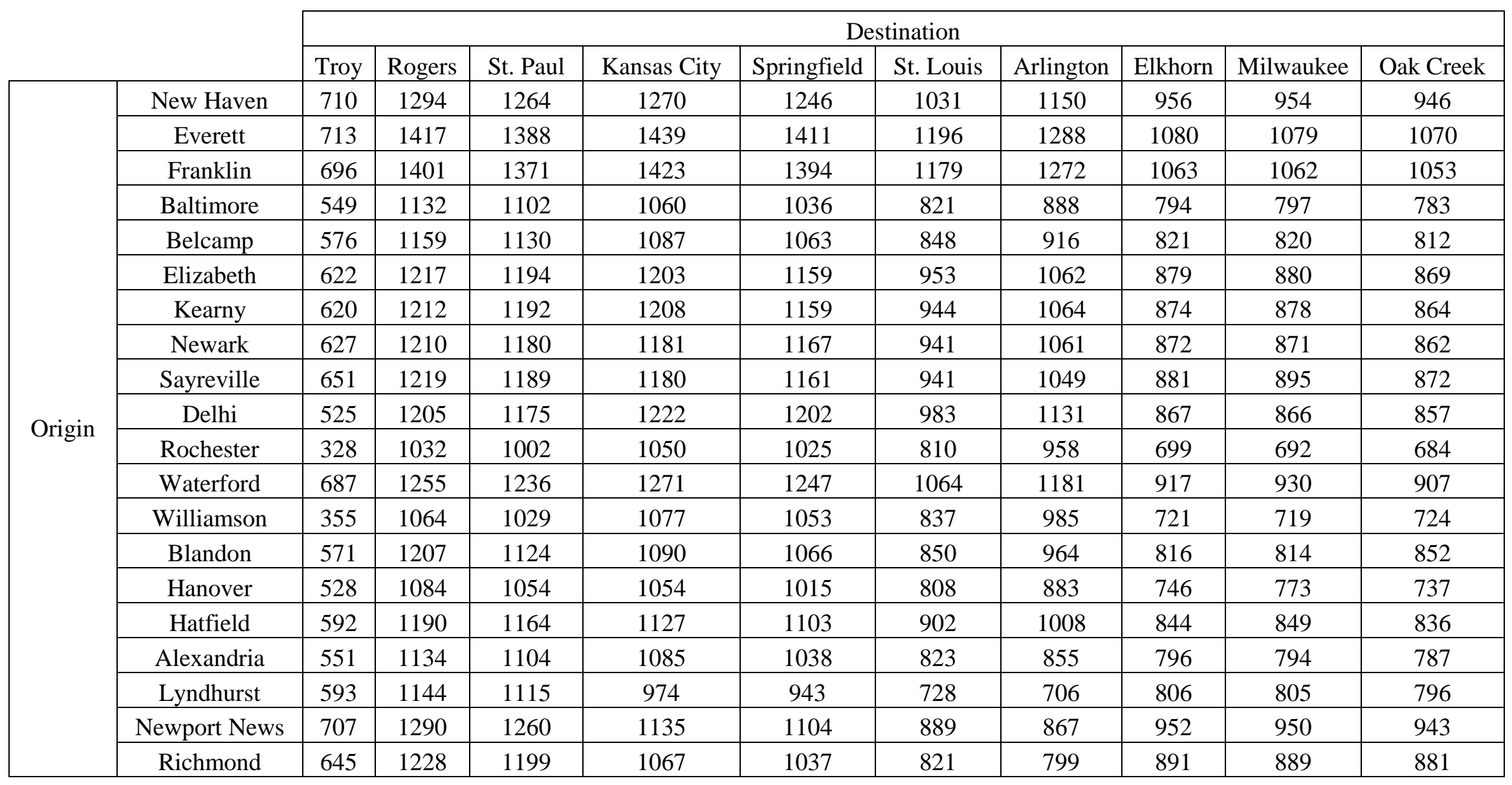


Table 26: Internode Mileage for Network 3 from Origin (i) to Cross-dock (k)

(Cross-docks 1 through 10 are shown)

\begin{tabular}{|c|c|c|c|c|c|c|c|c|c|c|c|}
\hline & \multicolumn{10}{|c|}{ Cross-dock } \\
\hline & & Fairfield & Bloomington & $\begin{array}{c}\text { Fort } \\
\text { Wayne }\end{array}$ & Hebron & Indianapolis & Lexington & Summit & Cumberland & Canton & Cincinnati \\
\hline \multirow{20}{*}{ Origin } & New Haven & 972 & 838 & 720 & 842 & 788 & 784 & 680 & 385 & 530 & 718 \\
\hline & Everett & 1128 & 990 & 847 & 966 & 940 & 923 & 818 & 525 & 663 & 858 \\
\hline & Franklin & 1111 & 973 & 830 & 949 & 912 & 906 & 801 & 508 & 646 & 841 \\
\hline & Baltimore & 765 & 628 & 560 & 680 & 579 & 538 & 434 & 139 & 366 & 508 \\
\hline & Belcamp & 792 & 655 & 586 & 707 & 606 & 566 & 461 & 166 & 396 & 535 \\
\hline & Elizabeth & 885 & 751 & 643 & 765 & 701 & 697 & 592 & 293 & 454 & 630 \\
\hline & Kearny & 886 & 752 & 638 & 760 & 702 & 698 & 593 & 298 & 448 & 631 \\
\hline & Newark & 883 & 749 & 636 & 758 & 699 & 695 & 590 & 291 & 447 & 628 \\
\hline & Sayreville & 884 & 749 & 660 & 767 & 699 & 691 & 586 & 289 & 470 & 628 \\
\hline & Delhi & 928 & 790 & 634 & 753 & 740 & 756 & 640 & 347 & 461 & 671 \\
\hline & Rochester & 756 & 618 & 461 & 580 & 568 & 584 & 520 & 341 & 302 & 501 \\
\hline & Waterford & 979 & 840 & 682 & 803 & 789 & 807 & 734 & 439 & 523 & 722 \\
\hline & Williamson & 783 & 645 & 489 & 607 & 595 & 611 & 548 & 332 & 329 & 528 \\
\hline & Blandon & 792 & 658 & 581 & 702 & 608 & 599 & 494 & 199 & 391 & 537 \\
\hline & Hanover & 745 & 588 & 538 & 632 & 565 & 518 & 414 & 119 & 317 & 488 \\
\hline & Hatfield & 830 & 695 & 610 & 732 & 646 & 637 & 532 & 237 & 420 & 575 \\
\hline & Alexandria & 767 & 630 & 561 & 682 & 581 & 541 & 436 & 141 & 371 & 510 \\
\hline & Lyndhurst & 624 & 570 & 543 & 667 & 534 & 398 & 293 & 165 & 415 & 427 \\
\hline & Newport News & 786 & 732 & 704 & 828 & 695 & 559 & 454 & 297 & 527 & 588 \\
\hline & Richmond & 718 & 664 & 636 & 760 & 628 & 491 & 387 & 235 & 466 & 521 \\
\hline
\end{tabular}


Table 27: Internode Mileage for Network 3 from Origin (i) to Cross-dock (k)

(Cross-docks 11 through 20 are shown)

\begin{tabular}{|c|c|c|c|c|c|c|c|c|c|c|c|}
\hline & \multicolumn{10}{|c|}{ Cross-dock } \\
\hline & & Columbus & Lima & Altoona & Mansfield & Oil City & Pittsburgh & Beckley & Buckhannon & Parkersburg & Wheeling \\
\hline \multirow{14}{*}{ Origin } & New Haven & 614 & 663 & 351 & 267 & 422 & 450 & 605 & 523 & 565 & 488 \\
\hline & Everett & 755 & 796 & 483 & 395 & 555 & 576 & 743 & 661 & 706 & 628 \\
\hline & Baltimore & 404 & 502 & 181 & 222 & 291 & 244 & 343 & 277 & 319 & 278 \\
\hline & Belcamp & 431 & 529 & 207 & 222 & 292 & 275 & 371 & 304 & 347 & 305 \\
\hline & Newark & 524 & 579 & 267 & 228 & 339 & 360 & 516 & 433 & 476 & 398 \\
\hline & Sayreville & 524 & 589 & 279 & 238 & 348 & 354 & 504 & 429 & 471 & 392 \\
\hline & Delhi & 564 & 596 & 281 & 157 & 342 & 374 & 568 & 483 & 528 & 434 \\
\hline & Rochester & 394 & 424 & 277 & 131 & 205 & 284 & 519 & 417 & 422 & 336 \\
\hline & Waterford & 615 & 646 & 366 & 232 & 428 & 470 & 659 & 577 & 620 & 530 \\
\hline & Hatfield & 471 & 553 & 233 & 202 & 312 & 307 & 466 & 375 & 418 & 345 \\
\hline & Alexandria & 406 & 504 & 182 & 270 & 315 & 250 & 310 & 224 & 322 & 280 \\
\hline & Lyndhurst & 384 & 471 & 224 & 359 & 357 & 292 & 161 & 147 & 299 & 289 \\
\hline & Newport News & 546 & 633 & 338 & 425 & 471 & 406 & 322 & 309 & 461 & 436 \\
\hline & Richmond & 478 & 565 & 276 & 363 & 409 & 344 & 254 & 241 & 393 & 374 \\
\hline
\end{tabular}


Table 28: Internode Mileage for Network 3 from Cross-dock (k) to Destination (j)

(Destinations 1 through 10 are shown)

\begin{tabular}{|c|c|c|c|c|c|c|c|c|c|c|c|}
\hline & \multicolumn{10}{|c|}{ Destination } \\
\hline & & Alsip & Chicago & Danville & $\begin{array}{c}\text { Des } \\
\text { Plaines }\end{array}$ & $\begin{array}{l}\text { Hanover } \\
\text { Park }\end{array}$ & Taylorville & $\begin{array}{c}\text { Mason } \\
\text { City }\end{array}$ & Louisville & Dearborn & Monroe \\
\hline \multirow{20}{*}{$\begin{array}{c}\text { Cross- } \\
\text { dock }\end{array}$} & Fairfield & 256 & 271 & 174 & 288 & 292 & 121 & 538 & 157 & 483 & 453 \\
\hline & Bloomington & 223 & 232 & 136 & 256 & 259 & 184 & 571 & 105 & 331 & 301 \\
\hline & Fort Wayne & 155 & 162 & 180 & 179 & 191 & 313 & 528 & 236 & 158 & 127 \\
\hline & Hebron & 47.4 & 56 & 110 & 80.1 & 83.5 & 196 & 420 & 250 & 261 & 251 \\
\hline & Indianapolis & 174 & 183 & 89.3 & 206 & 210 & 201 & 523 & 114 & 282 & 251 \\
\hline & Lexington & 365 & 373 & 281 & 398 & 401 & 364 & 715 & 80.6 & 341 & 310 \\
\hline & Summit & 424 & 432 & 340 & 457 & 460 & 470 & 774 & 187 & 322 & 291 \\
\hline & Cumberland & 556 & 561 & 529 & 579 & 592 & 641 & 929 & 472 & 381 & 350 \\
\hline & Canton & 372 & 389 & 389 & 396 & 420 & 501 & 756 & 333 & 208 & 177 \\
\hline & Cincinnati & 287 & 295 & 202 & 319 & 323 & 314 & 637 & 99.4 & 258 & 227 \\
\hline & Columbus & 318 & 356 & 264 & 342 & 384 & 376 & 699 & 206 & 199 & 163 \\
\hline & Lima & 222 & 228 & 262 & 247 & 258 & 374 & 594 & 224 & 133 & 103 \\
\hline & Altoona & 548 & 553 & 547 & 567 & 584 & 658 & 921 & 487 & 373 & 342 \\
\hline & Mansfield & 651 & 656 & 693 & 674 & 687 & 805 & 1023 & 637 & 415 & 445 \\
\hline & Oil City & 457 & 462 & 495 & 481 & 493 & 607 & 830 & 439 & 282 & 251 \\
\hline & Pittsburgh & 456 & 461 & 448 & 475 & 492 & 560 & 829 & 388 & 281 & 250 \\
\hline & Beckley & 542 & 550 & 459 & 574 & 578 & 589 & 893 & 306 & 416 & 386 \\
\hline & Buckhannon & 566 & 593 & 483 & 612 & 602 & 595 & 917 & 359 & 413 & 382 \\
\hline & Parkersburg & 458 & 464 & 375 & 453 & 492 & 485 & 807 & 286 & 326 & 279 \\
\hline & Wheeling & 445 & 482 & 391 & 505 & 510 & 502 & 825 & 331 & 289 & 272 \\
\hline
\end{tabular}


Table 29: Internode Mileage for Network 3 from Cross-dock (k) to Destination (j)

(Destinations 11 through 20 are shown)

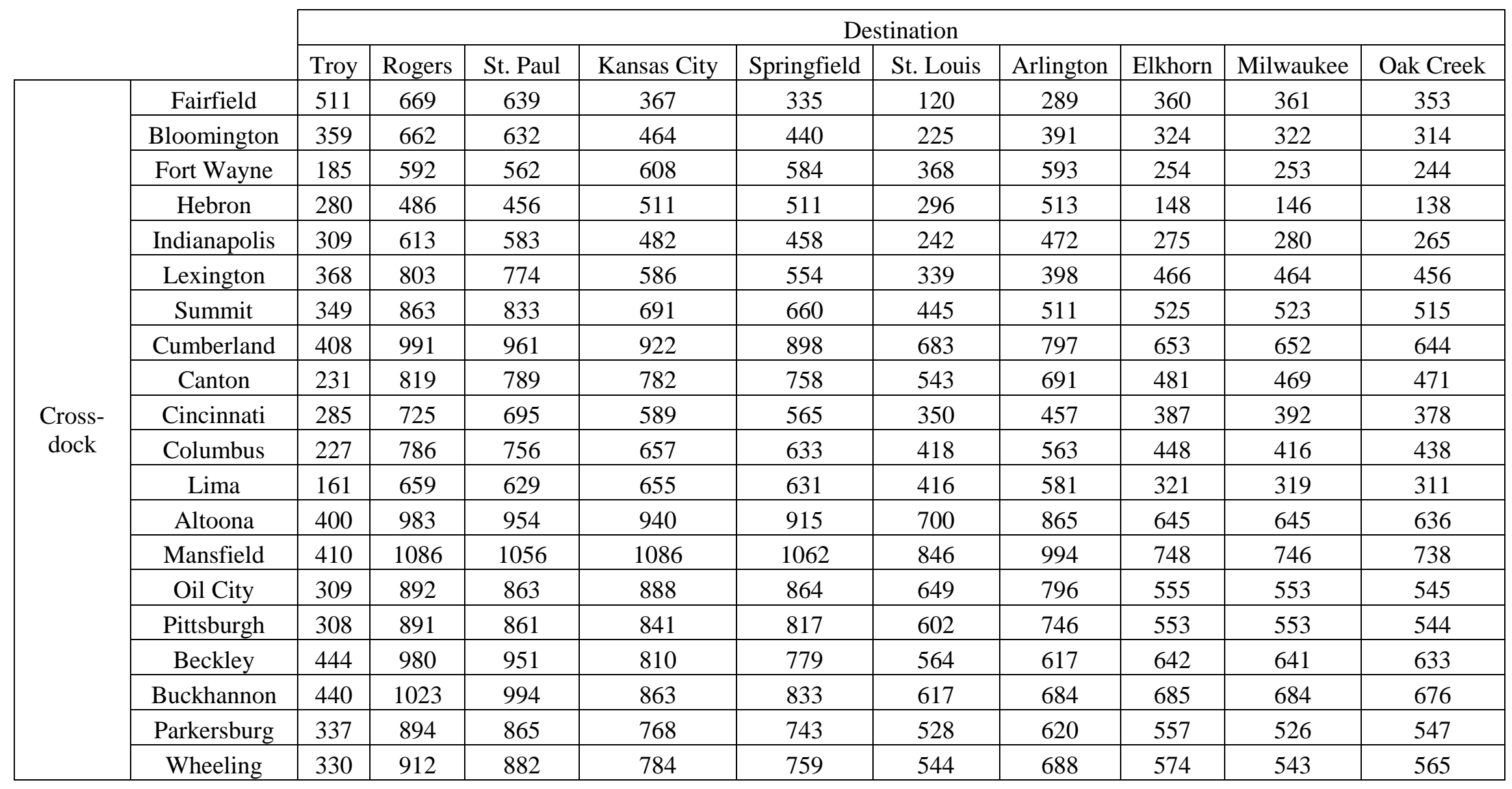


Table 30: Average Demands (in pallets) for Network 1

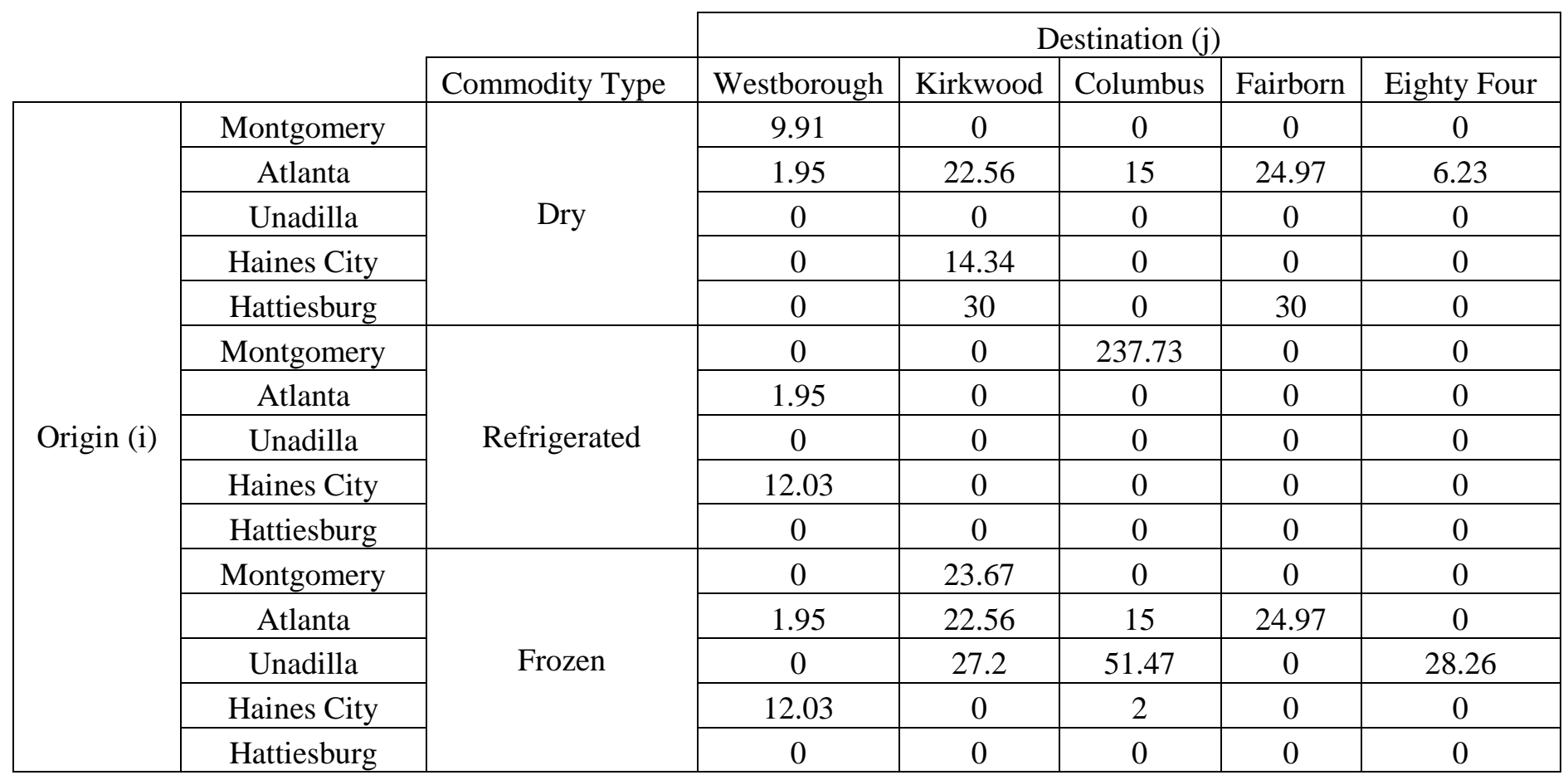


Table 31: Average Demands (in pallets) for Network 2

\begin{tabular}{|c|c|c|c|c|c|c|c|c|c|c|c|c|}
\hline & \multirow{3}{*}{\multicolumn{2}{|c|}{ 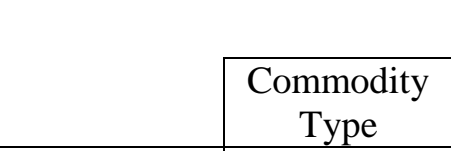 }} & \multirow{2}{*}{\multicolumn{10}{|c|}{ Destination $(\mathrm{j})$}} \\
\hline & & & & & & & & & & & & \\
\hline & & & Alsip & Danville & $\begin{array}{c}\text { Des } \\
\text { Plaines }\end{array}$ & $\begin{array}{c}\text { Hanover } \\
\text { Park } \\
\end{array}$ & Monroe & Troy & $\begin{array}{c}\text { Kansas } \\
\text { City }\end{array}$ & Springfield & $\begin{array}{c}\text { St. } \\
\text { Louis }\end{array}$ & Milwaukee \\
\hline \multirow{30}{*}{$\begin{array}{l}\text { Origin } \\
\text { (i) }\end{array}$} & Everett & \multirow{10}{*}{ Dry } & 0 & 0.71 & 0 & 0 & 0 & 0 & 1 & 0 & 0 & 0 \\
\hline & Franklin & & 0 & 0 & 0 & 0 & 0 & 0 & 0 & 0 & 0 & 0 \\
\hline & Baltimore & & 9.68 & 0 & 9.62 & 0 & 0 & 0 & 0 & 0 & 0 & 9.62 \\
\hline & Elizabeth & & 2 & 7.02 & 2.72 & 0 & 0 & 7.01 & 4.77 & 0 & 2.87 & 3.03 \\
\hline & Newark & & 0 & 0 & 0 & 0 & 0 & 0 & 0 & 0 & 0 & 0 \\
\hline & Sayreville & & 0 & 0 & 0 & 25.36 & 23.72 & 0 & 0 & 27.36 & 0 & 0 \\
\hline & Delhi & & 0 & 0 & 0 & 0 & 0 & 0 & 0 & 0 & 0 & 0 \\
\hline & Waterford & & 0 & 0 & 28.4 & 0 & 0 & 21.43 & 0 & 0 & 27.74 & 27.83 \\
\hline & Hanover & & 0 & 5.8 & 0 & 14.41 & 37.42 & 0 & 15.92 & 1 & 0 & 0 \\
\hline & Hatfield & & 47.63 & 0 & 12.44 & 24.54 & 27.75 & 4.83 & 0 & 0 & 6.52 & 17.28 \\
\hline & Everett & \multirow{10}{*}{ Refrigerated } & 0 & 0 & 0 & 0 & 0 & 0 & 0 & 0 & 0 & 0 \\
\hline & Franklin & & 0 & 17.7 & 0 & 0 & 0 & 0 & 15.65 & 0 & 0 & 0 \\
\hline & Baltimore & & 0 & 0 & 0 & 0 & 0 & 0 & 0 & 0 & 0 & 0 \\
\hline & Elizabeth & & 0 & 7.02 & 0 & 0 & 0 & 0 & 4.77 & 0 & 0 & 0 \\
\hline & Newark & & 0 & 0 & 0 & 0 & 0 & 0 & 0 & 0 & 0 & 0 \\
\hline & Sayreville & & 0 & 0 & 0 & 0 & 0 & 0 & 0 & 0 & 0 & 0 \\
\hline & Delhi & & 0 & 0 & 0 & 0 & 3.13 & 0 & 0 & 3 & 0 & 0 \\
\hline & Waterford & & 0 & 0 & 0 & 0 & 0 & 0 & 0 & 0 & 0 & 0 \\
\hline & Hanover & & 0 & 0 & 0 & 0 & 0 & 0 & 0 & 0 & 0 & 0 \\
\hline & Hatfield & & 0 & 0 & 0 & 0 & 0 & 0 & 0 & 0 & 0 & 0 \\
\hline & Everett & \multirow{10}{*}{ Frozen } & 0 & 0 & 0 & 0 & 0 & 0 & 0 & 0 & 0 & 0 \\
\hline & Franklin & & 0 & 0 & 0 & 0 & 0 & 0 & 0 & 0 & 0 & 0 \\
\hline & Baltimore & & 0 & 0 & 0 & 0 & 0 & 0 & 0 & 0 & 0 & 0 \\
\hline & Elizabeth & & 0 & 0 & 0 & 2 & 8.67 & 0 & 0 & 0 & 0 & 0 \\
\hline & Newark & & 0 & 0 & 0 & 2 & 12 & 0 & 0 & 14.83 & 0 & 0 \\
\hline & Sayreville & & 0 & 0 & 0 & 0 & 0 & 0 & 0 & 0 & 0 & 0 \\
\hline & Delhi & & 0 & 0 & 0 & 0 & 0 & 0 & 0 & 0 & 0 & 0 \\
\hline & Waterford & & 0 & 0 & 0 & 0 & 0 & 0 & 0 & 0 & 0 & 0 \\
\hline & Hanover & & 0 & 0 & 0 & 0 & 0 & 0 & 0 & 0 & 0 & 0 \\
\hline & Hatfield & & 0 & 0 & 0 & 0 & 0 & 0 & 0 & 0 & 0 & 0 \\
\hline
\end{tabular}


Table 32: Average Demands (in pallets) for Network 3

(Dry Commodity, Destinations 1 through 10)

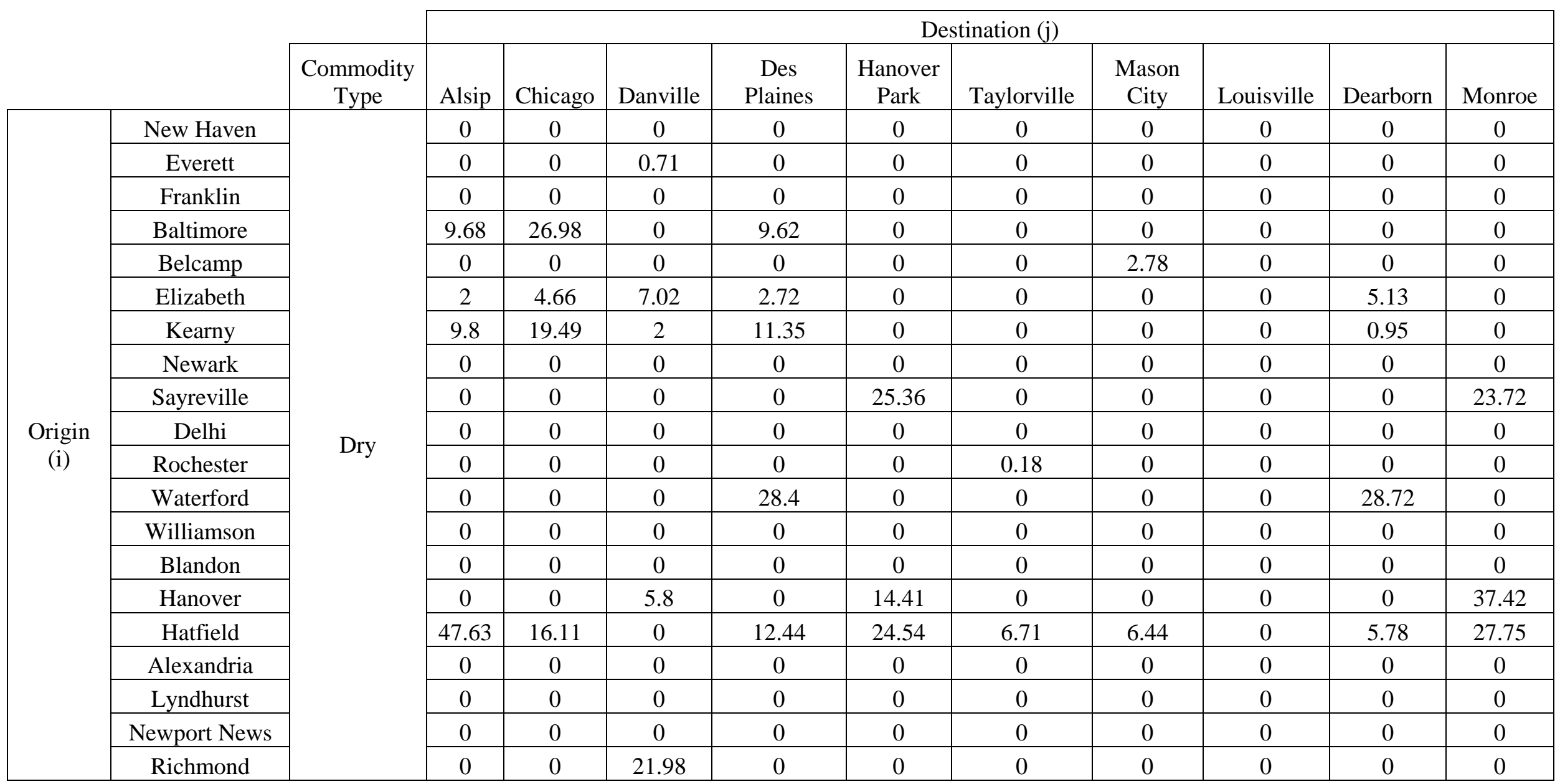


Table 33: Average Demands (in pallets) for Network 3

(Dry Commodity, Destinations 11 through 20)

\begin{tabular}{|c|c|c|c|c|c|c|c|c|c|c|c|c|}
\hline & \multirow[b]{2}{*}{$\begin{array}{c}\text { Commodity } \\
\text { Type }\end{array}$} & \multicolumn{10}{|c|}{ Destination (j) } \\
\hline & & & Troy & Rogers & St. Paul & $\begin{array}{c}\text { Kansas } \\
\text { City }\end{array}$ & Springfield & St. Louis & Arlington & Elkhorn & Milwaukee & $\begin{array}{c}\text { Oak } \\
\text { Creek }\end{array}$ \\
\hline \multirow{20}{*}{$\begin{array}{l}\text { Origin } \\
\text { (i) }\end{array}$} & New Haven & \multirow{20}{*}{ Dry } & 0 & 0 & 0 & 0 & 0 & 0 & 0 & 0 & 0 & 0 \\
\hline & Everett & & 0 & 0 & 0 & 1 & 0 & 0 & 0 & 0 & 0 & 0 \\
\hline & Franklin & & 0 & 0 & 0 & 0 & 0 & 0 & 0 & 0 & 0 & 0 \\
\hline & Baltimore & & 0 & 0 & 0 & 0 & 0 & 0 & 0 & 0 & 9.62 & 3.75 \\
\hline & Belcamp & & 0 & 0 & 0 & 0 & 0 & 0 & 4.83 & 0 & 0 & 0 \\
\hline & Elizabeth & & 7.01 & 0 & 5.02 & 4.77 & 0 & 2.87 & 0 & 0 & 3.03 & 0 \\
\hline & Kearny & & 5.6 & 0 & 6.66 & 1 & 0 & 0 & 0 & 0 & 13.9 & 0 \\
\hline & Newark & & 0 & 0 & 0 & 0 & 0 & 0 & 0 & 0 & 0 & 0 \\
\hline & Sayreville & & 0 & 0 & 0 & 0 & 27.36 & 0 & 0 & 0 & 0 & 0 \\
\hline & Delhi & & 0 & 0 & 0 & 0 & 0 & 0 & 0 & 0 & 0 & 0 \\
\hline & Rochester & & 0 & 0 & 0 & 0 & 0 & 0 & 0 & 0.23 & 0 & 0 \\
\hline & Waterford & & 21.43 & 0 & 28.25 & 0 & 0 & 27.74 & 0 & 0 & 27.83 & 0 \\
\hline & Williamson & & 0 & 8 & 0 & 0 & 0 & 0 & 0 & 0 & 0 & 7.13 \\
\hline & Blandon & & 0 & 0 & 0 & 0 & 0 & 0 & 0 & 0 & 0 & 0 \\
\hline & Hanover & & 0 & 0 & 0 & 15.92 & 1 & 0 & 16 & 0 & 0 & 0 \\
\hline & Hatfield & & 4.83 & 18.8 & 3.98 & 0 & 0 & 6.52 & 28 & 10.62 & 17.28 & 0 \\
\hline & Alexandria & & 0 & 0 & 0 & 0 & 0 & 0 & 0 & 0 & 0 & 0 \\
\hline & Lyndhurst & & 0 & 0 & 0 & 0 & 0 & 0 & 0 & 0 & 0 & 0 \\
\hline & Newport News & & 0 & 0 & 0 & 0 & 0 & 0 & 0 & 0 & 0 & 0 \\
\hline & Richmond & & 0 & 0 & 0 & 0 & 0 & 0 & 0 & 0 & 0 & 0 \\
\hline
\end{tabular}


Table 34: Average Demands (in pallets) for Network 3

(Refrigerated Commodity, Destinations 1 through 10)

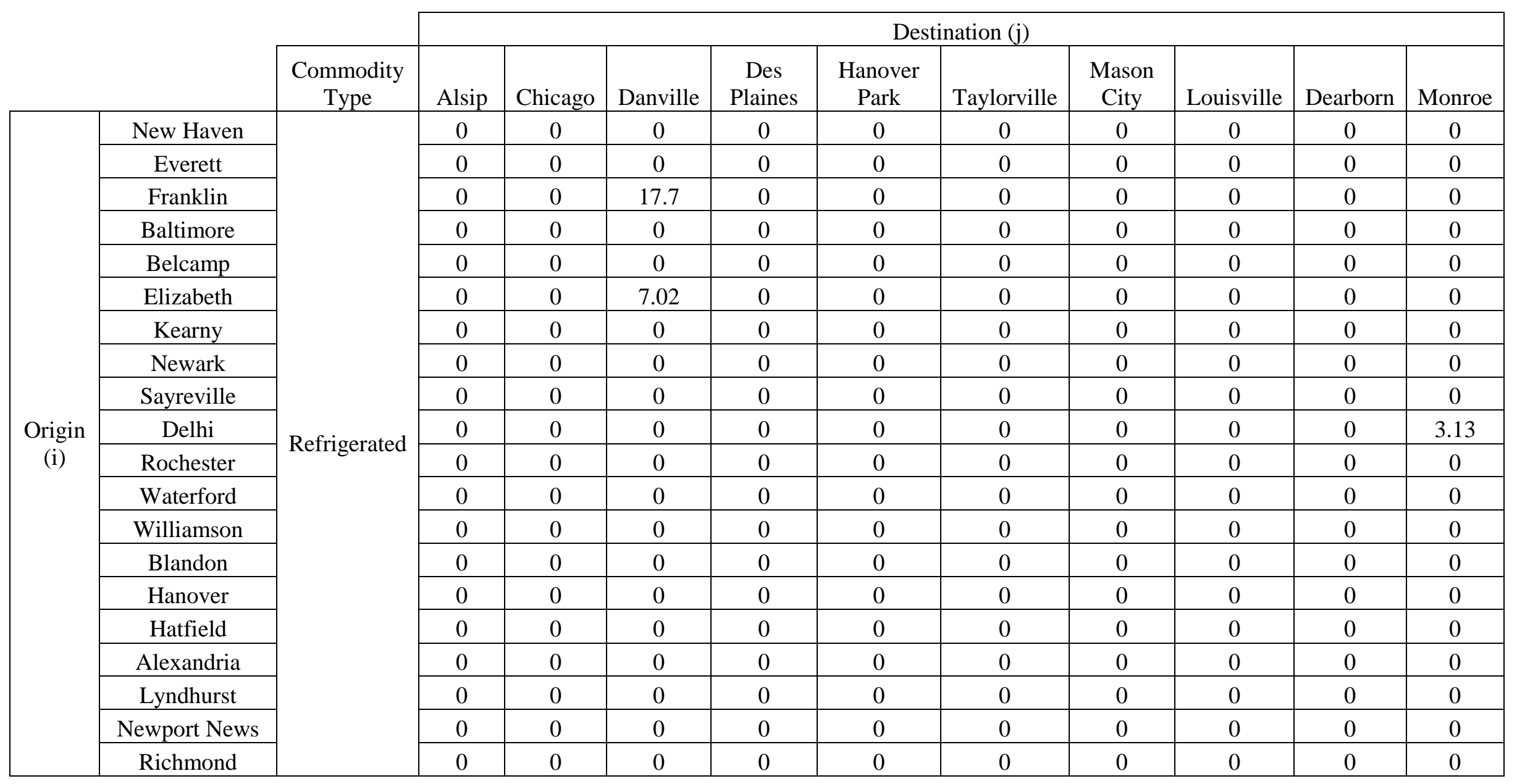


Table 35: Average Demands (in pallets) for Network 3 (Refrigerated Commodity, Destinations 11 through 20)

\begin{tabular}{|c|c|c|c|c|c|c|c|c|c|c|c|c|}
\hline & & \multicolumn{10}{|c|}{ Destination (j) } \\
\hline & & $\begin{array}{c}\text { Commodity } \\
\text { Type }\end{array}$ & Troy & Rogers & St. Paul & $\begin{array}{c}\text { Kansas } \\
\text { City }\end{array}$ & Springfield & St. Louis & Arlington & Elkhorn & Milwaukee & $\begin{array}{c}\text { Oak } \\
\text { Creek }\end{array}$ \\
\hline \multirow{20}{*}{$\begin{array}{l}\text { Origin } \\
\text { (i) }\end{array}$} & New Haven & \multirow{20}{*}{ Refrigerated } & 0 & 0 & 0 & 0 & 0 & 0 & 0 & 0 & 0 & 0 \\
\hline & Everett & & 0 & 0 & 0 & 0 & 0 & 0 & 0 & 0 & 0 & 0 \\
\hline & Franklin & & 0 & 0 & 0 & 15.65 & 0 & 0 & 0 & 0 & 0 & 0 \\
\hline & Baltimore & & 0 & 0 & 0 & 0 & 0 & 0 & 0 & 0 & 0 & 0 \\
\hline & Belcamp & & 0 & 0 & 0 & 0 & 0 & 0 & 0 & 0 & 0 & 0 \\
\hline & Elizabeth & & 0 & 0 & 0 & 4.77 & 0 & 0 & 0 & 0 & 0 & 0 \\
\hline & Kearny & & 0 & 0 & 0 & 0 & 0 & 0 & 0 & 0 & 0 & 0 \\
\hline & Newark & & 0 & 0 & 0 & 0 & 0 & 0 & 0 & 0 & 0 & 0 \\
\hline & Sayreville & & 0 & 0 & 0 & 0 & 0 & 0 & 0 & 0 & 0 & 0 \\
\hline & Delhi & & 0 & 0 & 0 & 0 & 3 & 0 & 0 & 0 & 0 & 0 \\
\hline & Rochester & & 0 & 0 & 0 & 0 & 0 & 0 & 0 & 0 & 0 & 0 \\
\hline & Waterford & & 0 & 0 & 0 & 0 & 0 & 0 & 0 & 0 & 0 & 0 \\
\hline & Williamson & & 0 & 0 & 0 & 0 & 0 & 0 & 0 & 0 & 0 & 0 \\
\hline & Blandon & & 0 & 0 & 0 & 0 & 0 & 0 & 0 & 0 & 0 & 0 \\
\hline & Hanover & & 0 & 0 & 0 & 0 & 0 & 0 & 0 & 0 & 0 & 0 \\
\hline & Hatfield & & 0 & 0 & 0 & 0 & 0 & 0 & 0 & 0 & 0 & 0 \\
\hline & Alexandria & & 0 & 0 & 0 & 0 & 0 & 0 & 0 & 0 & 0 & 0 \\
\hline & Lyndhurst & & 0 & 0 & 0 & 0 & 0 & 0 & 0 & 0 & 0 & 0 \\
\hline & Newport News & & 0 & 0 & 0 & 0 & 0 & 0 & 0 & 0 & 0 & 0 \\
\hline & Richmond & & 0 & 0 & 0 & 0 & 0 & 0 & 0 & 0 & 0 & 0 \\
\hline
\end{tabular}


Table 36: Average Demands (in pallets) for Network 3

(Frozen Commodity, Destinations 1 through 10)

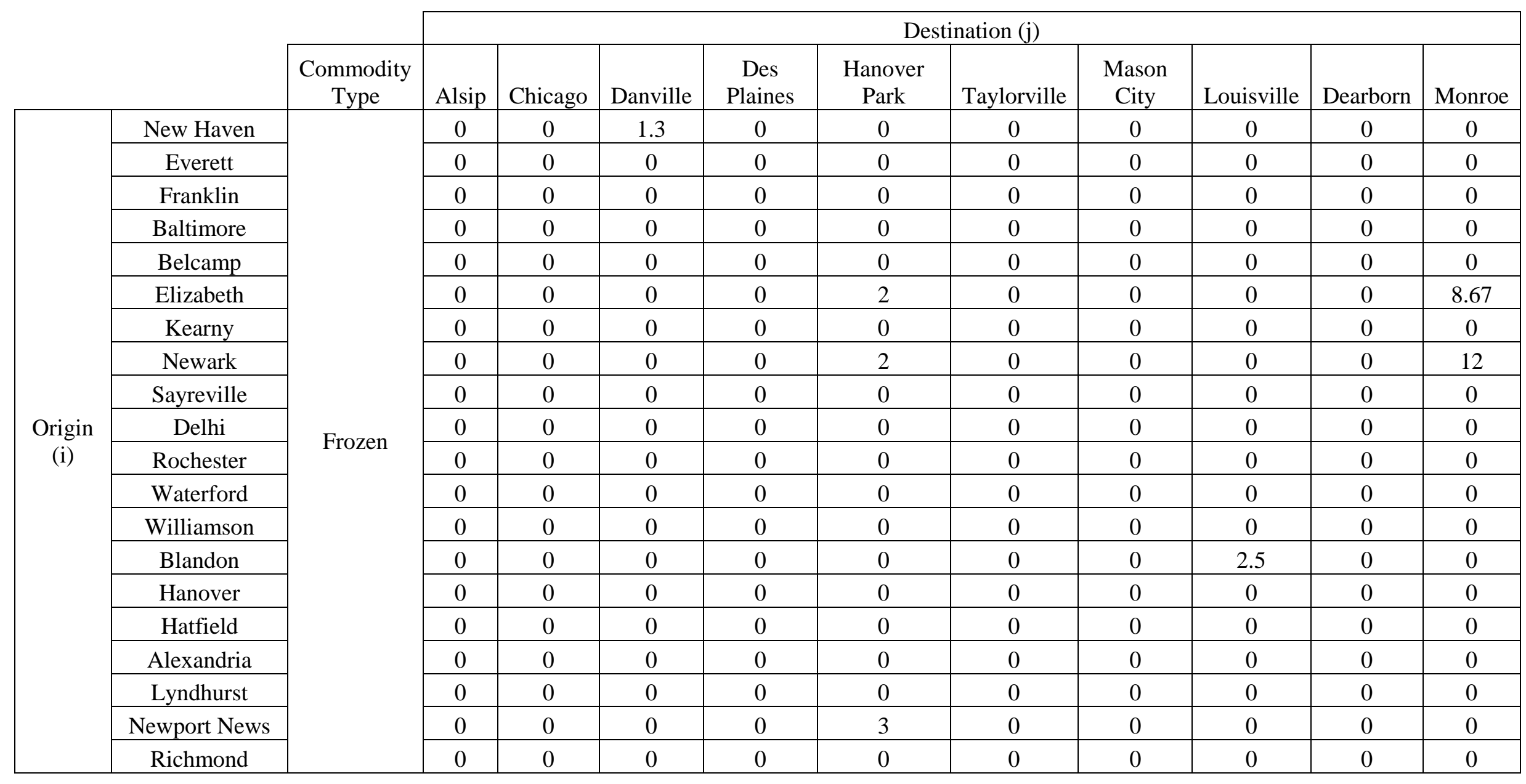


Table 37: Average Demands for Network 3

(Frozen Commodity, Destinations 11 through 20)

\begin{tabular}{|c|c|c|c|c|c|c|c|c|c|c|c|c|}
\hline & & \multirow{2}{*}{\multicolumn{10}{|c|}{ Destination $(\mathrm{j})$}} \\
\hline & & & & & & & & & & & & \\
\hline & & $\begin{array}{c}\text { Commodity } \\
\text { Type }\end{array}$ & Troy & Rogers & St. Paul & $\begin{array}{c}\text { Kansas } \\
\text { City }\end{array}$ & Springfield & St. Louis & Arlington & Elkhorn & Milwaukee & $\begin{array}{c}\text { Oak } \\
\text { Creek }\end{array}$ \\
\hline \multirow{20}{*}{$\begin{array}{l}\text { Origin } \\
\text { (i) }\end{array}$} & New Haven & \multirow{20}{*}{ Frozen } & 0 & 0 & 0 & 0 & 0 & 0 & 0 & 0 & 0 & 0 \\
\hline & Everett & & 0 & 0 & 0 & 0 & 0 & 0 & 0 & 0 & 0 & 0 \\
\hline & Franklin & & 0 & 0 & 0 & 0 & 0 & 0 & 0 & 0 & 0 & 0 \\
\hline & Baltimore & & 0 & 0 & 0 & 0 & 0 & 0 & 0 & 0 & 0 & 0 \\
\hline & Belcamp & & 0 & 0 & 0 & 0 & 0 & 0 & 0 & 0 & 0 & 0 \\
\hline & Elizabeth & & 0 & 0 & 0 & 0 & 0 & 0 & 0 & 0 & 0 & 0 \\
\hline & Kearny & & 0 & 0 & 0 & 0 & 0 & 0 & 0 & 0 & 0 & 0 \\
\hline & Newark & & 0 & 0 & 0 & 0 & 14.83 & 0 & 0 & 0 & 0 & 0 \\
\hline & Sayreville & & 0 & 0 & 0 & 0 & 0 & 0 & 0 & 0 & 0 & 0 \\
\hline & Delhi & & 0 & 0 & 0 & 0 & 0 & 0 & 0 & 0 & 0 & 0 \\
\hline & Rochester & & 0 & 0 & 0 & 0 & 0 & 0 & 0 & 0 & 0 & 0 \\
\hline & Waterford & & 0 & 0 & 0 & 0 & 0 & 0 & 0 & 0 & 0 & 0 \\
\hline & Williamson & & 0 & 0 & 0 & 0 & 0 & 0 & 0 & 0 & 0 & 0 \\
\hline & Blandon & & 0 & 2 & 0 & 0 & 0 & 0 & 0 & 0 & 0 & 2.17 \\
\hline & Hanover & & 0 & 0 & 0 & 0 & 0 & 0 & 0 & 0 & 0 & 0 \\
\hline & Hatfield & & 0 & 0 & 0 & 0 & 0 & 0 & 0 & 0 & 0 & 0 \\
\hline & Alexandria & & 0 & 0 & 0 & 1.11 & 0 & 0 & 0 & 0 & 0 & 0 \\
\hline & Lyndhurst & & 0 & 0 & 0 & 0 & 0 & 0 & 0 & 0 & 0 & 26.24 \\
\hline & Newport News & & 0 & 0 & 0 & 0 & 0 & 0 & 0 & 0 & 0 & 0 \\
\hline & Richmond & & 0 & 0 & 0 & 0 & 0 & 0 & 0 & 0 & 0 & 0 \\
\hline
\end{tabular}




\section{Appendix B}

GAMS Code for Network 1 Varying Omega from 0 to 3

(Corresponds to the results in Sections 5.2.1, 5.2.2, 5.2.3, and Appendix C for N1)

\$offlisting

\$offsymxref offsymlist

file demandUncert1 / demandUncert1.csv / ;

*Network $1(5 \mathrm{O}, 5 \mathrm{D}, 5 \mathrm{~K})$

set i 'origin'/Montgomery, Atlanta, Unadilla, Haines_City, Hattiesburg/;

set j 'destination' /Westborough, Kirkwood, Columbus, Fairborn, Eighty_Four/;

set k 'cross-docks'/Lexington, Charlotte, Knoxville, Charlottesville, Charleston/;

set 1 'commodity'/D, R, F/;

Table $s(i, j)$ 'distance from origin node $i$ to destination node $\mathrm{j}$ '

$\begin{array}{lccccc} & \text { Westborough } & \text { Kirkwood } & \text { Columbus } & \text { Fairborn } & \text { Eighty_Four } \\ \text { Montgomery } & 1233 & 1047 & 660 & 616 & 819 \\ \text { Atlanta } & 1082 & 897 & 570 & 524 & 674 \\ \text { Unadilla } & 1128 & 976 & 694 & 645 & 753 \\ \text { Haines_City } & 1310 & 1176 & 1025 & 982 & 982 \\ \text { Hattiesburg } & 1379 & 1197 & 799 & 755 & 960 ;\end{array}$

display $\mathrm{i}, \mathrm{j}, \mathrm{s}$;

Table s1(i,k) 'distance from origin node i to cross-dock node $\mathrm{k}^{\prime}$

Lexington Charlotte Knoxville Charlottesville Charleston

$\begin{array}{llllll}\text { Montgomery } & 494 & 405 & 343 & 671 & 661 \\ \text { Atlanta } & 380 & 245 & 214 & 511 & 502 \\ \text { Unadilla } & 501 & 333 & 334 & 603 & 596 \\ \text { Haines_City } & 830 & 562 & 664 & 847 & 825 \\ \text { Hattiesburg } & 635 & 622 & 489 & 855 & 798 ;\end{array}$

display i,j,s1;

Table $s 2(k, j)$ 'distance from cross-dock node $k$ to destination node $\mathrm{j}^{\prime}$

$\begin{array}{lccccc} & \text { Westborough } & \text { Kirkwood } & \text { Columbus } & \text { Fairborn } & \text { Eighty_Four } \\ \text { Lexington } & 891 & 696 & 191 & 148 & 351 \\ \text { Charlotte } & 808 & 646 & 426 & 454 & 422 \\ \text { Knoxville } & 892 & 709 & 357 & 314 & 467 \\ \text { Charlottesville } & 527 & 413 & 410 & 437 & 293 \\ \text { Charleston } & 717 & 533 & 162 & 189 & 202 \text {; }\end{array}$

display i,k,s2;

parameter c(l)'unit truckload cost for transporting commodity l' $/ \mathrm{D}=1.40, \mathrm{R}=1.60, \mathrm{~F}=1.80 /$; display 1,c; 
Table $q(1, i, j)$ 'amount of pallets of commodity 1 which needs to go from node $i$ to node $j$ ' Westborough Kirkwood Columbus Fairborn Eighty_Four

$\begin{array}{lcllll}\text { D.Montgomery } & 9.91 & 0 & 0 & 0 & 0 \\ \text { R.Montgomery } & 0 & 0 & 237.73 & 0 & 0 \\ \text { F.Montgomery } & 0 & 23.67 & 0 & 0 & 0 \\ \text { D.Atlanta } & 1.95 & 22.56 & 15 & 24.97 & 6.23 \\ \text { R.Atlanta } & 1.95 & 0 & 0 & 0 & 0 \\ \text { F.Atlanta } & 1.95 & 22.56 & 15 & 24.97 & 0 \\ \text { D.Unadilla } & 0 & 0 & 0 & 0 & 0 \\ \text { R.Unadilla } & 0 & 0 & 0 & 0 & 0 \\ \text { F.Unadilla } & 0 & 27.2 & 51.47 & 0 & 28.26 \\ \text { D.Haines_City } & 0 & 14.34 & 0 & 0 & 0 \\ \text { R.Haines_City } & 12.03 & 0 & 0 & 0 & 0 \\ \text { F.Haines_City } & 12.03 & 0 & 2 & 0 & 0 \\ \text { D.Hattiesburg } & 0 & 30 & 0 & 30 & 0 \\ \text { R.Hattiesburg } & 0 & 0 & 0 & 0 & 0 \\ \text { F.Hattiesburg } & 0 & 0 & 0 & 0 & 0 ;\end{array}$

parameter gamma 'discount factor';

gamma $=0.8$

display $1, \mathrm{i}, \mathrm{j}, \mathrm{q}$;

parameter $\mathrm{h}(\mathrm{k})$ 'unit cost of handling a pallet in a cross-dock at location $\mathrm{k}$ '

/Lexington=3, Charlotte=3,Knoxville=3, Charlottesville=3, Charleston=3/;

parameter u 'truck capacity';

$\mathrm{u}=28$;

parameter p 'number of cross-docks';

$\mathrm{p}=4$;

parameter w 'cross-dock capacity';

$\mathrm{w}=175$;

parameter omega 'bound on overall uncertainty';

set $\mathrm{m}$ 'number of uncertain parameters' $/ 1 * 3 /$;

parameter $b(i, j, 1, m)$ 'weights associated with $m$ random variables';

$\mathrm{b}(\mathrm{i}, \mathrm{j}, 1, \mathrm{~m})=$ uniform $(0,0.3) * \mathrm{q}(1, \mathrm{i}, \mathrm{j})$;

$*$ Variation in code for medium uncertainty $[\mathrm{b}(\mathrm{i}, \mathrm{j}, 1, \mathrm{~m})=$ uniform $(0,0.6) * \mathrm{q}(1, \mathrm{i}, \mathrm{j}) ;]$

$*$ Variation in code for high uncertainty $[\mathrm{b}(\mathrm{i}, \mathrm{j}, 1, \mathrm{~m})=$ uniform $(0,0.9) * \mathrm{q}(1, \mathrm{i}, \mathrm{j}) ;]$

variables

O 'objective value'

;

positive variables

$\mathrm{t} 2(\mathrm{j}, \mathrm{l}, \mathrm{k})$

$\mathrm{t} 1(\mathrm{i}, 1, \mathrm{k})$

$\mathrm{t} 3(\mathrm{k})$

$\mathrm{t} 4(\mathrm{i}, \mathrm{j}, \mathrm{l})$

$\mathrm{t} 5(\mathrm{k})$;

Binary variables 
$\mathrm{x}(\mathrm{i}, \mathrm{j}, 1, \mathrm{k})$ 'commodity $\mathrm{l}$ transported from node $\mathrm{i}$ to node $\mathrm{j}$ through cross-dock $\mathrm{k}$ $\mathrm{v}(\mathrm{i}, \mathrm{j}, 1)$ 'commodity 1 transported from node $\mathrm{i}$ to node $\mathrm{j}$ without using cross-dock k' $\mathrm{z}(\mathrm{k})$ 'cross-dock established at location $\mathrm{k}$ ' ; integer variables $y(i, j, l)$ 'number of trucks transporting commodity 1 from node $i$ to node $j$ ' $\mathrm{y} 1(\mathrm{i}, \mathrm{k}, \mathrm{l})$ 'number of trucks transporting commodity $\mathrm{l}$ from node i to node $\mathrm{k}$ ' $y 2(k, j, l)$ 'number of trucks transporting commodity 1 from node $k$ to node $j$ ' ;

equations

total_cost 'objective value'

number_crossdocks 'total number of cross-docks opened is equal to $\mathrm{P}^{\prime}$ routing $(\mathrm{i}, \mathrm{j}, 1)$ 'demand must be routed through a cross-dock or direct' truck_capacity $1(\mathrm{i}, \mathrm{k}, \mathrm{l})$ 'capacity constraint on trucks from origin to cross-dock' truck_capacity2(j,k,l) 'capacity constraint on trucks from cross-dock to destination' truck_capacity3(i,j,l) 'capacity constraint on trucks from origin to destination' crossdock_opened $(\mathrm{i}, \mathrm{j}, \mathrm{k}, \mathrm{l})$ 'cross-dock $\mathrm{k}$ can only be used if the cross-dock at $\mathrm{k}$ is opened' crossdock_capacity(k) 'capacity constraint on cross-docks' inequality7(i,l,k) 'helps to solve truck_capacity1' inequality $8(\mathrm{j}, 1, \mathrm{k})$ 'helps to solve truck_capacity2' inequality $9(\mathrm{k})$ 'helps to solve crossdock_capacity' inequality10(i,j,1) 'helps to solve truck_capacity3' inequality11(k) 'helps to solve objective' ; total_cost.. $\operatorname{sum}((\mathrm{i}, \mathrm{k}, \mathrm{l}), \mathrm{c}(\mathrm{l}) * \mathrm{~s} 1(\mathrm{i}, \mathrm{k}) * \mathrm{y} 1(\mathrm{i}, \mathrm{k}, \mathrm{l}))+(\mathrm{gamma} * \operatorname{sum}((\mathrm{k}, \mathrm{j}, \mathrm{l}), \mathrm{c}(\mathrm{l}) * \mathrm{~s} 2(\mathrm{k}, \mathrm{j}) * \mathrm{y} 2(\mathrm{k}, \mathrm{j}, \mathrm{l})))+\operatorname{sum}((\mathrm{i}, \mathrm{j}, \mathrm{l}), \mathrm{c}(\mathrm{l}) * \mathrm{~s}(\mathrm{i}, \mathrm{j}$ )$\left.^{*} \mathrm{y}(\mathrm{i}, \mathrm{j}, \mathrm{l})\right)+\operatorname{sum}(\mathrm{k}$, omega*h(k)*t5(k))+sum((k), h(k)*sum $((\mathrm{i}, \mathrm{j}, \mathrm{l}), \mathrm{x}(\mathrm{i}, \mathrm{j}, \mathrm{l}, \mathrm{k}) * \mathrm{q}(\mathrm{l}, \mathrm{i}, \mathrm{j})))=\mathrm{e}=\mathrm{O}$;

number_crossdocks.. sum $((\mathrm{k}), \mathrm{z}(\mathrm{k}))=\mathrm{e}=\mathrm{p}$;

$\operatorname{routing}(\mathrm{i}, \mathrm{j}, 1) . . \operatorname{sum}((\mathrm{k}), \mathrm{x}(\mathrm{i}, \mathrm{j}, 1, \mathrm{k}))+\mathrm{v}(\mathrm{i}, \mathrm{j}, \mathrm{l})=\mathrm{e}=1$;

truck_capacity $1(\mathrm{i}, \mathrm{k}, \mathrm{l}) . . \operatorname{sum}((\mathrm{j}), \mathrm{q}(1, \mathrm{i}, \mathrm{j}) * \mathrm{x}(\mathrm{i}, \mathrm{j}, 1, \mathrm{k}))+$ omega*t1(i,l,k)=l=u*y1(i,k,l);

truck_capacity2(j,k,l).. sum((i),q(l,i,j)*x(i,j,l,k))+omega*t2(j,1,k)=l=u*y2(k,j,l);

truck_capacity3(i,j,l)..q(1,i,j)*v(i,j,l)+omega*t4(i,j,l)=l=u*y(i,j,l);

crossdock_opened(i,j,k,1)..x(i,j,1,k)=l=z(k);

crossdock_capacity(k)..sum $((\mathrm{i}, \mathrm{j}, 1), \mathrm{q}(1, \mathrm{i}, \mathrm{j}) * \mathrm{x}(\mathrm{i}, \mathrm{j}, 1, \mathrm{k}))+$ omega*t3(k)=l=w*z(k);

inequality $7(\mathrm{i}, 1, \mathrm{k}) . .(\operatorname{sum}(\mathrm{m}, \mathrm{sqr}(\operatorname{sum}(\mathrm{j}, \mathrm{b}(\mathrm{i}, \mathrm{j}, 1, \mathrm{~m}) * \mathrm{x}(\mathrm{i}, \mathrm{j}, 1, \mathrm{k})))))=\mathrm{l}=\operatorname{sqr}(\mathrm{t} 1(\mathrm{i}, 1, \mathrm{k}))$; inequality $8(\mathrm{j}, 1, \mathrm{k}) . .(\operatorname{sum}(\mathrm{m}, \mathrm{sqr}(\operatorname{sum}(\mathrm{i}, \mathrm{b}(\mathrm{i}, \mathrm{j}, 1, \mathrm{~m}) * \mathrm{x}(\mathrm{i}, \mathrm{j}, 1, \mathrm{k})))))=\mathrm{l}=\operatorname{sqr}(\mathrm{t} 2(\mathrm{j}, 1, \mathrm{k}))$; inequality9(k)..(sum(m,sqr(sum((l,i,j),b(i,j,l,m)*x(i,j,l,k)))))=l=sqr(t3(k)) ; inequality10(i,j,l).. sum $(\mathrm{m}, \mathrm{sqr}(\mathrm{b}(\mathrm{i}, \mathrm{j}, \mathrm{l}, \mathrm{m}) * \mathrm{v}(\mathrm{i}, \mathrm{j}, \mathrm{l})))=\mathrm{l}=\operatorname{sqr}(\mathrm{t} 4(\mathrm{i}, \mathrm{j}, \mathrm{l}))$; inequality11(k) .. $\operatorname{sum}(\mathrm{m}, \operatorname{sum}((\mathrm{i}, \mathrm{j}, 1), \operatorname{sqr}(\mathrm{x}(\mathrm{i}, \mathrm{j}, \mathrm{l}, \mathrm{k}) * \mathrm{~b}(\mathrm{i}, \mathrm{j}, \mathrm{l}, \mathrm{m}))))=\mathrm{l}=\operatorname{sqr}(\mathrm{t}(\mathrm{k}))$; 
model test/all/;

option miqcp=cplex;

set level

level/1*31/;

demandUncert 1. ap $=0$;

omega $=0$;

solve test minimizing $\mathrm{O}$ using MIQCP;

parameter base_cost;

base_cost $=0.1$;

parameter relative_cost;

loop(level,

put demandUncert1 ;

Put "Omega,Date, Time, TotalCost, RunningTime, SolverStatus, ModelStatus, Relative Cost" / ;

demandUncert1.ap $=1$;

put omega "," system.date "," system.time "," ;

solve test minimizing $\mathrm{O}$ using MIQCP;

relative_cost $=0.1 /$ base_cost;

put o.1:0:3 "," test.Resusd:0:3 "," test.solvestat:0:0 "," test.modelstat:0:0 ","relative_cost / ; put / "k, z" / ;

$\operatorname{loop}((\mathrm{k}) \$(\mathrm{z} .1(\mathrm{k})>0)$, put k.tl:0:0 "," z.l(k):0:0 /);

display z.1, y1.1,y2.1, y.1,x.1,v.1,o.1,omega;

omega=omega $+0.1 ;$; 
GAMS Code for Network 1 Using Random Demands to Test Deterministic and Robust Model Performance with Uncertainty with Average Demands

(Corresponds to the results in Section 5.3.1 for N1)

\$offlisting

\$offsymxref offsymlist

execseed $=1 \mathrm{e} 8 *($ frac $($ jnow $))$;

file demandUncert1 / demandUncert1.csv / ;

*Network $1(5 \mathrm{O}, 5 \mathrm{D}, 5 \mathrm{~K})$

set i 'origin'/Montgomery, Atlanta, Unadilla, Haines_City, Hattiesburg/;

set j 'destination' /Westborough, Kirkwood, Columbus, Fairborn, Eighty_Four/;

set k 'cross-docks'/Lexington, Charlotte, Knoxville, Charlottesville, Charleston/;

set 1 'commodity'/D, R, F/;

Table $s(i, j)$ 'distance from origin node $i$ to destination node $j$ '

Westborough Kirkwood Columbus Fairborn Eighty_Four

$\begin{array}{llrrrr}\text { Montgomery } & 1233 & 1047 & 660 & 616 & 819 \\ \text { Atlanta } & 1082 & 897 & 570 & 524 & 674 \\ \text { Unadilla } & 1128 & 976 & 694 & 645 & 753 \\ \text { Haines_City } & 1310 & 1176 & 1025 & 982 & 982 \\ \text { Hattiesburg } & 1379 & 1197 & 799 & 755 & 960 ;\end{array}$

display i,j,s;

Table s1(i,k) 'distance from origin node $\mathrm{i}$ to cross-dock node $\mathrm{k}$ '

Lexington Charlotte Knoxville Charlottesville Charleston

$\begin{array}{llllll}\text { Montgomery } & 494 & 405 & 343 & 671 & 661\end{array}$

$\begin{array}{llllll}\text { Atlanta } & 380 & 245 & 214 & 511 & 502\end{array}$

$\begin{array}{llllll}\text { Unadilla } & 501 & 333 & 334 & 603 & 596\end{array}$

Haines_City $830 \quad 562 \quad 664 \quad 847 \quad 825$

$\begin{array}{llllll}\text { Hattiesburg } & 635 & 622 & 489 & 855 & 798 \text {; }\end{array}$

display i,j,s1;

Table $s 2(k, j)$ 'distance from cross-dock node $k$ to destination node $\mathrm{j}$ '

$\begin{array}{lccccc} & \text { Westborough } & \text { Kirkwood } & \text { Columbus } & \text { Fairborn } & \text { Eighty_Four } \\ \text { Lexington } & 891 & 696 & 191 & 148 & 351 \\ \text { Charlotte } & 808 & 646 & 426 & 454 & 422 \\ \text { Knoxville } & 892 & 709 & 357 & 314 & 467 \\ \text { Charlottesville } & 527 & 413 & 410 & 437 & 293 \\ \text { Charleston } & 717 & 533 & 162 & 189 & 202 ;\end{array}$

display i,k,s2;

parameter c(l)'unit truckload cost for transporting commodity l' $/ \mathrm{D}=1.40, \mathrm{R}=1.60, \mathrm{~F}=1.80 /$; display $1, \mathrm{c}$; 
Table $q(1, i, j)$ 'amount of pallets of commodity 1 which needs to go from node i to node j' Westborough Kirkwood Columbus Fairborn Eighty_Four

$\begin{array}{lcllll}\text { D.Montgomery } & 9.91 & 0 & 0 & 0 & 0 \\ \text { R.Montgomery } & 0 & 0 & 237.73 & 0 & 0 \\ \text { F.Montgomery } & 0 & 23.67 & 0 & 0 & 0 \\ \text { D.Atlanta } & 1.95 & 22.56 & 15 & 24.97 & 6.23 \\ \text { R.Atlanta } & 1.95 & 0 & 0 & 0 & 0 \\ \text { F.Atlanta } & 1.95 & 22.56 & 15 & 24.97 & 0 \\ \text { D.Unadilla } & 0 & 0 & 0 & 0 & 0 \\ \text { R.Unadilla } & 0 & 0 & 0 & 0 & 0 \\ \text { F.Unadilla } & 0 & 27.2 & 51.47 & 0 & 28.26 \\ \text { D.Haines_City } & 0 & 14.34 & 0 & 0 & 0 \\ \text { R.Haines_City } & 12.03 & 0 & 0 & 0 & 0 \\ \text { F.Haines_City } & 12.03 & 0 & 2 & 0 & 0 \\ \text { D.Hattiesburg } & 0 & 30 & 0 & 30 & 0 \\ \text { R.Hattiesburg } & 0 & 0 & 0 & 0 & 0 \\ \text { F.Hattiesburg } & 0 & 0 & 0 & 0 & 0 ;\end{array}$

parameter gamma 'discount factor';

gamma $=0.8$

display $1, \mathrm{i}, \mathrm{j}, \mathrm{q}$;

parameter $\mathrm{h}(\mathrm{k})$ 'unit cost of handling a pallet in a cross-dock at location $\mathrm{k}^{\prime}$

/Lexington $=3$, Charlotte $=3$, Knoxville $=3$, Charlottesville $=3$, Charleston=3/;

parameter u 'truck capacity';

$\mathrm{u}=28$;

parameter p 'number of cross-docks';

$\mathrm{p}=4$;

parameter w 'cross-dock capacity';

$\mathrm{w}=175$;

parameter omega 'bound on overall uncertainty';

set $m$ 'number of uncertain parameters' $/ 1 * 3 /$;

parameter $\mathrm{b}(\mathrm{i}, \mathrm{j}, \mathrm{l}, \mathrm{m})$ 'weights associated with $\mathrm{m}$ random variables';

$\mathrm{b}(\mathrm{i}, \mathrm{j}, \mathrm{l}, \mathrm{m})=\operatorname{uniform}(0,0.9)^{*} \mathrm{q}(1, \mathrm{i}, \mathrm{j})$;

variables

O 'objective value'

;

positive variables

$\mathrm{t} 2(\mathrm{j}, 1, \mathrm{k})$

$\mathrm{t} 1(\mathrm{i}, 1, \mathrm{k})$

t3(k)

$\mathrm{t} 4(\mathrm{i}, \mathrm{j}, \mathrm{l})$

$\mathrm{t} 5(\mathrm{k})$;

Binary variables

$\mathrm{x}(\mathrm{i}, \mathrm{j}, 1, \mathrm{k})$ 'commodity 1 transported from node $\mathrm{i}$ to node $\mathrm{j}$ through cross-dock $\mathrm{k}$ '

$\mathrm{v}(\mathrm{i}, \mathrm{j}, 1)$ 'commodity 1 transported from node $\mathrm{i}$ to node $\mathrm{j}$ without using cross-dock $\mathrm{k}$ ' 
$\mathrm{z}(\mathrm{k})$ 'cross-dock established at location $\mathrm{k}$ '

integer variables

$y(i, j, 1)$ 'number of trucks transporting commodity 1 from node $i$ to node $j$ '

$\mathrm{y} 1(\mathrm{i}, \mathrm{k}, 1)$ 'number of trucks transporting commodity 1 from node $\mathrm{i}$ to node $\mathrm{k}$ '

$\mathrm{y} 2(\mathrm{k}, \mathrm{j}, \mathrm{l})$ 'number of trucks transporting commodity $\mathrm{l}$ from node $\mathrm{k}$ to node $\mathrm{j}$ '

;

equations

total_cost 'objective value'

number_crossdocks 'total number of cross-docks opened is equal to $\mathrm{P}^{\prime}$

routing $(\mathrm{i}, \mathrm{j}, \mathrm{l})$ 'demand must be routed through a cross-dock or direct'

truck_capacity1(i,k,l) 'capacity constraint on trucks from origin to cross-dock'

truck_capacity $2(\mathrm{j}, \mathrm{k}, \mathrm{l})$ 'capacity constraint on trucks from cross-dock to destination'

truck_capacity3(i,j,l) 'capacity constraint on trucks from origin to destination'

crossdock_opened( $\mathrm{i}, \mathrm{j}, \mathrm{k}, \mathrm{l})$ 'cross-dock $\mathrm{k}$ can only be used if the cross-dock at $\mathrm{k}$ is opened'

crossdock_capacity(k) 'capacity constraint on cross-docks'

inequality $7(\mathrm{i}, 1, \mathrm{k})$ 'helps to solve truck_capacity1'

inequality8(j,1,k) 'helps to solve truck_capacity2'

inequality9(k) 'helps to solve crossdock_capacity'

inequality10(i,j,l) 'helps to solve truck_capacity3'

inequality11(k) 'helps to solve objective'

;

total_cost..

$\left.\operatorname{sum}\left((\mathrm{i}, \mathrm{k}, \mathrm{l}), \mathrm{c}(\mathrm{l})^{*} \mathrm{~s} 1(\mathrm{i}, \mathrm{k})^{*} \mathrm{y} 1(\mathrm{i}, \mathrm{k}, \mathrm{l})\right)+\left(\mathrm{gamma}{ }^{*} \operatorname{sum}((\mathrm{k}, \mathrm{j}, \mathrm{l}), \mathrm{c}(\mathrm{l}))^{*} \mathrm{~s} 2(\mathrm{k}, \mathrm{j}) * \mathrm{y} 2(\mathrm{k}, \mathrm{j}, \mathrm{l})\right)\right)+\operatorname{sum}((\mathrm{i}, \mathrm{j}, 1), \mathrm{c}(\mathrm{l}) * \mathrm{~s}(\mathrm{i}, \mathrm{j}$

)$\left.^{*} \mathrm{y}(\mathrm{i}, \mathrm{j}, \mathrm{l})\right)+\operatorname{sum}\left(\mathrm{k}, \operatorname{omega}{ }^{*} \mathrm{~h}(\mathrm{k}) * \mathrm{t} 5(\mathrm{k})\right)+\operatorname{sum}\left((\mathrm{k}), \mathrm{h}(\mathrm{k})^{*} \operatorname{sum}\left((\mathrm{i}, \mathrm{j}, \mathrm{l}), \mathrm{x}(\mathrm{i}, \mathrm{j}, \mathrm{l}, \mathrm{k})^{*} \mathrm{q}(\mathrm{l}, \mathrm{i}, \mathrm{j})\right)\right)=\mathrm{e}=\mathrm{O}$;

number_crossdocks.. sum((k), z(k))=e=p;

$\operatorname{routing}(\mathrm{i}, \mathrm{j}, 1) . . \operatorname{sum}((\mathrm{k}), \mathrm{x}(\mathrm{i}, \mathrm{j}, 1, \mathrm{k}))+\mathrm{v}(\mathrm{i}, \mathrm{j}, \mathrm{l})=\mathrm{e}=1$;

truck_capacity1(i,k,l).. sum((j),q(l,i,j)*x(i,j,l,k))+omega*t1(i,l,k)=l=u*y1(i,k,l);

truck_capacity2(j,k,l).. sum((i),q(1,i,j)*x(i,j,l,k))+omega*t2(j,l,k)=l=u*y2(k,j,l);

truck_capacity3(i,j,l)..q(l,i,j)*v(i,j,l)+omega*t4(i,j,l)=l=u*y(i,j,l);

crossdock_opened(i,j,k,l)..x(i,j,l,k)=l=z(k);

crossdock_capacity(k)..sum((i,j,l),q(1,i,j)*x(i,j,l,k))+omega*t3(k)=l=w*z(k);

inequality7(i,l,k).. $(\operatorname{sum}(\mathrm{m}, \operatorname{sqr}(\operatorname{sum}(\mathrm{j}, \mathrm{b}(\mathrm{i}, \mathrm{j}, 1, \mathrm{~m}) * \mathrm{x}(\mathrm{i}, \mathrm{j}, 1, \mathrm{k})))))=\mathrm{l}=\operatorname{sqr}(\mathrm{t} 1(\mathrm{i}, 1, \mathrm{k}))$;

inequality $8(\mathrm{j}, 1, \mathrm{k}) . .(\operatorname{sum}(\mathrm{m}, \operatorname{sqr}(\operatorname{sum}(\mathrm{i}, \mathrm{b}(\mathrm{i}, \mathrm{j}, 1, \mathrm{~m}) * \mathrm{x}(\mathrm{i}, \mathrm{j}, 1, \mathrm{k})))))=\mathrm{l}=\operatorname{sqr}(\mathrm{t} 2(\mathrm{j}, 1, \mathrm{k}))$;

inequality9(k)..( $\operatorname{sum}(\mathrm{m}, \operatorname{sqr}(\operatorname{sum}((1, \mathrm{i}, \mathrm{j}), \mathrm{b}(\mathrm{i}, \mathrm{j}, 1, \mathrm{~m}) * \mathrm{x}(\mathrm{i}, \mathrm{j}, 1, \mathrm{k})))))=\mathrm{l}=\operatorname{sqr}(\mathrm{t} 3(\mathrm{k}))$;

inequality10(i,j,l).. $\operatorname{sum}(m, \operatorname{sqr}(b(i, j, l, m) * v(i, j, l)))=l=\operatorname{sqr}(t 4(i, j, l))$;

inequality11(k) .. sum(m,sum((i,j,l),sqr(x(i,j,l,k)*b(i,j,l,m))))=l=sqr(t5(k));

model test/all/; 
option miqcp $=$ cplex;

set level

level/1*31/;

demandUncert 1. ap $=0$;

omega $=0$;

parameter rand_demand $(1, \mathrm{i}, \mathrm{j})$;

parameter add_dir_truck(i,j,l);

rand_demand $(1, \mathrm{i}, \mathrm{j})=0$;

parameter induce_demand;

induce_demand $=0$;

rand_demand $(1, \mathrm{i}, \mathrm{j})=0$;

parameter base_demand $(1, \mathrm{i}, \mathrm{j})$;

base_demand $(1, \mathrm{i}, \mathrm{j})=\mathrm{q}(1, \mathrm{i}, \mathrm{j})$;

parameter simulated_cost;

simulated_cost $=0$;

put demandUncert1 ;

Put "Date, Time, TotalCost, RunningTime, SolverStatus, ModelStatus , Relative Cost" / ;

demandUncert $1 . \mathrm{ap}=1$;

put system.date "," system.time "," ;

solve test minimizing O using MIQCP;

put o.1:0:3 "," test.Resusd:0:3 "," test.solvestat:0:0 "," test.modelstat:0:0 / ;

put / "k, z" / ;

$\operatorname{loop}((\mathrm{k}) \$(\mathrm{z} .1(\mathrm{k})>0)$, put k.tl:0:0 "," z.l(k):0:0 /);

display z.1, y1.1,y2.1, y.1,x.1,v.1,o.1,omega;

parameter base_location(k), base_assignment,

base_inf(k),base_y1(i,k,l),base_y2(k,j,l), base_y(i,j,l),base_v(i,j,l),

base_inf1(i,k,l),base_inf2(k,j,l),base_inf3(i,j,l),base_cost;

base_location $(\mathrm{k})=\mathrm{z} .1(\mathrm{k})$;

base_assignment $(\mathrm{i}, \mathrm{j}, 1, \mathrm{k})=\mathrm{x} .1(\mathrm{i}, \mathrm{j}, \mathrm{l}, \mathrm{k})$;

base_y1 $(\mathrm{i}, \mathrm{k}, \mathrm{l})=\mathrm{y} 1.1(\mathrm{i}, \mathrm{k}, \mathrm{l})$;

base_y2(k,j,l)=y2.1(k,j,l);

base_y $(\mathrm{i}, \mathrm{j}, \mathrm{l})=\mathrm{y} \cdot \mathrm{l}(\mathrm{i}, \mathrm{j}, \mathrm{l})$;

base_v $(\mathrm{i}, \mathrm{j}, \mathrm{l})=\mathrm{v} .1(\mathrm{i}, \mathrm{j}, \mathrm{l})$;

omega=3;

Put "Omega,Date, Time, TotalCost, RunningTime, SolverStatus, ModelStatus "/ ;

demandUncert 1. ap $=1$;

put omega "," system.date "," system.time "," ;

solve test minimizing O using MIQCP;

put o.1:0:3 "," test.Resusd:0:3 "," test.solvestat:0:0 "," test.modelstat:0:0 /;

put / "k, z" / ;

$\operatorname{loop}((\mathrm{k}) \$(\mathrm{z} .1(\mathrm{k})>0)$, put k.tl:0:0 "," z.l(k):0:0 /); 
parameter robust_location, robust_assignment, robust_inf(k), sum_robust_inf, sum_base_inf, robust_y1(i,k,l),robust_y2(k,j,l),robust_y(i,j,l),robust_v(i,j,l),robust_inf1(i,k,l),robust_inf2(k,j,l),r obust_inf3(i,j,1),robust_cost;

robust_location $(\mathrm{k})=\mathrm{z} .1(\mathrm{k})$;

robust_assignment $(\mathrm{i}, \mathrm{j}, \mathrm{l}, \mathrm{k})=\mathrm{x} .1(\mathrm{i}, \mathrm{j}, \mathrm{l}, \mathrm{k})$;

robust_y1 $(\mathrm{i}, \mathrm{k}, \mathrm{l})=\mathrm{y} 1.1(\mathrm{i}, \mathrm{k}, \mathrm{l})$;

robust_y2(k,j,l)=y2.1(k,j,l);

robust_y(i,j,l)=y.l(i,j,l);

robust_v(i,j,l)=v.l(i,j,l);

loop(level,

rand_demand $(1, \mathrm{i}, \mathrm{j})=0$;

rand_demand $(1, \mathrm{i}, \mathrm{j})=\operatorname{sum}(\mathrm{m}, \mathrm{uniform}(0,0.9) *$ base_demand $(1, \mathrm{i}, \mathrm{j}))+$ base_demand $(1, \mathrm{i}, \mathrm{j})$;

$q(1, i, j)=$ rand_demand $(1, i, j)$;

robust_inf $(\mathrm{k})=\mathrm{w}^{*}$ robust_location(k)-sum $((\mathrm{i}, \mathrm{j}, \mathrm{l}), \mathrm{q}(\mathrm{l}, \mathrm{i}, \mathrm{j}) *$ robust_assignment $(\mathrm{i}, \mathrm{j}, 1, \mathrm{k}))$;

base_inf $(\mathrm{k})=\mathrm{w}^{*}$ base_location $(\mathrm{k})$-sum $((\mathrm{i}, \mathrm{j}, \mathrm{l}), \mathrm{q}(\mathrm{l}, \mathrm{i}, \mathrm{j}) *$ base_assignment $(\mathrm{i}, \mathrm{j}, 1, \mathrm{k}))$;

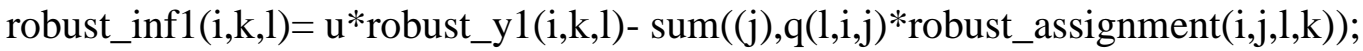

base_inf $1(\mathrm{i}, \mathrm{k}, \mathrm{l})=\mathrm{u}^{*}$ base_y1(i,k,l)- $\operatorname{sum}((\mathrm{j}), \mathrm{q}(\mathrm{l}, \mathrm{i}, \mathrm{j}) *$ base_assignment $(\mathrm{i}, \mathrm{j}, \mathrm{l}, \mathrm{k}))$;

robust_inf $2(\mathrm{k}, \mathrm{j}, \mathrm{l})=\mathrm{u}^{*}$ robust_y2(k,j,l)-sum((i),q(l,i,j)*robust_assignment $\left.(\mathrm{i}, \mathrm{j}, \mathrm{l}, \mathrm{k})\right)$;

base_inf $2(\mathrm{k}, \mathrm{j}, \mathrm{l})=\mathrm{u}^{*}$ base_y2(k,j,l)-sum $((\mathrm{i}), \mathrm{q}(\mathrm{l}, \mathrm{i}, \mathrm{j}) *$ base_assignment $(\mathrm{i}, \mathrm{j}, \mathrm{l}, \mathrm{k}))$;

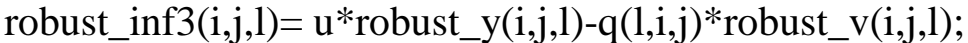

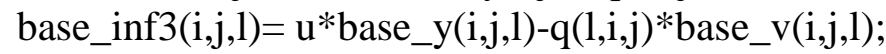

robust_cost=sum $((\mathrm{i}, \mathrm{k}, \mathrm{l}), \mathrm{c}(\mathrm{l}) * \mathrm{~s} 1(\mathrm{i}, \mathrm{k}) *$ robust_y1(i,k,l))+(gamma*sum$((\mathrm{k}, \mathrm{j}, \mathrm{l}), \mathrm{c}(\mathrm{l}) * \mathrm{~s} 2(\mathrm{k}, \mathrm{j}) *$ robust_y2 $(\mathrm{k}, \mathrm{j}, \mathrm{l})))+\operatorname{sum}((\mathrm{i}, \mathrm{j}, \mathrm{l}), \mathrm{c}(\mathrm{l}) * \mathrm{~s}(\mathrm{i}, \mathrm{j}) *$ robust_y(i,j,l))+sum((k),

$\mathrm{h}(\mathrm{k})^{*} \operatorname{sum}\left((\mathrm{i}, \mathrm{j}, \mathrm{l})\right.$, robust_assignment $\left.\left.(\mathrm{i}, \mathrm{j}, 1, \mathrm{k})^{*} \mathrm{q}(\mathrm{l}, \mathrm{i}, \mathrm{j})\right)\right)$;

base_cost $=\operatorname{sum}\left((\mathrm{i}, \mathrm{k}, \mathrm{l}), \mathrm{c}(\mathrm{l}) * \mathrm{~s} 1(\mathrm{i}, \mathrm{k}) *\right.$ base_y1(i,k,l))+(gamma*sum $\left((\mathrm{k}, \mathrm{j}, \mathrm{l}), \mathrm{c}(\mathrm{l}) * \mathrm{~s} 2(\mathrm{k}, \mathrm{j}) * \mathrm{base} \_\mathrm{y} 2(\mathrm{k}, \mathrm{j}, 1\right.$

)$)+\operatorname{sum}((\mathrm{i}, \mathrm{j}, \mathrm{l}), \mathrm{c}(\mathrm{l}) * \mathrm{~s}(\mathrm{i}, \mathrm{j}) *$ base_y(i,j,l))+sum((k),

$\mathrm{h}(\mathrm{k})^{*} \operatorname{sum}((\mathrm{i}, \mathrm{j}, \mathrm{l})$, base_assignment $\left.(\mathrm{i}, \mathrm{j}, 1, \mathrm{k}) * \mathrm{q}(\mathrm{l}, \mathrm{i}, \mathrm{j}))\right)$;

sum_robust_inf $=\operatorname{sum}(\mathrm{k}$, robust_inf $(\mathrm{k}))+\operatorname{sum}((\mathrm{i}, \mathrm{k}, \mathrm{l})$,

robust_inf1(i,k,l))+sum((k,j,l),robust_inf2(k,j,l))+sum((i,j,l),robust_inf3(i,j,l));

sum_base_inf $=\operatorname{sum}\left(\mathrm{k}, \mathrm{base} \_\right.$inf $\left.(\mathrm{k})\right)+\operatorname{sum}((\mathrm{i}, \mathrm{k}, \mathrm{l})$,

base_inf1(i,k,l))+sum((k,j,l),base_inf2(k,j,l))+sum((i,j,l),base_inf3(i,j,l));

Put "Deterministic ,Base Cost, Robust, Robust Cost"/;

put sum_base_inf "," base_cost "," sum_robust_inf "," robust_cost /;

) 
GAMS Code for Network 1 Using Random Demands to Test Deterministic and Robust Model Performance with Uncertainty with Inflated Demands

(Corresponds to the results in Section 5.3.2 for N1)

\$offlisting

\$offsymxref offsymlist

execseed $=1 \mathrm{e} 8 *($ frac $($ jnow $))$;

file demandUncert1 / demandUncert1.csv / ;

*Network $1(5 \mathrm{O}, 5 \mathrm{D}, 5 \mathrm{~K})$

set i 'origin'/Montgomery, Atlanta, Unadilla, Haines_City, Hattiesburg/;

set j 'destination' /Westborough, Kirkwood, Columbus, Fairborn, Eighty_Four/;

set k 'cross-docks'/Lexington, Charlotte, Knoxville, Charlottesville, Charleston/;

set 1 'commodity'/D, R, F/;

Table $s(i, j)$ 'distance from origin node $i$ to destination node $\mathrm{j}$ '

Westborough Kirkwood Columbus Fairborn Eighty_Four

$\begin{array}{lrrrrr}\text { Montgomery } & 1233 & 1047 & 660 & 616 & 819 \\ \text { Atlanta } & 1082 & 897 & 570 & 524 & 674 \\ \text { Unadilla } & 1128 & 976 & 694 & 645 & 753 \\ \text { Haines_City } & 1310 & 1176 & 1025 & 982 & 982 \\ \text { Hattiesburg } & 1379 & 1197 & 799 & 755 & 960 ;\end{array}$

display i,j,s;

Table s1(i,k) 'distance from origin node i to cross-dock node k'

Lexington Charlotte Knoxville Charlottesville Charleston

$\begin{array}{llllll}\text { Montgomery } & 494 & 405 & 343 & 671 & 661 \\ \text { Atlanta } & 380 & 245 & 214 & 511 & 502 \\ \text { Unadilla } & 501 & 333 & 334 & 603 & 596 \\ \text { Haines_City } & 830 & 562 & 664 & 847 & 825 \\ \text { Hattiesburg } & 635 & 622 & 489 & 855 & 798 \text {; }\end{array}$

display i,j,s1;

Table $s 2(k, j)$ 'distance from cross-dock node $k$ to destination node $\mathrm{j}$ '

Westborough Kirkwood Columbus Fairborn Eighty_Four

$\begin{array}{lccccc}\text { Lexington } & 891 & 696 & 191 & 148 & 351 \\ \text { Charlotte } & 808 & 646 & 426 & 454 & 422 \\ \text { Knoxville } & 892 & 709 & 357 & 314 & 467 \\ \text { Charlottesville } & 527 & 413 & 410 & 437 & 293 \\ \text { Charleston } & 717 & 533 & 162 & 189 & 202 ;\end{array}$

display i,k,s2;

parameter c(l)'unit truckload cost for transporting commodity l' $/ \mathrm{D}=1.40, \mathrm{R}=1.60, \mathrm{~F}=1.80 /$; display 1,c;

Table $q(1, i, j)$ 'amount of pallets of commodity 1 which needs to go from node $\mathrm{i}$ to node $\mathrm{j}^{\prime}$ 


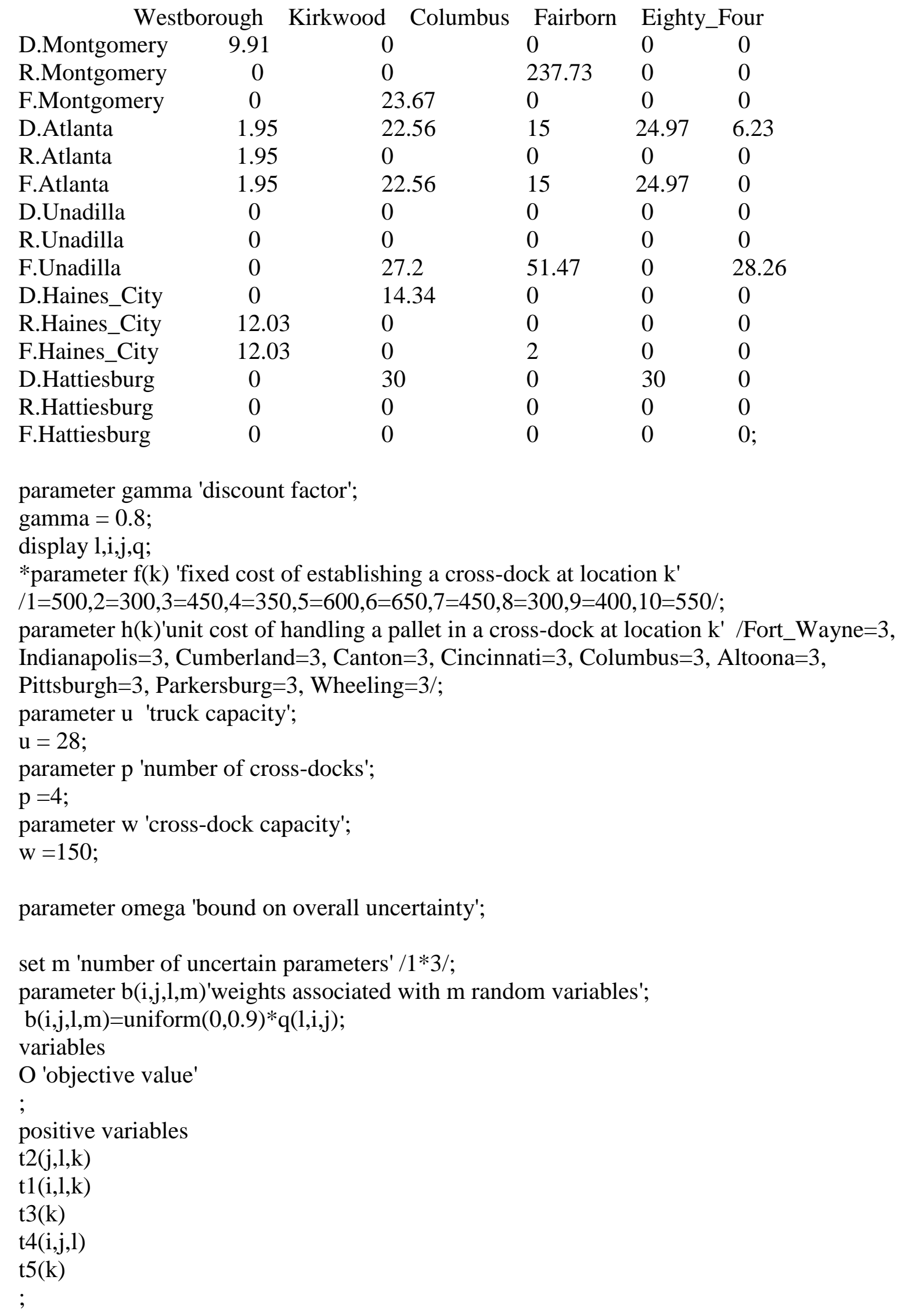


Binary variables

$\mathrm{x}(\mathrm{i}, \mathrm{j}, 1, \mathrm{k})$ 'commodity 1 transported from node $\mathrm{i}$ to node $\mathrm{j}$ through cross-dock $\mathrm{k}$

$\mathrm{v}(\mathrm{i}, \mathrm{j}, \mathrm{l})$ 'commodity 1 transported from node $\mathrm{i}$ to node $\mathrm{j}$ without using cross-dock $\mathrm{k}$ '

$\mathrm{z}(\mathrm{k})$ 'cross-dock established at location $\mathrm{k}$ '

;

integer variables

$y(i, j, 1)$ 'number of trucks transporting commodity 1 from node $i$ to node $j$ '

$\mathrm{y} 1(\mathrm{i}, \mathrm{k}, \mathrm{l})$ 'number of trucks transporting commodity 1 from node $\mathrm{i}$ to node $\mathrm{k}$ '

$\mathrm{y} 2(\mathrm{k}, \mathrm{j}, \mathrm{l})$ 'number of trucks transporting commodity 1 from node $\mathrm{k}$ to node $\mathrm{j}$ '

;

equations

total_cost 'objective value'

number_crossdocks 'total number of cross-docks opened is equal to $\mathrm{P}^{\prime}$

routing $(\overline{\mathrm{i}}, \mathrm{j}, \mathrm{l})$ 'demand must be routed through a cross-dock or direct'

truck_capacity $1(\mathrm{i}, \mathrm{k}, \mathrm{l})$ 'capacity constraint on trucks from origin to cross-dock'

truck_capacity2(j,k,l) 'capacity constraint on trucks from cross-dock to destination'

truck_capacity3(i,j,l) 'capacity constraint on trucks from origin to destination'

crossdock_opened(i,j,k,l) 'cross-dock k can only be used if the cross-dock at k is opened'

crossdock_capacity(k) 'capacity constraint on cross-docks'

inequality $7(\mathrm{i}, \mathrm{l}, \mathrm{k})$ 'helps to solve truck_capacity1'

inequality $8(\mathrm{j}, 1, \mathrm{k})$ 'helps to solve truck_capacity2'

inequality9(k) 'helps to solve crossdock_capacity'

inequality10(i,j,l) 'helps to solve truck_capacity3'

inequality11(k) 'helps to solve objective'

;

total_cost.

$\operatorname{sum}\left((\mathrm{i}, \mathrm{k}, \mathrm{l}), \mathrm{c}(\mathrm{l})^{*} \mathrm{~s} 1(\mathrm{i}, \mathrm{k})^{*} \mathrm{y} 1(\mathrm{i}, \mathrm{k}, \mathrm{l})\right)+\left(\mathrm{gamma}^{*} \operatorname{sum}\left((\mathrm{k}, \mathrm{j}, \mathrm{l}), \mathrm{c}(\mathrm{l}) * \mathrm{~s} 2(\mathrm{k}, \mathrm{j})^{*} \mathrm{y} 2(\mathrm{k}, \mathrm{j}, \mathrm{l})\right)\right)+\operatorname{sum}((\mathrm{i}, \mathrm{j}, \mathrm{l}), \mathrm{c}(\mathrm{l}) * \mathrm{~s}(\mathrm{i}, \mathrm{j}$

)$\left.^{*} \mathrm{y}(\mathrm{i}, \mathrm{j}, \mathrm{l})\right)+\operatorname{sum}(\mathrm{k}, \operatorname{omega} * \mathrm{~h}(\mathrm{k}) * \mathrm{t} 5(\mathrm{k}))+\operatorname{sum}\left((\mathrm{k}), \mathrm{h}(\mathrm{k}) * \operatorname{sum}\left((\mathrm{i}, \mathrm{j}, \mathrm{l}), \mathrm{x}(\mathrm{i}, \mathrm{j}, 1, \mathrm{k})^{*} \mathrm{q}(\mathrm{l}, \mathrm{i}, \mathrm{j})\right)\right)=\mathrm{e}=\mathrm{O}$;

number_crossdocks.. sum $((\mathrm{k}), \mathrm{z}(\mathrm{k}))=\mathrm{e}=\mathrm{p}$;

$\operatorname{routing}(\mathrm{i}, \mathrm{j}, 1) . . \operatorname{sum}((\mathrm{k}), \mathrm{x}(\mathrm{i}, \mathrm{j}, 1, \mathrm{k}))+\mathrm{v}(\mathrm{i}, \mathrm{j}, \mathrm{l})=\mathrm{e}=1$;

truck_capacity1(i,k,l).. sum((j),q(1,i,j)*x(i,j,l,k))+omega*t1(i,l,k)=l=u*y1(i,k,l);

truck_capacity2(j,k,1).. sum((i),q(1,i,j)*x(i,j,l,k))+omega*t2(j,1,k)=l=u*y2(k,j,l);

truck_capacity3(i,j,l)..q(l,i,j)*v(i,j,l)+omega*t4(i,j,l)=l=u*y(i,j,l);

crossdock_opened(i,j,k,l)..x(i,j,l,k)=l=z(k);

crossdock_capacity(k)..sum((i,j,l),q(1,i,j)*x(i,j,1,k))+omega*t3(k)=l=w*z(k);

inequality $7(\mathrm{i}, 1, \mathrm{k}) . .(\operatorname{sum}(\mathrm{m}, \operatorname{sqr}(\operatorname{sum}(\mathrm{j}, \mathrm{b}(\mathrm{i}, \mathrm{j}, 1, \mathrm{~m}) * \mathrm{x}(\mathrm{i}, \mathrm{j}, 1, \mathrm{k})))))=\mathrm{l}=\operatorname{sqr}(\mathrm{t} 1(\mathrm{i}, \mathrm{l}, \mathrm{k}))$;

inequality8(j,l,k).. $(\operatorname{sum}(\mathrm{m}, \operatorname{sqr}(\operatorname{sum}(\mathrm{i}, \mathrm{b}(\mathrm{i}, \mathrm{j}, 1, \mathrm{~m}) * x(\mathrm{i}, \mathrm{j}, 1, \mathrm{k})))))=\mathrm{l}=\operatorname{sqr}(\mathrm{t} 2(\mathrm{j}, 1, \mathrm{k}))$;

inequality9(k)..(sum $(\mathrm{m}, \operatorname{sqr}(\operatorname{sum}((1, \mathrm{i}, \mathrm{j}), \mathrm{b}(\mathrm{i}, \mathrm{j}, \mathrm{l}, \mathrm{m}) * \mathrm{x}(\mathrm{i}, \mathrm{j}, \mathrm{l}, \mathrm{k})))))=\mathrm{l}=\operatorname{sqr}(\mathrm{t} 3(\mathrm{k}))$;

inequality10(i,j,l).. $\operatorname{sum}(\mathrm{m}, \operatorname{sqr}(\mathrm{b}(\mathrm{i}, \mathrm{j}, \mathrm{l}, \mathrm{m}) * \mathrm{v}(\mathrm{i}, \mathrm{j}, \mathrm{l})))=\mathrm{l}=\operatorname{sqr}(\mathrm{t} 4(\mathrm{i}, \mathrm{j}, \mathrm{l}))$; 


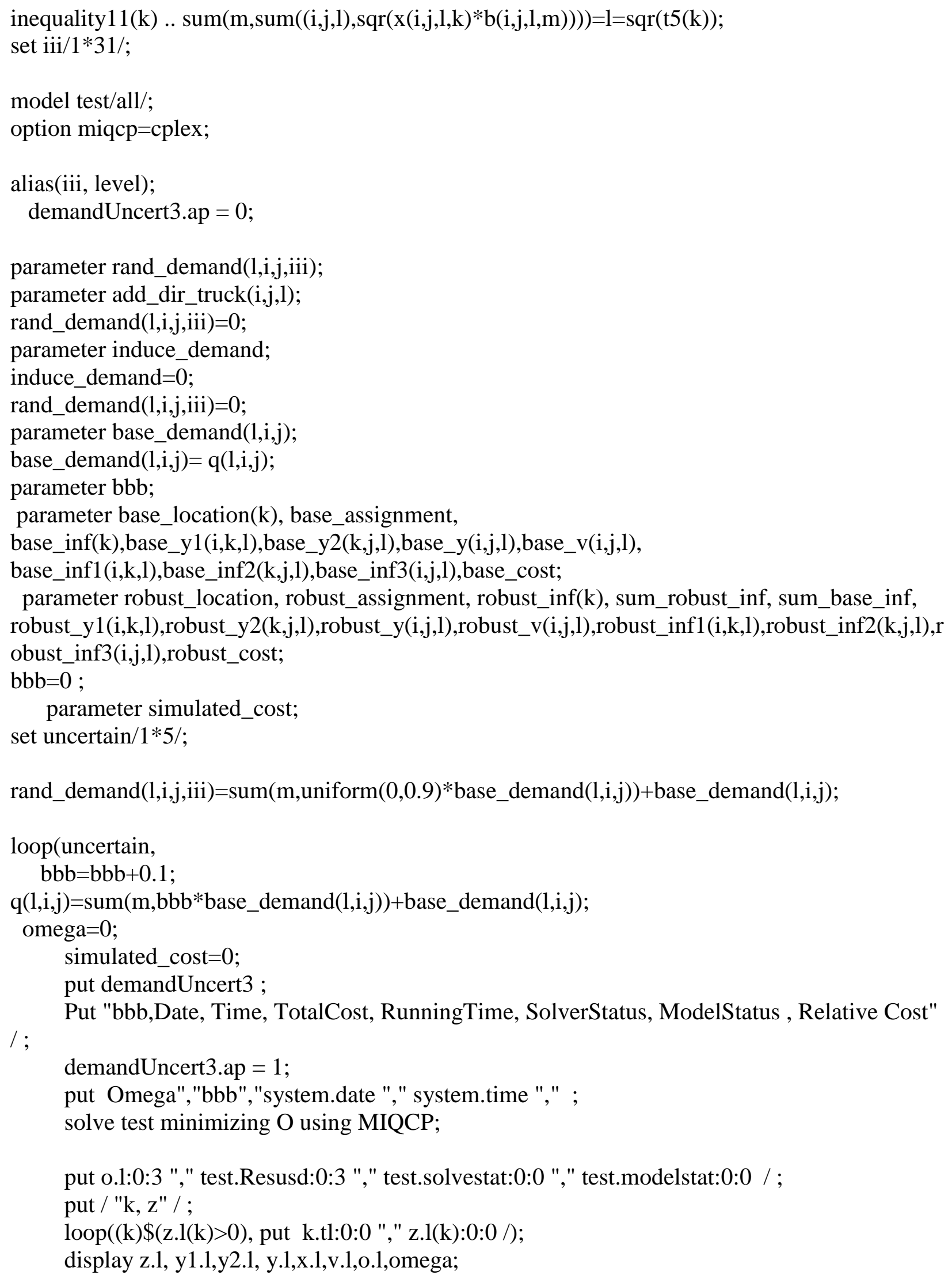




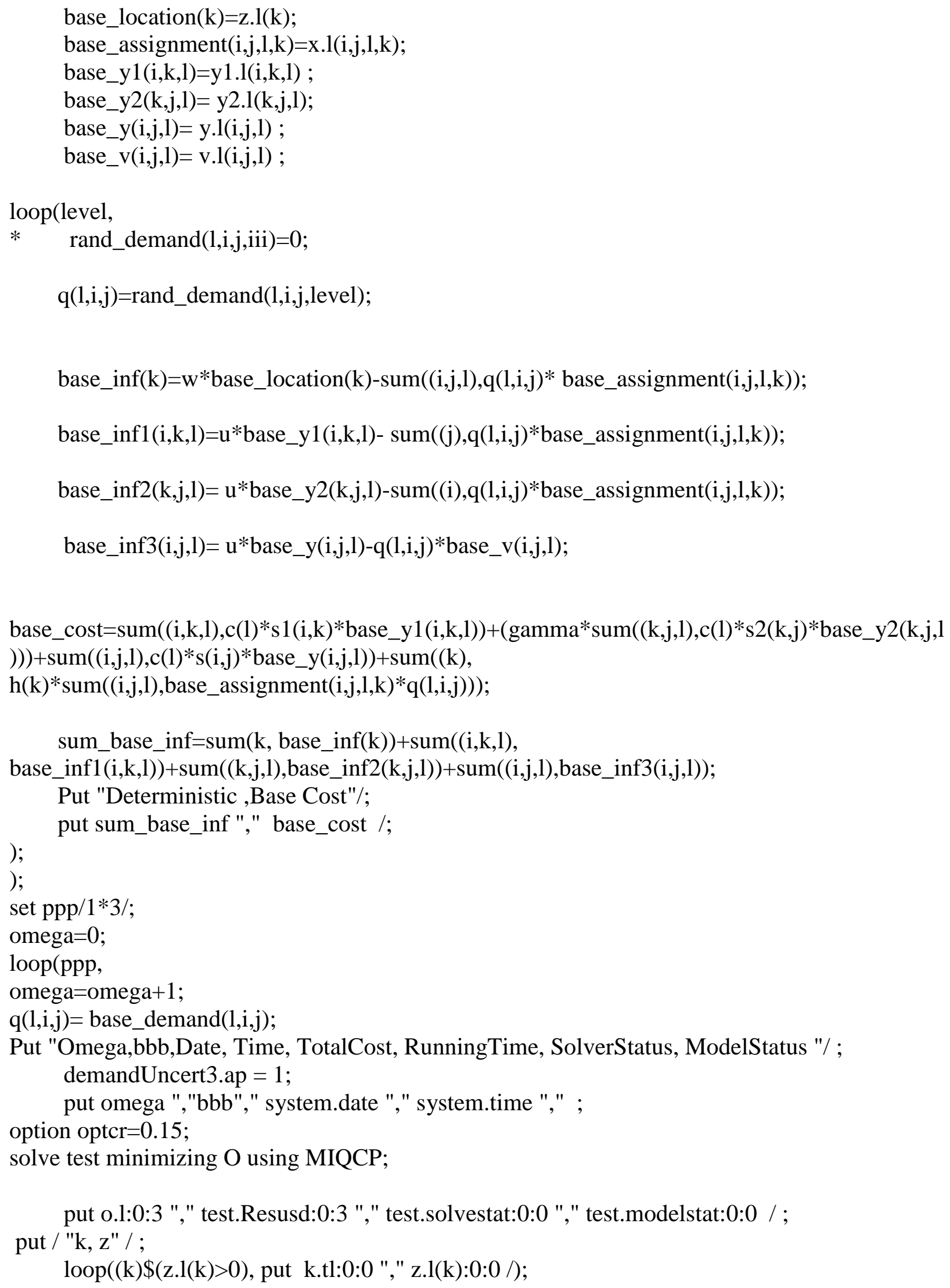


robust_location $(\mathrm{k})=\mathrm{z} .1(\mathrm{k})$;

robust_assignment $(\mathrm{i}, \mathrm{j}, 1, \mathrm{k})=\mathrm{x} .1(\mathrm{i}, \mathrm{j}, 1, \mathrm{k})$;

robust_y1 $(\mathrm{i}, \mathrm{k}, \mathrm{l})=\mathrm{y} 1.1(\mathrm{i}, \mathrm{k}, \mathrm{l})$;

robust_y2(k,j,l)=y2.1(k,j,1);

robust_y $(\mathrm{i}, \mathrm{j}, 1)=\mathrm{y} .1(\mathrm{i}, \mathrm{j}, \mathrm{l})$;

robust_v(i,j,l)=v.l(i,j,l);

loop(level,

$\mathrm{q}(1, \mathrm{i}, \mathrm{j})=$ rand_demand $(1, \mathrm{i}, \mathrm{j}$, level $)$;

robust_inf(k)=w*robust_location $(\mathrm{k})-\operatorname{sum}((\mathrm{i}, \mathrm{j}, \mathrm{l}), \mathrm{q}(\mathrm{l}, \mathrm{i}, \mathrm{j}) *$ robust_assignment $(\mathrm{i}, \mathrm{j}, 1, \mathrm{k}))$;

robust_inf1(i,k,l)= u*robust_y1(i,k,l)-sum((j),q(l,i,j)*robust_assignment $(\mathrm{i}, \mathrm{j}, 1, \mathrm{k}))$;

robust_inf2(k,j,l)=u*robust_y2(k,j,l)-sum((i),q(1,i,j)*robust_assignment $(i, j, 1, k))$;

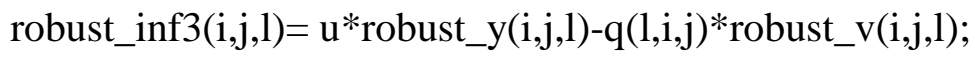

robust_cost=sum((i,k,l),c(l)*s1(i,k)*robust_y1(i,k,l))+(gamma*sum((k,j,l),c(l)*s2(k,j)*robust_y2 $(\mathrm{k}, \mathrm{j}, \mathrm{l})))+\operatorname{sum}((\mathrm{i}, \mathrm{j}, \mathrm{l}), \mathrm{c}(\mathrm{l}) * \mathrm{~s}(\mathrm{i}, \mathrm{j}) *$ robust_y(i,j,l))+sum((k),

$\mathrm{h}(\mathrm{k}) * \operatorname{sum}((\mathrm{i}, \mathrm{j}, \mathrm{l})$,robust_assignment $(\mathrm{i}, \mathrm{j}, \mathrm{l}, \mathrm{k}) * \mathrm{q}(\mathrm{l}, \mathrm{i}, \mathrm{j})))$;

sum_robust_inf $=$ sum $(k$, robust_inf $(k))+\operatorname{sum}((i, k, l)$, robust_inf1(i,k,l))+sum((k,j,l),robust_inf2(k,j,l))+sum((i,j,l),robust_inf3(i,j,l));

Put " Robust, Robust Cost"/;

)$;)$;

put sum_robust_inf "," robust_cost /;

display rand_demand; 


\section{Appendix C}

Table 38: Cross-docks Opened for Network 1 with Medium Uncertainty

\begin{tabular}{|c|c|c|c|c|c|c|c|}
\hline Omega & CD's Opened & Omega & CD's Opened & Omega & CD's Opened & Omega & CD's Opened \\
\hline 0.0 & $\begin{array}{c}\text { Charlotte } \\
\text { Knoxville } \\
\text { Charlottesville } \\
\text { Charleston }\end{array}$ & 0.8 & $\begin{array}{l}\text { Lexington } \\
\text { Charlotte } \\
\text { Knoxville } \\
\text { Charleston } \\
\end{array}$ & 1.6 & $\begin{array}{l}\text { Lexington } \\
\text { Charlotte } \\
\text { Knoxville } \\
\text { Charleston } \\
\end{array}$ & 2.4 & $\begin{array}{c}\text { Lexington } \\
\text { Charlotte } \\
\text { Charlottesville } \\
\text { Charleston }\end{array}$ \\
\hline 0.1 & $\begin{array}{l}\text { Lexington } \\
\text { Charlotte } \\
\text { Knoxville } \\
\text { Charleston } \\
\end{array}$ & 0.9 & $\begin{array}{l}\text { Lexington } \\
\text { Charlotte } \\
\text { Knoxville } \\
\text { Charleston } \\
\end{array}$ & 1.7 & $\begin{array}{l}\text { Lexington } \\
\text { Charlotte } \\
\text { Knoxville } \\
\text { Charleston } \\
\end{array}$ & 2.5 & $\begin{array}{c}\text { Lexington } \\
\text { Charlotte } \\
\text { Knoxville } \\
\text { Charlottesville }\end{array}$ \\
\hline 0.2 & $\begin{array}{c}\text { Charlotte } \\
\text { Knoxville } \\
\text { Charlottesville } \\
\text { Charleston } \\
\end{array}$ & 1.0 & $\begin{array}{l}\text { Lexington } \\
\text { Charlotte } \\
\text { Knoxville } \\
\text { Charleston } \\
\end{array}$ & 1.8 & $\begin{array}{c}\text { Charlotte } \\
\text { Knoxville } \\
\text { Charlottesville } \\
\text { Charleston } \\
\end{array}$ & 2.6 & $\begin{array}{c}\text { Lexington } \\
\text { Charlotte } \\
\text { Knoxville } \\
\text { Charlottesville }\end{array}$ \\
\hline 0.3 & $\begin{array}{l}\text { Lexington } \\
\text { Charlotte } \\
\text { Knoxville } \\
\text { Charleston } \\
\end{array}$ & 1.1 & $\begin{array}{l}\text { Lexington } \\
\text { Charlotte } \\
\text { Knoxville } \\
\text { Charleston } \\
\end{array}$ & 1.9 & $\begin{array}{l}\text { Lexington } \\
\text { Charlotte } \\
\text { Knoxville } \\
\text { Charleston } \\
\end{array}$ & 2.7 & $\begin{array}{l}\text { Lexington } \\
\text { Charlotte } \\
\text { Knoxville } \\
\text { Charleston } \\
\end{array}$ \\
\hline 0.4 & $\begin{array}{c}\text { Lexington } \\
\text { Charlotte } \\
\text { Knoxville } \\
\text { Charlottesville } \\
\end{array}$ & 1.2 & $\begin{array}{l}\text { Lexington } \\
\text { Charlotte } \\
\text { Knoxville } \\
\text { Charleston } \\
\end{array}$ & 2.0 & $\begin{array}{l}\text { Lexington } \\
\text { Charlotte } \\
\text { Knoxville } \\
\text { Charleston } \\
\end{array}$ & 2.8 & $\begin{array}{c}\text { Lexington } \\
\text { Charlotte } \\
\text { Knoxville } \\
\text { Charlottesville }\end{array}$ \\
\hline 0.5 & $\begin{array}{l}\text { Lexington } \\
\text { Charlotte } \\
\text { Knoxville } \\
\text { Charleston } \\
\end{array}$ & 1.3 & $\begin{array}{c}\text { Lexington } \\
\text { Charlotte } \\
\text { Knoxville } \\
\text { Charlottesville } \\
\end{array}$ & 2.1 & $\begin{array}{l}\text { Lexington } \\
\text { Charlotte } \\
\text { Knoxville } \\
\text { Charleston } \\
\end{array}$ & 2.9 & $\begin{array}{l}\text { Lexington } \\
\text { Charlotte } \\
\text { Knoxville } \\
\text { Charleston } \\
\end{array}$ \\
\hline 0.6 & $\begin{array}{l}\text { Lexington } \\
\text { Charlotte } \\
\text { Knoxville } \\
\text { Charleston } \\
\end{array}$ & 1.4 & $\begin{array}{l}\text { Lexington } \\
\text { Charlotte } \\
\text { Knoxville } \\
\text { Charleston } \\
\end{array}$ & 2.2 & $\begin{array}{l}\text { Lexington } \\
\text { Charlotte } \\
\text { Knoxville } \\
\text { Charleston } \\
\end{array}$ & 3.0 & $\begin{array}{c}\text { Charlotte } \\
\text { Knoxville } \\
\text { Charlottesville } \\
\text { Charleston }\end{array}$ \\
\hline 0.7 & $\begin{array}{l}\text { Lexington } \\
\text { Charlotte } \\
\text { Knoxville } \\
\text { Charleston } \\
\end{array}$ & 1.5 & $\begin{array}{l}\text { Lexington } \\
\text { Charlotte } \\
\text { Knoxville } \\
\text { Charleston } \\
\end{array}$ & 2.3 & $\begin{array}{c}\text { Lexington } \\
\text { Charlotte } \\
\text { Knoxville } \\
\text { Charlottesville } \\
\end{array}$ & & \\
\hline
\end{tabular}


Table 39: Cross-docks Opened for Network 1 with High Uncertainty

\begin{tabular}{|c|c|c|c|c|c|c|c|}
\hline Omega & CD's Opened & Omega & CD's Opened & Omega & CD's Opened & Omega & CD's Opened \\
\hline 0.0 & $\begin{array}{c}\text { Charlotte } \\
\text { Knoxville } \\
\text { Charlottesville } \\
\text { Charleston } \\
\end{array}$ & 0.8 & $\begin{array}{l}\text { Lexington } \\
\text { Charlotte } \\
\text { Knoxville } \\
\text { Charleston } \\
\end{array}$ & 1.6 & $\begin{array}{c}\text { Charlotte } \\
\text { Knoxville } \\
\text { Charlottesville } \\
\text { Charleston }\end{array}$ & 2.4 & $\begin{array}{l}\text { Lexington } \\
\text { Charlotte } \\
\text { Knoxville } \\
\text { Charleston } \\
\end{array}$ \\
\hline 0.1 & $\begin{array}{c}\text { Lexington } \\
\text { Charlotte } \\
\text { Knoxville } \\
\text { Charlottesville } \\
\end{array}$ & 0.9 & $\begin{array}{l}\text { Lexington } \\
\text { Charlotte } \\
\text { Knoxville } \\
\text { Charleston } \\
\end{array}$ & 1.7 & $\begin{array}{c}\text { Lexington } \\
\text { Charlotte } \\
\text { Charlottesville } \\
\text { Charleston } \\
\end{array}$ & 2.5 & $\begin{array}{c}\text { Lexington } \\
\text { Charlotte } \\
\text { Knoxville } \\
\text { Charlottesville }\end{array}$ \\
\hline 0.2 & $\begin{array}{c}\text { Lexington } \\
\text { Charlotte } \\
\text { Knoxville } \\
\text { Charlottesville } \\
\end{array}$ & 1.0 & $\begin{array}{c}\text { Lexington } \\
\text { Charlotte } \\
\text { Knoxville } \\
\text { Charlottesville } \\
\end{array}$ & 1.8 & $\begin{array}{c}\text { Lexington } \\
\text { Charlotte } \\
\text { Knoxville } \\
\text { Charlottesville } \\
\end{array}$ & 2.6 & $\begin{array}{c}\text { Lexington } \\
\text { Charlotte } \\
\text { Knoxville } \\
\text { Charlottesville }\end{array}$ \\
\hline 0.3 & $\begin{array}{c}\text { Lexington } \\
\text { Charlotte } \\
\text { Knoxville } \\
\text { Charlottesville } \\
\end{array}$ & 1.1 & $\begin{array}{c}\text { Charlotte } \\
\text { Knoxville } \\
\text { Charlottesville } \\
\text { Charleston } \\
\end{array}$ & 1.9 & $\begin{array}{c}\text { Lexington } \\
\text { Charlotte } \\
\text { Knoxville } \\
\text { Charlottesville }\end{array}$ & 2.7 & $\begin{array}{c}\text { Lexington } \\
\text { Charlotte } \\
\text { Knoxville } \\
\text { Charlottesville }\end{array}$ \\
\hline 0.4 & $\begin{array}{l}\text { Lexington } \\
\text { Charlotte } \\
\text { Knoxville } \\
\text { Charleston } \\
\end{array}$ & 1.2 & $\begin{array}{l}\text { Lexington } \\
\text { Charlotte } \\
\text { Knoxville } \\
\text { Charleston } \\
\end{array}$ & 2.0 & $\begin{array}{c}\text { Lexington } \\
\text { Charlotte } \\
\text { Knoxville } \\
\text { Charlottesville } \\
\end{array}$ & 2.8 & $\begin{array}{l}\text { Lexington } \\
\text { Charlotte } \\
\text { Knoxville } \\
\text { Charleston } \\
\end{array}$ \\
\hline 0.5 & $\begin{array}{l}\text { Lexington } \\
\text { Charlotte } \\
\text { Knoxville } \\
\text { Charleston } \\
\end{array}$ & 1.3 & $\begin{array}{l}\text { Lexington } \\
\text { Charlotte } \\
\text { Knoxville } \\
\text { Charleston } \\
\end{array}$ & 2.1 & $\begin{array}{l}\text { Lexington } \\
\text { Charlotte } \\
\text { Knoxville } \\
\text { Charleston } \\
\end{array}$ & 2.9 & $\begin{array}{l}\text { Lexington } \\
\text { Charlotte } \\
\text { Knoxville } \\
\text { Charleston } \\
\end{array}$ \\
\hline 0.6 & $\begin{array}{c}\text { Lexington } \\
\text { Charlotte } \\
\text { Knoxville } \\
\text { Charlottesville } \\
\end{array}$ & 1.4 & $\begin{array}{l}\text { Lexington } \\
\text { Charlotte } \\
\text { Knoxville } \\
\text { Charleston } \\
\end{array}$ & 2.2 & $\begin{array}{c}\text { Lexington } \\
\text { Charlotte } \\
\text { Knoxville } \\
\text { Charlottesville }\end{array}$ & 3.0 & $\begin{array}{c}\text { Lexington } \\
\text { Charlotte } \\
\text { Knoxville } \\
\text { Charlottesville }\end{array}$ \\
\hline 0.7 & $\begin{array}{l}\text { Lexington } \\
\text { Charlotte } \\
\text { Knoxville } \\
\text { Charleston } \\
\end{array}$ & 1.5 & $\begin{array}{c}\text { Lexington } \\
\text { Charlotte } \\
\text { Knoxville } \\
\text { Charlottesville } \\
\end{array}$ & 2.3 & $\begin{array}{l}\text { Lexington } \\
\text { Charlotte } \\
\text { Knoxville } \\
\text { Charleston } \\
\end{array}$ & & \\
\hline
\end{tabular}


Table 40: Cross-docks Opened for Network 2 with Low Uncertainty

\begin{tabular}{|c|c|c|c|c|c|c|c|}
\hline Omega & CD's Opened & Omega & CD's Opened & Omega & CD's Opened & Omega & CD's Opened \\
\hline 0.0 & $\begin{array}{c}\text { Fort_Wayne } \\
\text { Cincinnati } \\
\text { Altoona } \\
\text { Pittsburgh }\end{array}$ & 0.8 & $\begin{array}{c}\text { Cumberland } \\
\text { Canton } \\
\text { Altoona } \\
\text { Pittsburgh }\end{array}$ & 1.6 & $\begin{array}{c}\text { Cumberland } \\
\text { Altoona } \\
\text { Pittsburgh } \\
\text { Wheeling }\end{array}$ & 2.4 & $\begin{array}{c}\text { Cumberland } \\
\text { Cincinnati } \\
\text { Altoona } \\
\text { Pittsburgh }\end{array}$ \\
\hline 0.1 & $\begin{array}{c}\text { Indianapolis } \\
\text { Altoona } \\
\text { Pittsburgh } \\
\text { Wheeling }\end{array}$ & 0.9 & $\begin{array}{c}\text { Cumberland } \\
\text { Columbus } \\
\text { Altoona } \\
\text { Pittsburgh } \\
\end{array}$ & 1.7 & $\begin{array}{c}\text { Canton } \\
\text { Columbus } \\
\text { Altoona } \\
\text { Wheeling } \\
\end{array}$ & 2.5 & $\begin{array}{c}\text { Indianapolis } \\
\text { Columbus } \\
\text { Altoona } \\
\text { Pittsburgh } \\
\end{array}$ \\
\hline 0.2 & $\begin{array}{c}\text { Fort_Wayne } \\
\text { Cumberland } \\
\text { Altoona } \\
\text { Pittsburgh } \\
\end{array}$ & 1.0 & $\begin{array}{c}\text { Cumberland } \\
\text { Canton } \\
\text { Altoona } \\
\text { Pittsburgh } \\
\end{array}$ & 1.8 & $\begin{array}{c}\text { Fort_Wayne } \\
\text { Cumberland } \\
\text { Altoona } \\
\text { Pittsburgh } \\
\end{array}$ & 2.6 & $\begin{array}{c}\text { Fort_Wayne } \\
\text { Cumberland } \\
\text { Canton } \\
\text { Altoona } \\
\end{array}$ \\
\hline 0.3 & $\begin{array}{c}\text { Fort_Wayne } \\
\text { Canton } \\
\text { Altoona } \\
\text { Pittsburgh }\end{array}$ & 1.1 & $\begin{array}{c}\text { Fort_Wayne } \\
\text { Cumberland } \\
\text { Altoona } \\
\text { Pittsburgh }\end{array}$ & 1.9 & $\begin{array}{c}\text { Indianapolis } \\
\text { Altoona } \\
\text { Pittsburgh } \\
\text { Wheeling }\end{array}$ & 2.7 & $\begin{array}{c}\text { Cumberland } \\
\text { Columbus } \\
\text { Altoona } \\
\text { Pittsburgh } \\
\end{array}$ \\
\hline 0.4 & $\begin{array}{c}\text { Cumberland } \\
\text { Canton } \\
\text { Altoona } \\
\text { Pittsburgh } \\
\end{array}$ & 1.2 & $\begin{array}{c}\text { Fort_Wayne } \\
\text { Cumberland } \\
\text { Altoona } \\
\text { Pittsburgh } \\
\end{array}$ & 2.0 & $\begin{array}{c}\text { Fort_Wayne } \\
\text { Indianapolis } \\
\text { Canton } \\
\text { Altoona } \\
\end{array}$ & 2.8 & $\begin{array}{c}\text { Cumberland } \\
\text { Altoona } \\
\text { Pittsburgh } \\
\text { Wheeling }\end{array}$ \\
\hline 0.5 & $\begin{array}{c}\text { Cumberland } \\
\text { Columbus } \\
\text { Altoona } \\
\text { Wheeling } \\
\end{array}$ & 1.3 & $\begin{array}{c}\text { Fort_Wayne } \\
\text { Cumberland } \\
\text { Altoona } \\
\text { Pittsburgh } \\
\end{array}$ & 2.1 & $\begin{array}{c}\text { Columbus } \\
\text { Altoona } \\
\text { Pittsburgh } \\
\text { Wheeling } \\
\end{array}$ & 2.9 & $\begin{array}{c}\text { Cumberland } \\
\text { Canton } \\
\text { Columbus } \\
\text { Pittsburgh } \\
\end{array}$ \\
\hline 0.6 & $\begin{array}{c}\text { Cumberland } \\
\text { Columbus } \\
\text { Altoona } \\
\text { Pittsburgh }\end{array}$ & 1.4 & $\begin{array}{c}\text { Cumberland } \\
\text { Altoona } \\
\text { Pittsburgh } \\
\text { Wheeling }\end{array}$ & 2.2 & $\begin{array}{c}\text { Indianapolis } \\
\text { Canton } \\
\text { Altoona } \\
\text { Pittsburgh } \\
\end{array}$ & 3.0 & $\begin{array}{c}\text { Canton } \\
\text { Columbus } \\
\text { Altoona } \\
\text { Pittsburgh } \\
\end{array}$ \\
\hline 0.7 & $\begin{array}{c}\text { Fort_Wayne } \\
\text { Cumberland } \\
\text { Altoona } \\
\text { Pittsburgh } \\
\end{array}$ & 1.5 & $\begin{array}{c}\text { Cumberland } \\
\text { Canton } \\
\text { Altoona } \\
\text { Pittsburgh } \\
\end{array}$ & 2.3 & $\begin{array}{c}\text { Cumberland } \\
\text { Columbus } \\
\text { Altoona } \\
\text { Pittsburgh } \\
\end{array}$ & & \\
\hline
\end{tabular}


Table 41: Cross-docks Opened for Network 2 with High Uncertainty

\begin{tabular}{|c|c|c|c|c|c|c|c|}
\hline Omega & CD's Opened & Omega & CD's Opened & Omega & CD's Opened & Omega & CD's Opened \\
\hline 0.0 & $\begin{array}{c}\text { Fort_Wayne } \\
\text { Altoona } \\
\text { Pittsburgh } \\
\text { Wheeling }\end{array}$ & 0.8 & $\begin{array}{c}\text { Cumberland } \\
\text { Canton } \\
\text { Columbus } \\
\text { Altoona }\end{array}$ & 1.6 & $\begin{array}{c}\text { Cumberland } \\
\text { Altoona } \\
\text { Pittsburgh } \\
\text { Wheeling }\end{array}$ & 2.4 & $\begin{array}{c}\text { Cumberland } \\
\text { Columbus } \\
\text { Altoona } \\
\text { Pittsburgh }\end{array}$ \\
\hline 0.1 & $\begin{array}{c}\text { Cumberland } \\
\text { Canton } \\
\text { Altoona } \\
\text { Pittsburgh } \\
\end{array}$ & 0.9 & $\begin{array}{l}\text { Cumberland } \\
\text { Columbus } \\
\text { Altoona } \\
\text { Pittsburgh } \\
\end{array}$ & 1.7 & $\begin{array}{c}\text { Cumberland } \\
\text { Columbus } \\
\text { Altoona } \\
\text { Pittsburgh } \\
\end{array}$ & 2.5 & $\begin{array}{c}\text { Cumberland } \\
\text { Columbus } \\
\text { Altoona } \\
\text { Wheeling } \\
\end{array}$ \\
\hline 0.2 & $\begin{array}{c}\text { Cumberland } \\
\text { Altoona } \\
\text { Pittsburgh } \\
\text { Wheeling } \\
\end{array}$ & 1.0 & $\begin{array}{c}\text { Canton } \\
\text { Altoona } \\
\text { Pittsburgh } \\
\text { Wheeling } \\
\end{array}$ & 1.8 & $\begin{array}{c}\text { Indianapolis } \\
\text { Cumberland } \\
\text { Altoona } \\
\text { Pittsburgh } \\
\end{array}$ & 2.6 & $\begin{array}{c}\text { Fort_Wayne } \\
\text { Cumberland } \\
\text { Altoona } \\
\text { Pittsburgh } \\
\end{array}$ \\
\hline 0.3 & $\begin{array}{l}\text { Cumberland } \\
\text { Canton } \\
\text { Altoona } \\
\text { Pittsburgh }\end{array}$ & 1.1 & $\begin{array}{l}\text { Cumberland } \\
\text { Canton } \\
\text { Columbus } \\
\text { Pittsburgh }\end{array}$ & 1.9 & $\begin{array}{c}\text { Cumberland } \\
\text { Columbus } \\
\text { Altoona } \\
\text { Pittsburgh }\end{array}$ & 2.7 & $\begin{array}{c}\text { Columbus } \\
\text { Altoona } \\
\text { Pittsburgh } \\
\text { Wheeling } \\
\end{array}$ \\
\hline 0.4 & $\begin{array}{c}\text { Fort_Wayne } \\
\text { Cumberland } \\
\text { Altoona } \\
\text { Wheeling } \\
\end{array}$ & 1.2 & $\begin{array}{c}\text { Fort_Wayne } \\
\text { Columbus } \\
\text { Altoona } \\
\text { Wheeling } \\
\end{array}$ & 2.0 & $\begin{array}{c}\text { Cumberland } \\
\text { Columbus } \\
\text { Altoona } \\
\text { Pittsburgh } \\
\end{array}$ & 2.8 & $\begin{array}{c}\text { Canton } \\
\text { Cincinnati } \\
\text { Altoona } \\
\text { Wheeling } \\
\end{array}$ \\
\hline 0.5 & $\begin{array}{c}\text { Cumberland } \\
\text { Canton } \\
\text { Altoona } \\
\text { Pittsburgh }\end{array}$ & 1.3 & $\begin{array}{c}\text { Indianapolis } \\
\text { Cumberland } \\
\text { Altoona } \\
\text { Pittsburgh }\end{array}$ & 2.1 & $\begin{array}{c}\text { Fort_Wayne } \\
\text { Cumberland } \\
\text { Altoona } \\
\text { Pittsburgh }\end{array}$ & 2.9 & $\begin{array}{c}\text { Cumberland } \\
\text { Columbus } \\
\text { Altoona } \\
\text { Wheeling }\end{array}$ \\
\hline 0.6 & $\begin{array}{c}\text { Canton } \\
\text { Altoona } \\
\text { Pittsburgh } \\
\text { Wheeling } \\
\end{array}$ & 1.4 & $\begin{array}{c}\text { Cumberland } \\
\text { Columbus } \\
\text { Altoona } \\
\text { Wheeling }\end{array}$ & 2.2 & $\begin{array}{c}\text { Indianapolis } \\
\text { Cumberland } \\
\text { Altoona } \\
\text { Pittsburgh }\end{array}$ & 3.0 & $\begin{array}{c}\text { Fort_Wayne } \\
\text { Canton } \\
\text { Pittsburgh } \\
\text { Wheeling }\end{array}$ \\
\hline 0.7 & $\begin{array}{c}\text { Cumberland } \\
\text { Altoona } \\
\text { Pittsburgh } \\
\text { Wheeling }\end{array}$ & 1.5 & $\begin{array}{c}\text { Fort_Wayne } \\
\text { Altoona } \\
\text { Pittsburgh } \\
\text { Wheeling }\end{array}$ & 2.3 & $\begin{array}{l}\text { Cumberland } \\
\text { Altoona } \\
\text { Pittsburgh } \\
\text { Parkersburg }\end{array}$ & & \\
\hline
\end{tabular}


Table 42: Cross-docks Opened for Network 3 for Low Uncertainty

\begin{tabular}{|c|c|c|c|c|c|c|c|}
\hline Omega & CD's Opened & Omega & CD's Opened & Omega & CD's Opened & Omega & CD's Opened \\
\hline 0.0 & $\begin{array}{c}\text { Fort_Wayne } \\
\text { Cumberland } \\
\text { Altoona } \\
\text { Wheeling }\end{array}$ & 0.8 & $\begin{array}{c}\text { Cumberland } \\
\text { Altoona } \\
\text { Oil_City } \\
\text { Pittsburgh }\end{array}$ & 1.6 & $\begin{array}{c}\text { Fort_Wayne } \\
\text { Cumberland } \\
\text { Altoona } \\
\text { Oil_City }\end{array}$ & 2.4 & $\begin{array}{c}\text { Cumberland } \\
\text { Lima } \\
\text { Altoona } \\
\text { Pittsburgh }\end{array}$ \\
\hline 0.1 & $\begin{array}{c}\text { Fort_Wayne } \\
\text { Cumberland } \\
\text { Mansfield } \\
\text { Pittsburgh }\end{array}$ & 0.9 & $\begin{array}{c}\text { Cumberland } \\
\text { Lima } \\
\text { Altoona } \\
\text { Mansfield } \\
\end{array}$ & 1.7 & $\begin{array}{c}\text { Cumberland } \\
\text { Columbus } \\
\text { Oil_City } \\
\text { Pittsburgh }\end{array}$ & 2.5 & $\begin{array}{c}\text { Fort_Wayne } \\
\text { Altoona } \\
\text { Oil_City } \\
\text { Pittsburgh } \\
\end{array}$ \\
\hline 0.2 & $\begin{array}{c}\text { Hebron } \\
\text { Cumberland } \\
\text { Altoona } \\
\text { Oil_City } \\
\end{array}$ & 1.0 & $\begin{array}{c}\text { Altoona } \\
\text { Mansfield } \\
\text { Oil_City } \\
\text { Pittsburgh } \\
\end{array}$ & 1.8 & $\begin{array}{c}\text { Fort_Wayne } \\
\text { Cumberland } \\
\text { Altoona } \\
\text { Oil_City } \\
\end{array}$ & 2.6 & $\begin{array}{c}\text { Columbus } \\
\text { Altoona } \\
\text { Mansfield } \\
\text { Oil_City } \\
\end{array}$ \\
\hline 0.3 & $\begin{array}{c}\text { Canton } \\
\text { Lima } \\
\text { Altoona } \\
\text { Pittsburgh } \\
\end{array}$ & 1.1 & $\begin{array}{c}\text { Cumberland } \\
\text { Columbus } \\
\text { Lima } \\
\text { Oil_City } \\
\end{array}$ & 1.9 & $\begin{array}{c}\text { Fort_Wayne } \\
\text { Cumberland } \\
\text { Altoona } \\
\text { Pittsburgh }\end{array}$ & 2.7 & $\begin{array}{c}\text { Cumberland } \\
\text { Altoona } \\
\text { Oil_City } \\
\text { Wheeling }\end{array}$ \\
\hline 0.4 & $\begin{array}{l}\text { Hebron } \\
\text { Canton } \\
\text { Altoona } \\
\text { Oil_City }\end{array}$ & 1.2 & $\begin{array}{c}\text { Cumberland } \\
\text { Canton } \\
\text { Altoona } \\
\text { Mansfield } \\
\end{array}$ & 2.0 & $\begin{array}{c}\text { Fort_Wayne } \\
\text { Cumberland } \\
\text { Canton } \\
\text { Columbus } \\
\end{array}$ & 2.8 & $\begin{array}{c}\text { Indianapolis } \\
\text { Cumberland } \\
\text { Altoona } \\
\text { Pittsburgh } \\
\end{array}$ \\
\hline 0.5 & $\begin{array}{c}\text { Fort_Wayne } \\
\text { Altoona } \\
\text { Oil_City } \\
\text { Pittsburgh } \\
\end{array}$ & 1.3 & $\begin{array}{c}\text { Fort_Wayne } \\
\text { Altoona } \\
\text { Mansfield } \\
\text { Pittsburgh } \\
\end{array}$ & 2.1 & $\begin{array}{c}\text { Hebron } \\
\text { Cumberland } \\
\text { Columbus } \\
\text { Altoona } \\
\end{array}$ & 2.9 & $\begin{array}{c}\text { Fort_Wayne } \\
\text { Cumberland } \\
\text { Oil_City } \\
\text { Wheeling }\end{array}$ \\
\hline 0.6 & $\begin{array}{c}\text { Cumberland } \\
\text { Canton } \\
\text { Altoona } \\
\text { Oil_City }\end{array}$ & 1.4 & $\begin{array}{c}\text { Fort_Wayne } \\
\text { Cumberland } \\
\text { Altoona } \\
\text { Oil_City }\end{array}$ & 2.2 & $\begin{array}{c}\text { Fort_Wayne } \\
\text { Cumberland } \\
\text { Altoona } \\
\text { Oil_City }\end{array}$ & 3.0 & $\begin{array}{c}\text { Bloomington } \\
\text { Cumberland } \\
\text { Altoona } \\
\text { Pittsburgh } \\
\end{array}$ \\
\hline 0.7 & $\begin{array}{c}\text { Cumberland } \\
\text { Lima } \\
\text { Altoona } \\
\text { Mansfield } \\
\end{array}$ & 1.5 & $\begin{array}{c}\text { Fort_Wayne } \\
\text { Cumberland } \\
\text { Canton } \\
\text { Altoona } \\
\end{array}$ & 2.3 & $\begin{array}{c}\text { Fort_Wayne } \\
\text { Cumberland } \\
\text { Altoona } \\
\text { Oil_City } \\
\end{array}$ & & \\
\hline
\end{tabular}


Table 43: Cross-docks Opened for Network 3 with Medium Uncertainty

\begin{tabular}{|c|c|c|c|c|c|c|c|}
\hline Omega & CD's Opened & Omega & CD's Opened & Omega & CD's Opened & Omega & CD's Opened \\
\hline 0.0 & $\begin{array}{l}\text { Cumberland } \\
\text { Lima } \\
\text { Altoona } \\
\text { Mansfield }\end{array}$ & 0.8 & $\begin{array}{c}\text { Fort_Wayne } \\
\text { Cumberland } \\
\text { Altoona } \\
\text { Oil_City }\end{array}$ & 1.6 & $\begin{array}{c}\text { Cumberland } \\
\text { Oil_City } \\
\text { Pittsburgh } \\
\text { Wheeling }\end{array}$ & 2.4 & $\begin{array}{c}\text { Hebron } \\
\text { Cumberland } \\
\text { Columbus } \\
\text { Altoona }\end{array}$ \\
\hline 0.1 & $\begin{array}{c}\text { Cumberland } \\
\text { Lima } \\
\text { Altoona } \\
\text { Wheeling } \\
\end{array}$ & 0.9 & $\begin{array}{c}\text { Fort_Wayne } \\
\text { Cumberland } \\
\text { Oil_City } \\
\text { Wheeling }\end{array}$ & 1.7 & $\begin{array}{c}\text { Fort_Wayne } \\
\text { Mansfield } \\
\text { Oil_City } \\
\text { Pittsburgh }\end{array}$ & 2.5 & $\begin{array}{c}\text { Fort_Wayne } \\
\text { Mansfield } \\
\text { Pittsburgh } \\
\text { Wheeling }\end{array}$ \\
\hline 0.2 & $\begin{array}{c}\text { Hebron } \\
\text { Cumberland } \\
\text { Altoona } \\
\text { Oil_City } \\
\end{array}$ & 1.0 & $\begin{array}{c}\text { Fort_Wayne } \\
\text { Cumberland } \\
\text { Mansfield } \\
\text { Pittsburgh }\end{array}$ & 1.8 & $\begin{array}{c}\text { Cumberland } \\
\text { Lima } \\
\text { Altoona } \\
\text { Mansfield } \\
\end{array}$ & 2.6 & $\begin{array}{c}\text { Hebron } \\
\text { Cumberland } \\
\text { Altoona } \\
\text { Oil_City } \\
\end{array}$ \\
\hline 0.3 & $\begin{array}{c}\text { Cumberland } \\
\text { Altoona } \\
\text { Oil_City } \\
\text { Pittsburgh } \\
\end{array}$ & 1.1 & $\begin{array}{c}\text { Fort_Wayne } \\
\text { Cumberland } \\
\text { Altoona } \\
\text { Pittsburgh }\end{array}$ & 1.9 & $\begin{array}{c}\text { Cumberland } \\
\text { Lima } \\
\text { Oil_City } \\
\text { Pittsburgh } \\
\end{array}$ & 2.7 & $\begin{array}{c}\text { Cumberland } \\
\text { Lima } \\
\text { Altoona } \\
\text { Pittsburgh }\end{array}$ \\
\hline 0.4 & $\begin{array}{c}\text { Cumberland } \\
\text { Altoona } \\
\text { Oil_City } \\
\text { Pittsburgh } \\
\end{array}$ & 1.2 & $\begin{array}{c}\text { Cumberland } \\
\text { Lima } \\
\text { Oil_City } \\
\text { Pittsburgh } \\
\end{array}$ & 2.0 & $\begin{array}{c}\text { Fort_Wayne } \\
\text { Cumberland } \\
\text { Altoona } \\
\text { Oil_City }\end{array}$ & 2.8 & $\begin{array}{c}\text { Fort_Wayne } \\
\text { Cumberland } \\
\text { Altoona } \\
\text { Oil_City }\end{array}$ \\
\hline 0.5 & $\begin{array}{c}\text { Fort_Wayne } \\
\text { Canton } \\
\text { Altoona } \\
\text { Pittsburgh } \\
\end{array}$ & 1.3 & $\begin{array}{c}\text { Fort_Wayne } \\
\text { Columbus } \\
\text { Altoona } \\
\text { Pittsburgh } \\
\end{array}$ & 2.1 & $\begin{array}{c}\text { Canton } \\
\text { Altoona } \\
\text { Oil_City } \\
\text { Pittsburgh } \\
\end{array}$ & 2.9 & $\begin{array}{c}\text { Fort_Wayne } \\
\text { Cumberland } \\
\text { Altoona } \\
\text { Mansfield }\end{array}$ \\
\hline 0.6 & $\begin{array}{l}\text { Cumberland } \\
\text { Canton } \\
\text { Altoona } \\
\text { Mansfield }\end{array}$ & 1.4 & $\begin{array}{c}\text { Fort_Wayne } \\
\text { Cumberland } \\
\text { Altoona } \\
\text { Oil_City }\end{array}$ & 2.2 & $\begin{array}{c}\text { Cumberland } \\
\text { Canton } \\
\text { Altoona } \\
\text { Pittsburgh } \\
\end{array}$ & 3.0 & $\begin{array}{c}\text { Cumberland } \\
\text { Canton } \\
\text { Altoona } \\
\text { Pittsburgh }\end{array}$ \\
\hline 0.7 & $\begin{array}{c}\text { Fort_Wayne } \\
\text { Cumberland } \\
\text { Altoona } \\
\text { Oil_City }\end{array}$ & 1.5 & $\begin{array}{c}\text { Fort_Wayne } \\
\text { Cumberland } \\
\text { Oil_City } \\
\text { Pittsburgh }\end{array}$ & 2.3 & $\begin{array}{c}\text { Fort_Wayne } \\
\text { Cumberland } \\
\text { Altoona } \\
\text { Oil_City }\end{array}$ & & \\
\hline
\end{tabular}




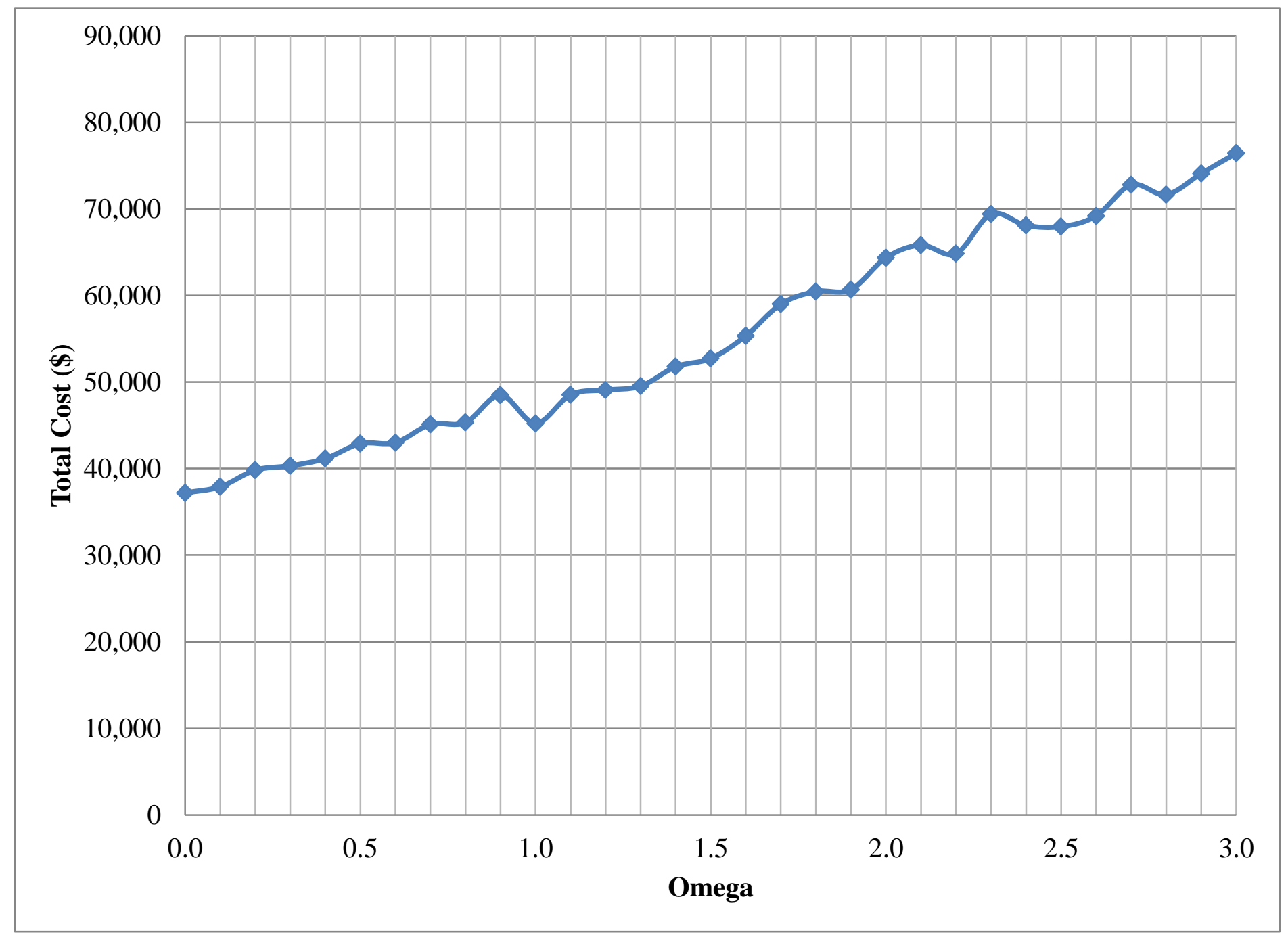

Figure 12: Total Cost for Network 1 with Medium Uncertainty 


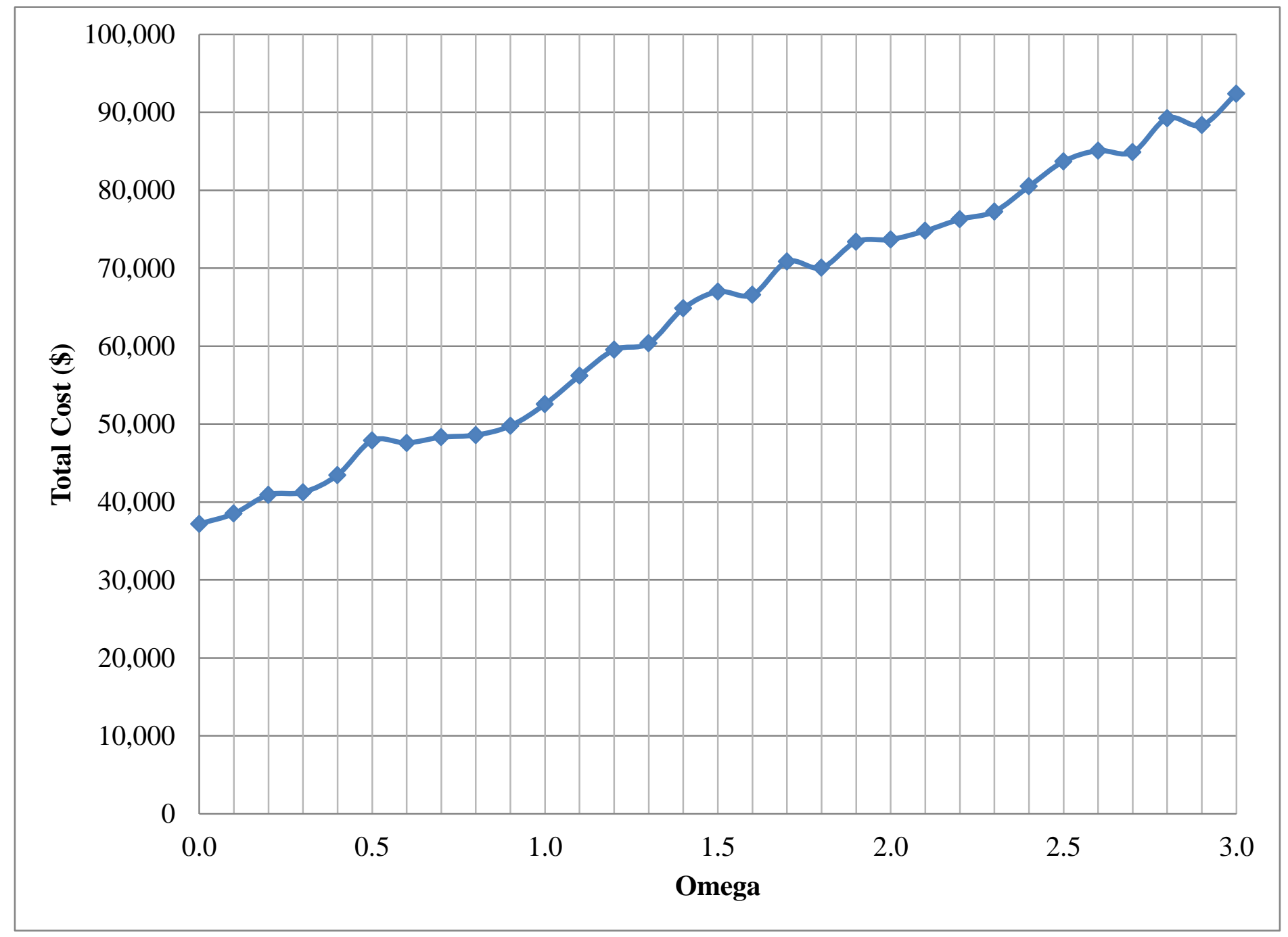

Figure 13: Total Cost for Network 1 with High Uncertainty 


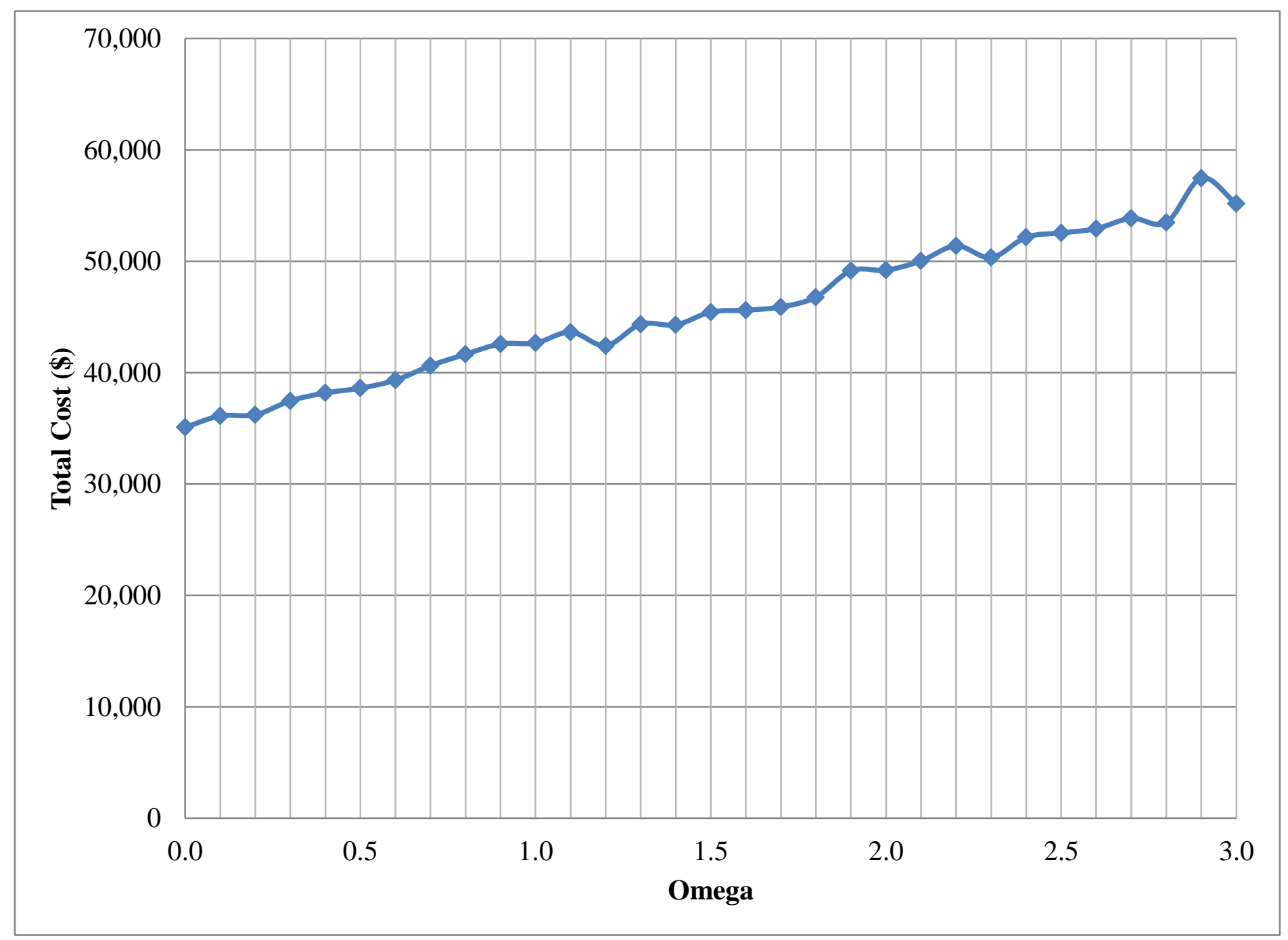

Figure 14: Total Cost for Network 2 with Low Uncertainty 


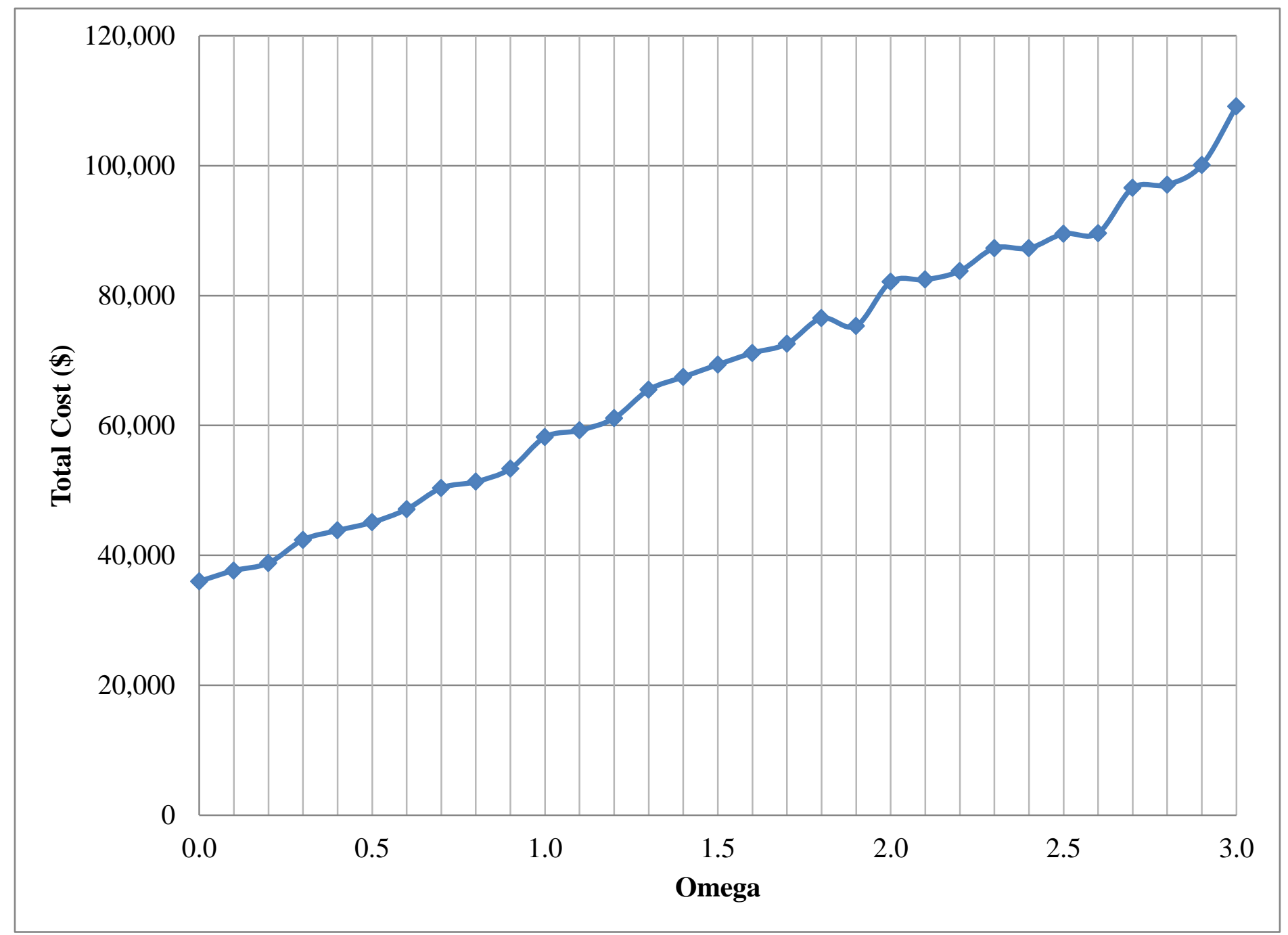

Figure 15: Total Cost for Network 2 with High Uncertainty 


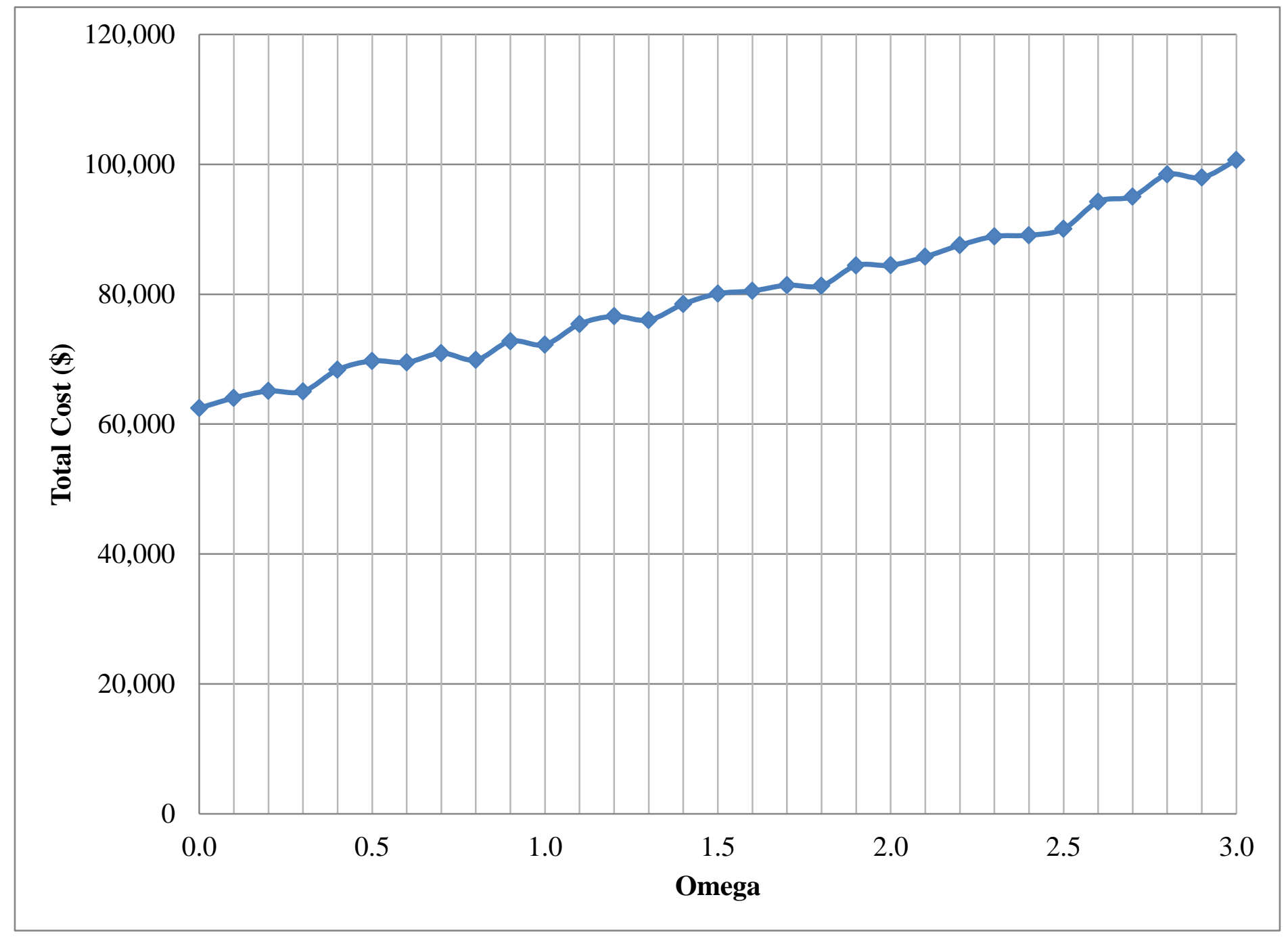

Figure 16: Total Cost for Network 3 with Low Uncertainty 


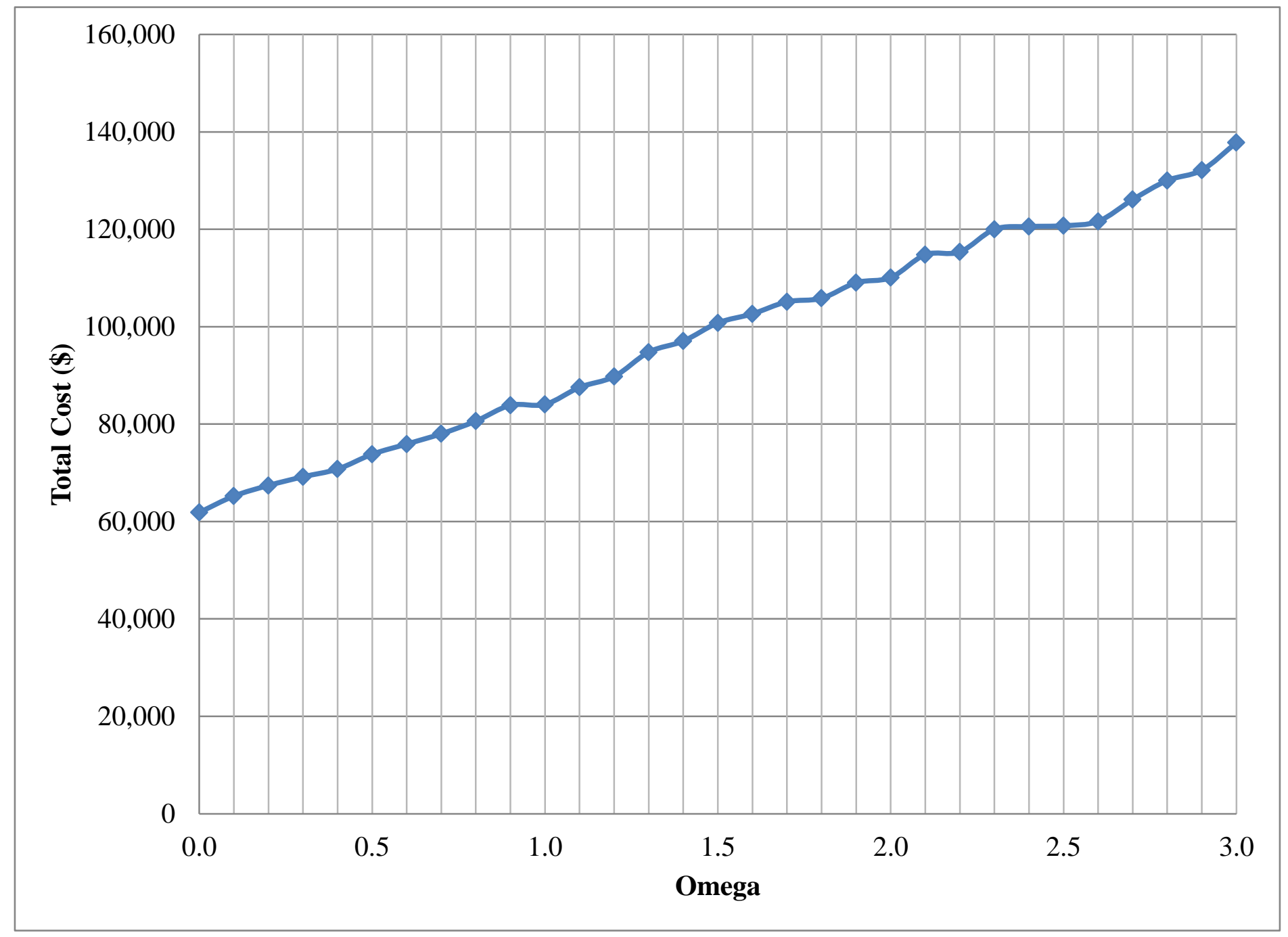

Figure 17: Total Cost for Network 3 with Medium Uncertainty 


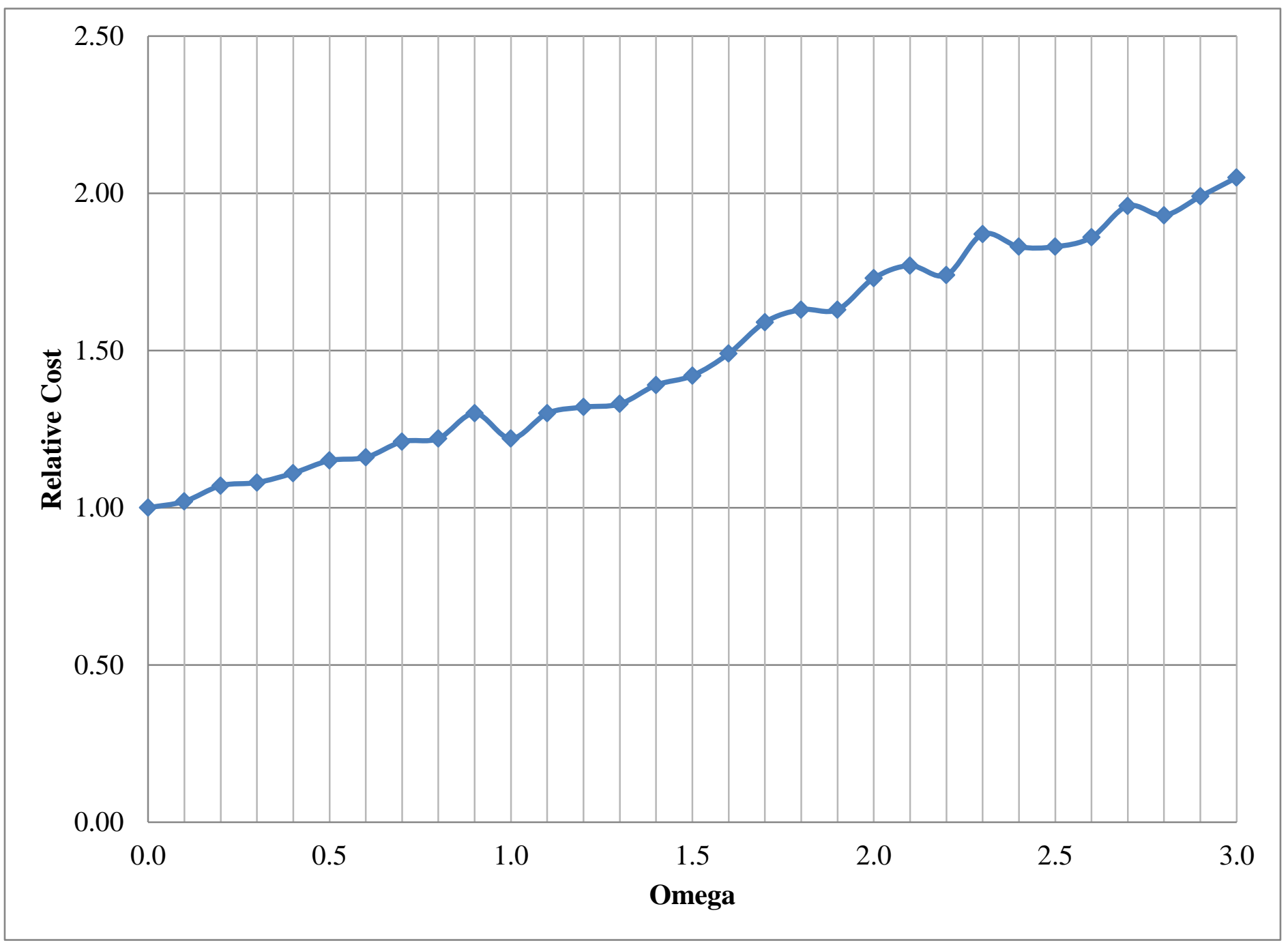

Figure 18: Relative Cost for Network 1 with Medium Uncertainty 


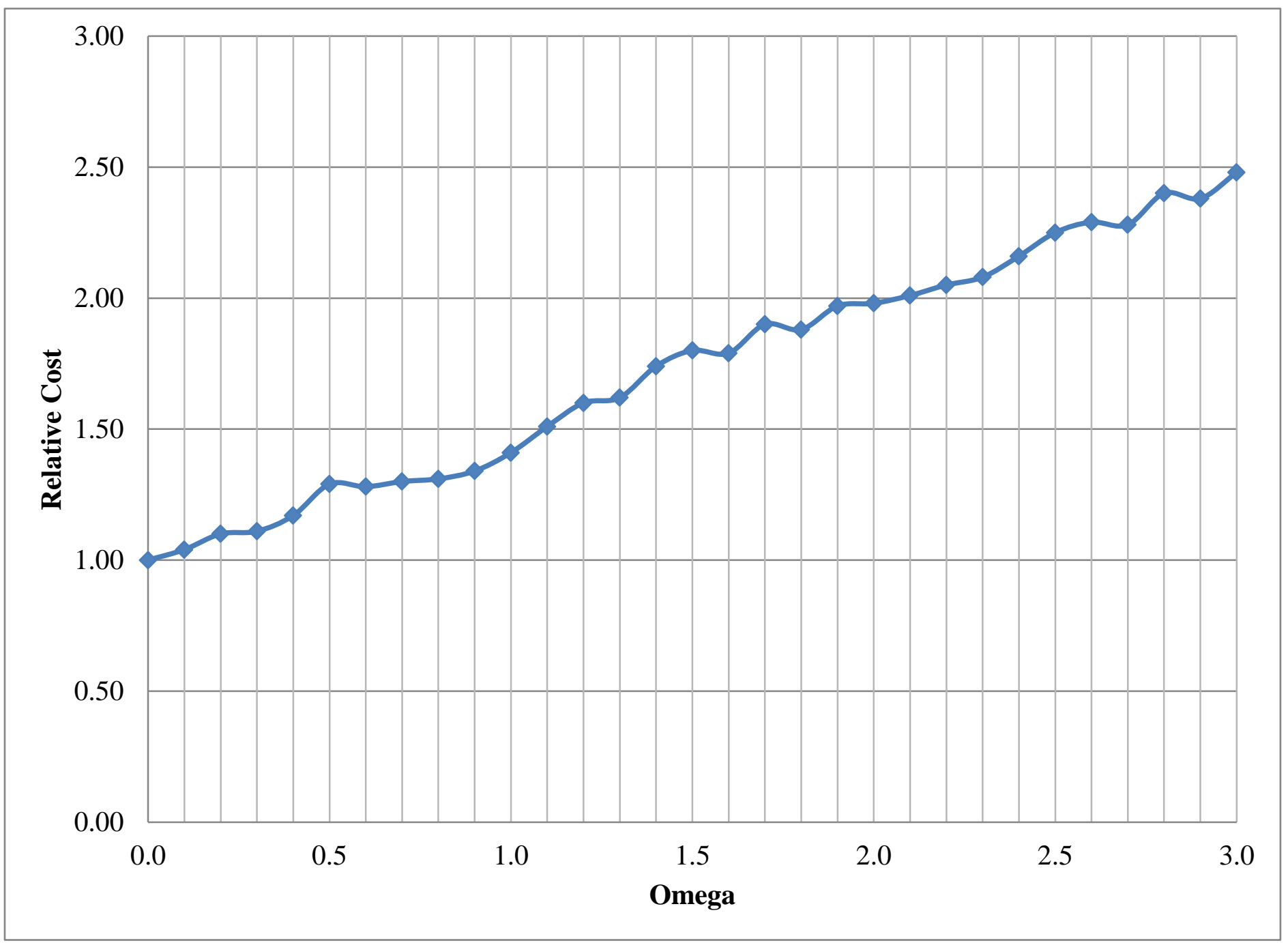

Figure 19: Relative Cost for Network 1 with High Uncertainty 


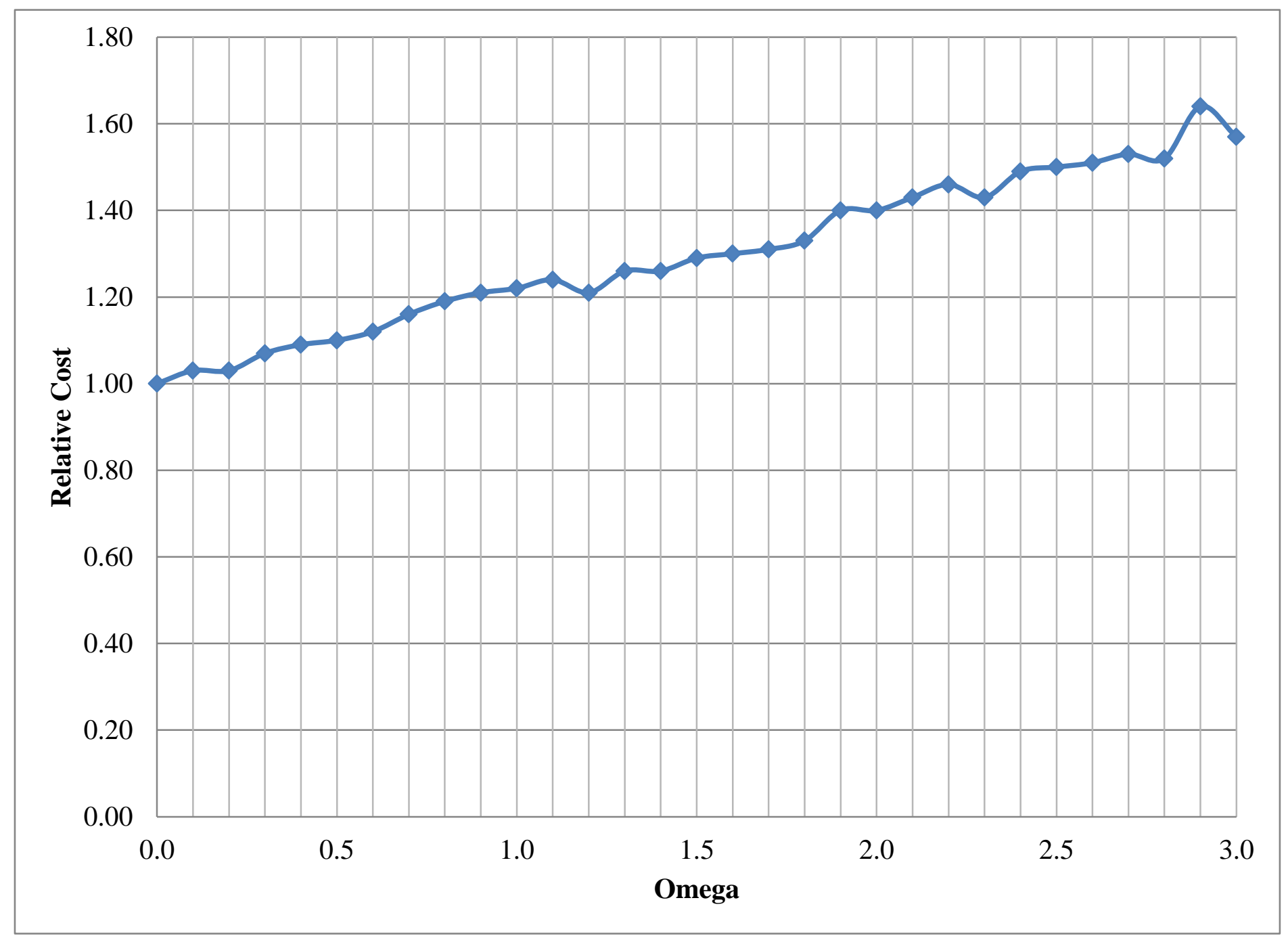

Figure 20: Relative Cost for Network 2 with Low Uncertainty 


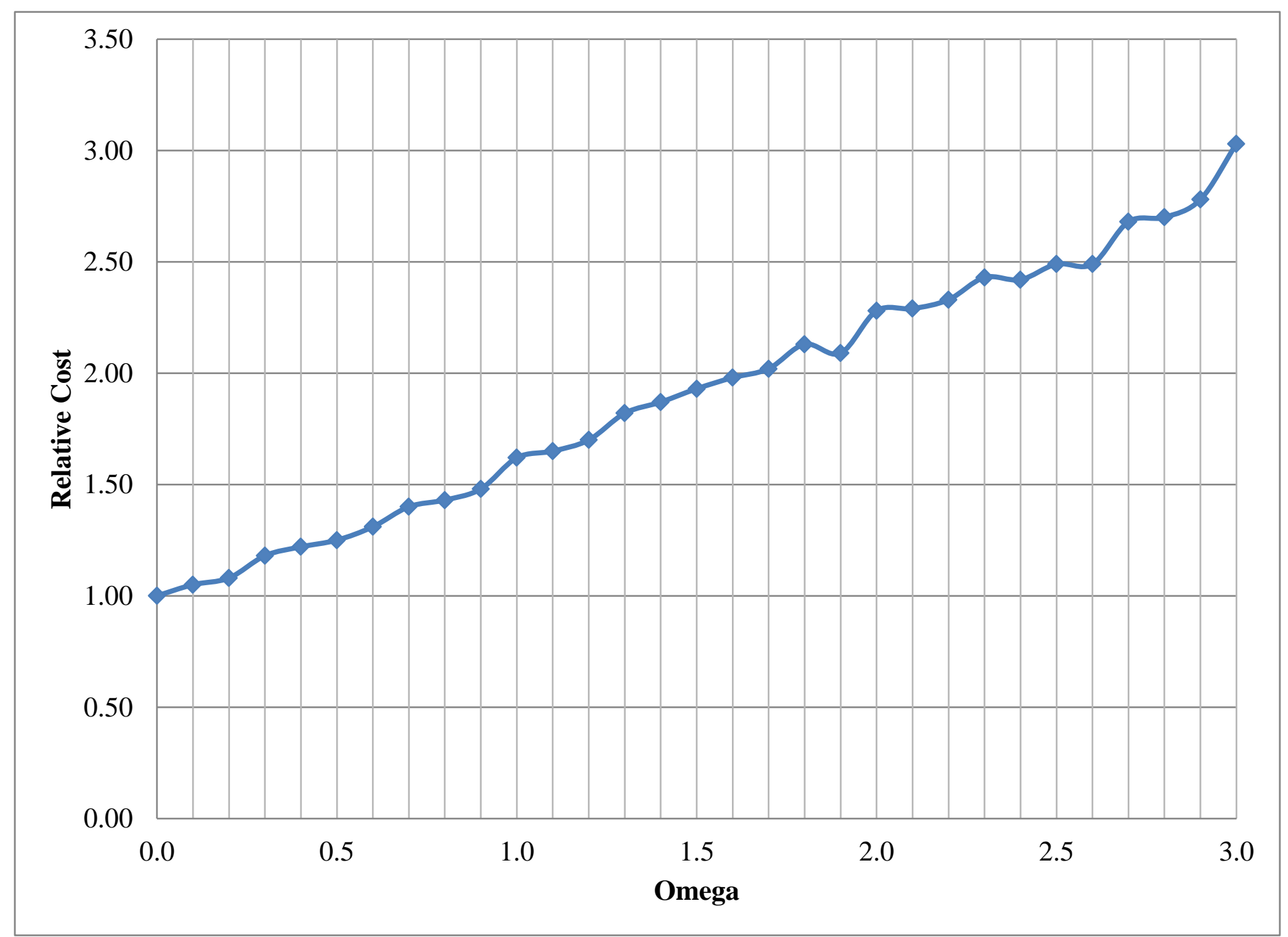

Figure 21: Relative Cost for Network 2 with High Uncertainty 


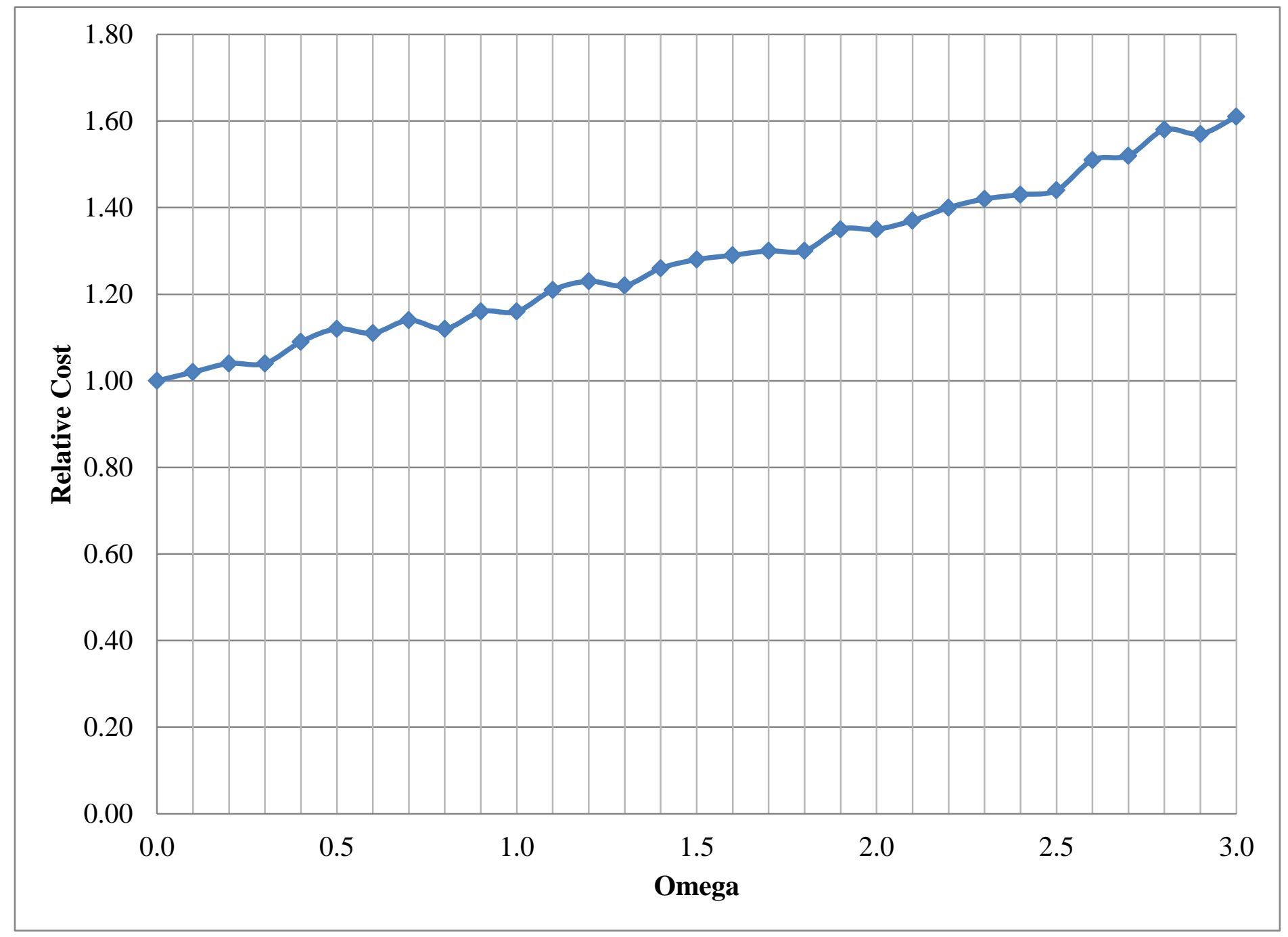

Figure 22: Relative Cost for Network 3 with Low Uncertainty 


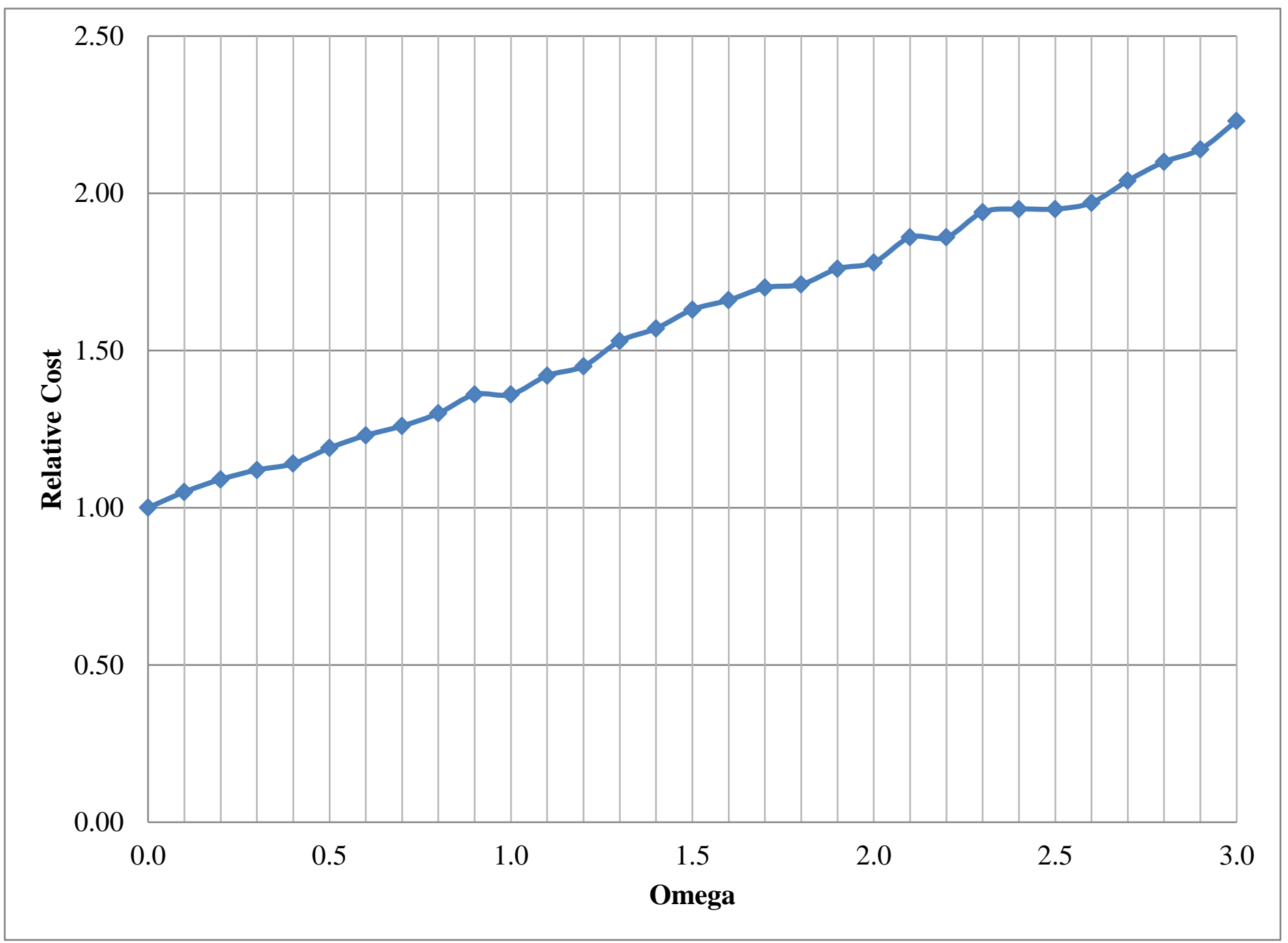

Figure 23: Relative Cost for Network 3 with Medium Uncertainty 